Louisiana State University

LSU Digital Commons

LSU Doctoral Dissertations

Graduate School

2007

\title{
The experiences of refugee youth from the conflicts in the Sudan: a collective case study
}

Michele Kelly

Louisiana State University and Agricultural and Mechanical College

Follow this and additional works at: https://digitalcommons.Isu.edu/gradschool_dissertations

Part of the Human Ecology Commons

\section{Recommended Citation}

Kelly, Michele, "The experiences of refugee youth from the conflicts in the Sudan: a collective case study" (2007). LSU Doctoral Dissertations. 2435.

https://digitalcommons.Isu.edu/gradschool_dissertations/2435

This Dissertation is brought to you for free and open access by the Graduate School at LSU Digital Commons. It has been accepted for inclusion in LSU Doctoral Dissertations by an authorized graduate school editor of LSU Digital Commons. For more information, please contactgradetd@lsu.edu. 


\title{
THE EXPERIENCES OF REFUGEE YOUTH FROM THE CONFLICTS IN THE SUDAN: A COLLECTIVE CASE STUDY
}

\author{
A Dissertation \\ Submitted to the Graduate Faculty of the \\ Louisiana State University and \\ Agricultural and Mechanical College \\ in partial fulfillment of the \\ requirements for the degree of \\ Doctor of Philosophy \\ in \\ The School of Human Ecology \\ by \\ Michele Kelly \\ B.S., St. Mary's Dominican College, 1982 \\ M.S.W., Tulane University, 1985 \\ August 2007
}




\section{ACKNOWLEDGEMENTS}

I would like to quote Urie Bronfenbrenner, psychologist, specialist, and theorist in human ecology:

If we can lay claim to an achievement, it only means that other human beings have been willing and enabled to commit to us ... right up to this moment.

Thus my achievement of writing and successfully defending this dissertation is only possible because others have committed to it as well.

First and foremost, I am grateful to the individual Lost Boys of the Sudan who participated in the study. I was touched by their willingness to participate in the study. Their courage in living and recounting the narrative of their journey is inspirational. I am also thankful for the willingness and assistance of the administrator and staff of Catholic Social Services for facilitating the study.

I am especially grateful to my committee chair, Dean Pamela Monroe, for her guidance and assistance. I greatly appreciated her qualities of calm and unwavering patience. They were most needed. I would also like to thank my committee members, Dr. Joan Hymel Benedict; Dean Mary E. “Betsy” Garrison; my Dean’s Representative, Dr. Lisa K. Lundy; and Dr. Ioan I. Negulescu for their advice, guidance, patience, and understanding.

And, of course, my husband, Ghazi Assali, and my parents, Dr. Thomas and Dolores Kelly whose support and encouragement and willingness to do whatever they could to assist me in achieving this goal knew no end. As well as my son, Patrick, who unselfishly shared his mother and unconditionally accepted this sibling called "dissertation."

I am deeply indebted to Patrick Stack, Esq., my editor, who willingly and cheerfully answered my numerous questions regarding proper comma placement and other grammatical minutia. Also, Theresa Wellman, a remarkable transcriptionist, and Chris Tranchina, an 
incredible graphic artist, both of whom assisted me with numerous technical tasks and were willing to work long hours, well into the night.

Finally, I am incredibly appreciative of my dear friends who were enthusiastic, supportive, encouraging, and provided sound advice. They include Drs. Stan DeLoach, Georgette Ioup, Mary Troy Johnston, Maureen Prevost, Frances Robichaux, and Denese Ashbaugh-Vlosky. And to the others, some of whom would prefer to remain anonymous, as well as to the others who believe that what they did was too small to mention, but nevertheless committed to me in achieving this goal. 


\section{TABLE OF CONTENTS}

Page

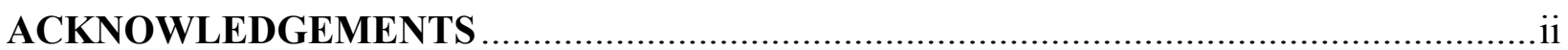

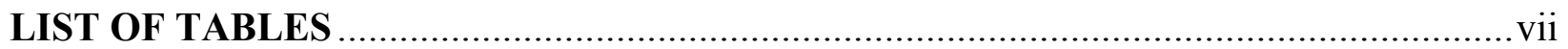

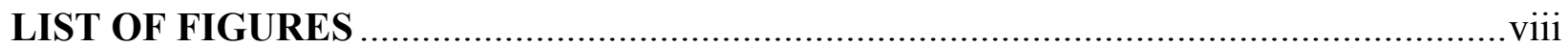

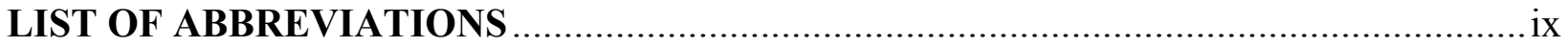

ABSTRACT

CHAPTER ONE: INTRODUCTION .............................................................. 1

A Story: The Genesis of My Personal Interest in the Area of Study .................................. 1

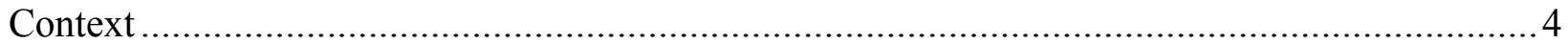

Overview of the Sudan ............................................................................... 4

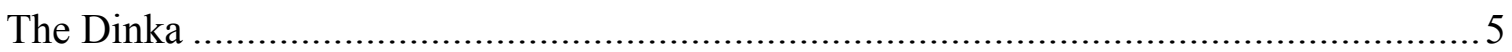

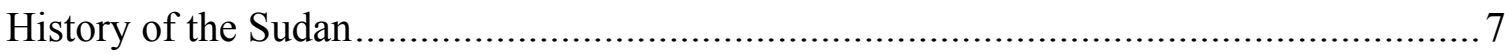

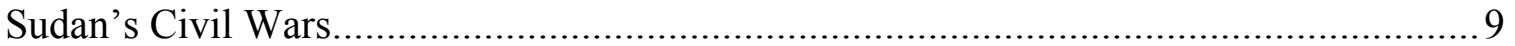

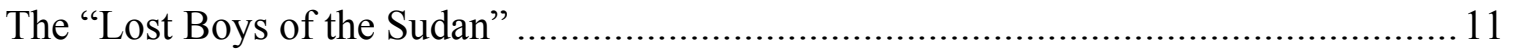

Kakuma Refugee Camp................................................................................. 13

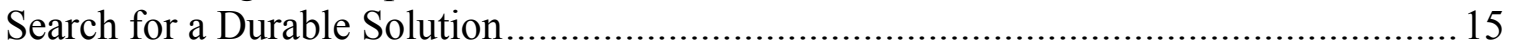

Resettlement in the United States .................................................................... 16

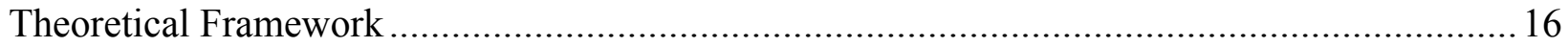

Ecological Framework..................................................................................... 16

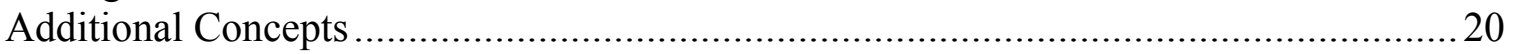

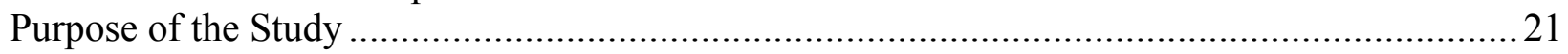

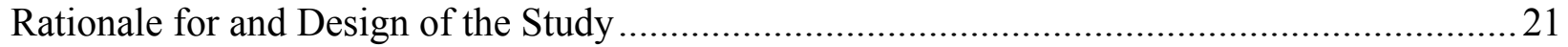

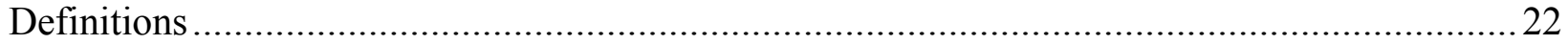

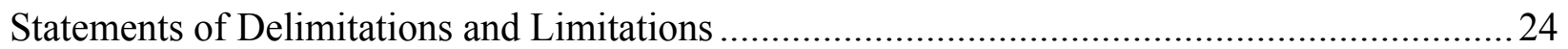

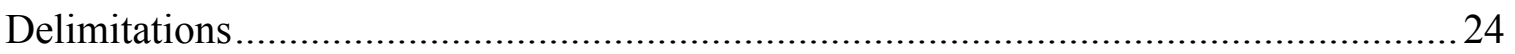

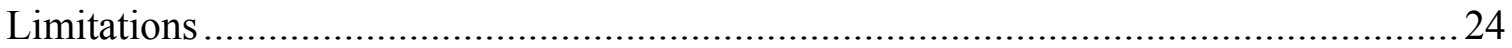

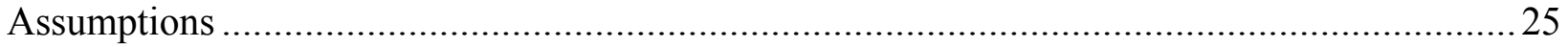

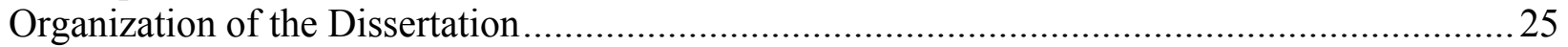

CHAPTER TWO: REVIEW OF THE LITERATURE ............................................ 28

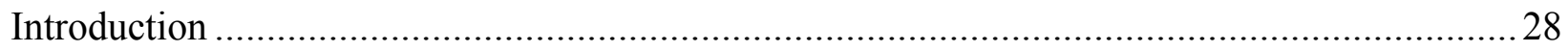

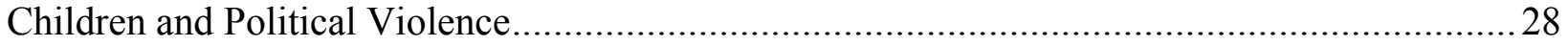

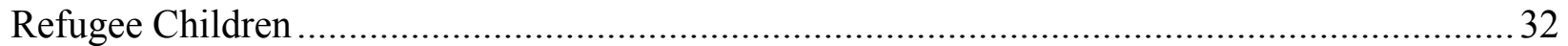

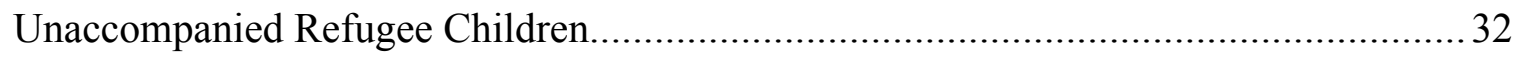

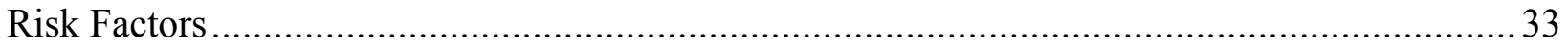

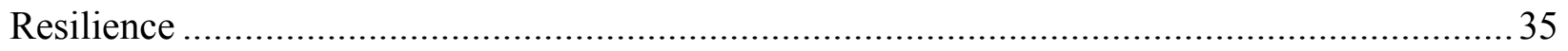

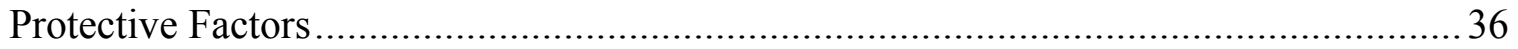




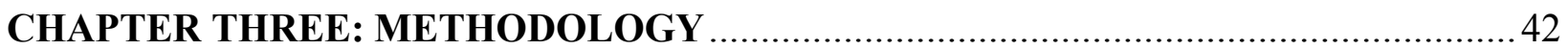

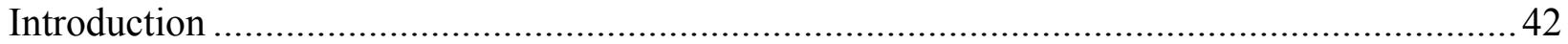

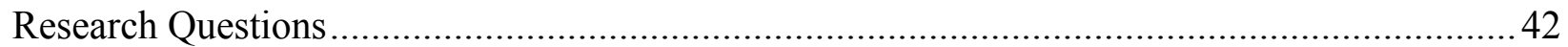

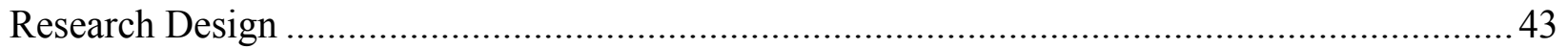

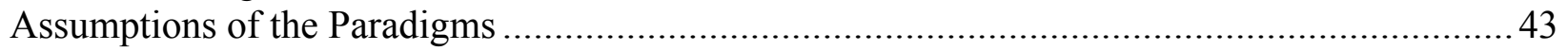

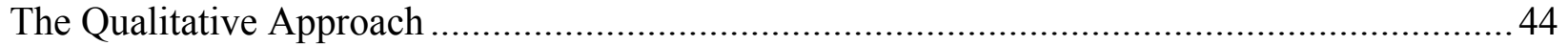

Characteristics of and Rationale for the Qualitative Approach ........................................ 44

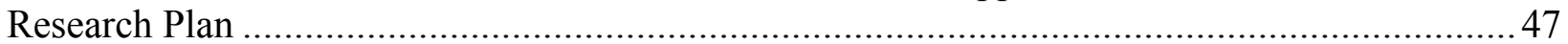

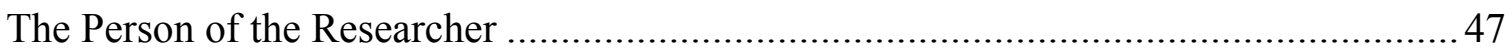

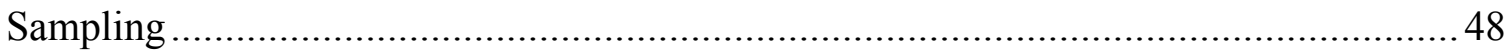

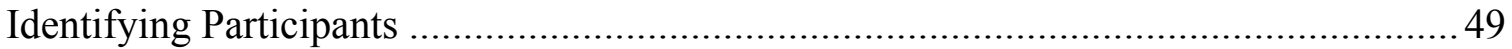

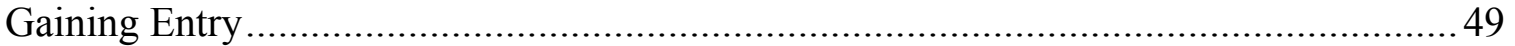

Rights of Participants and Confidentiality............................................................... 50

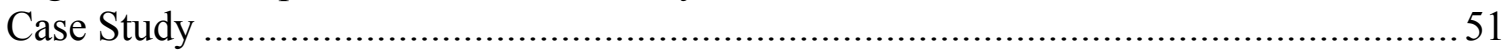

CHAPTER FOUR: PRESENTATION OF THE PARTICIPANTS ...............................5

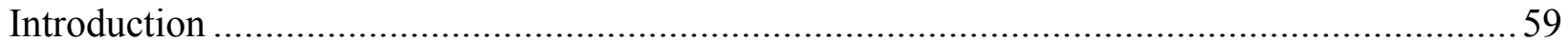

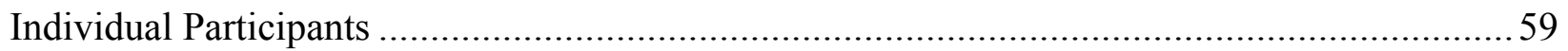

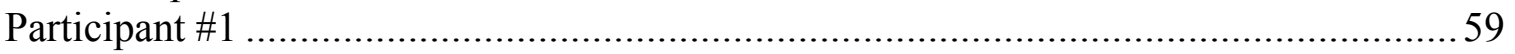

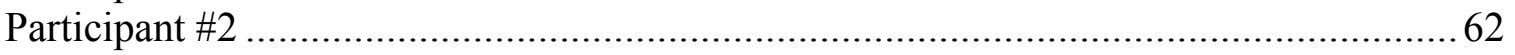

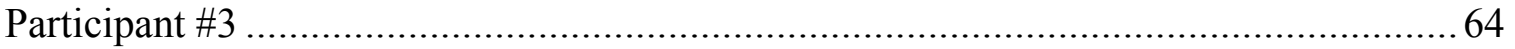

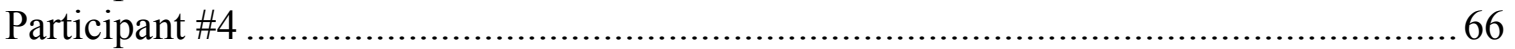

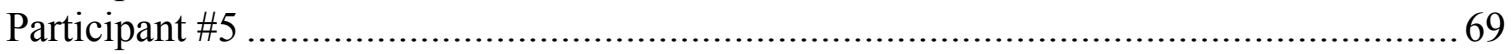

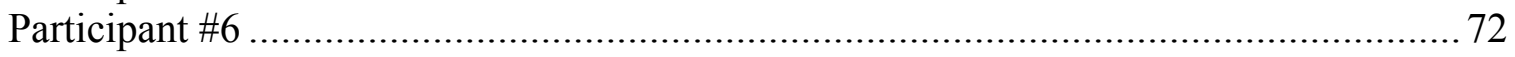

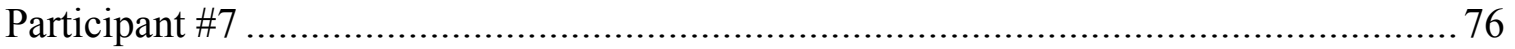

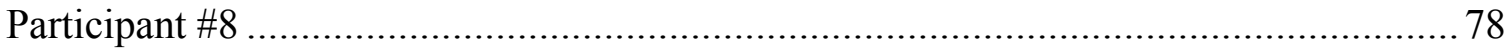

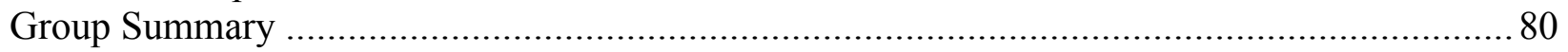

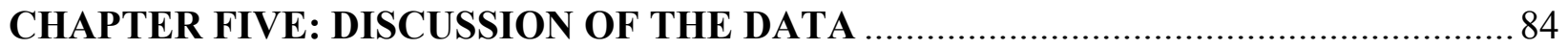

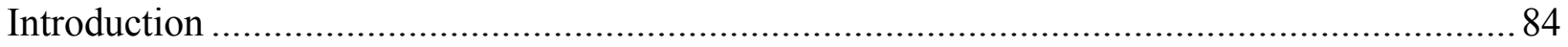

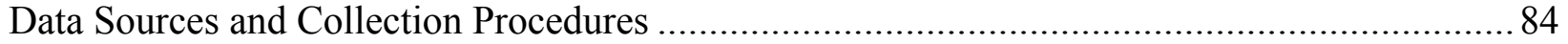

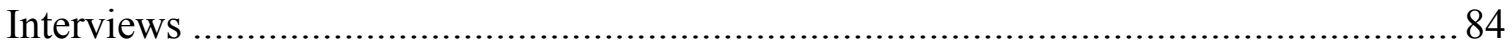

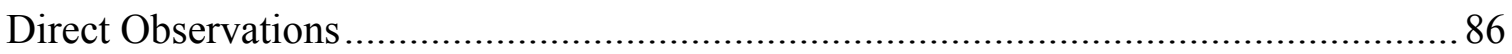

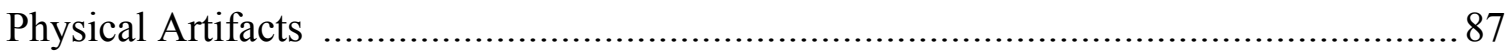

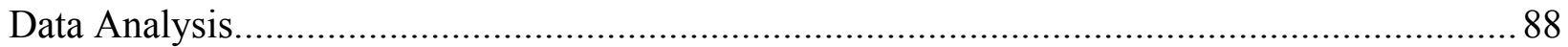

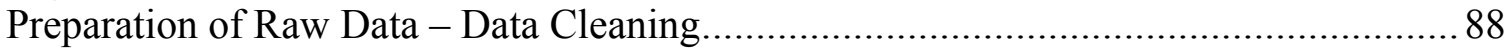

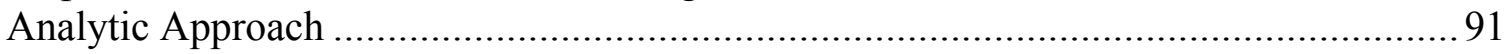

Analytic Process and Procedures .............................................................................. 92

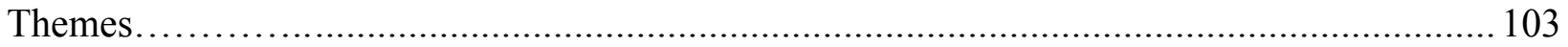

Theme \#1: Danger, Destruction, and Death ………….............................................. 103

Theme \#2: Struggle for Survival......................................................................... 108

Theme \#3: Assistance Provided by Others............................................................... 110

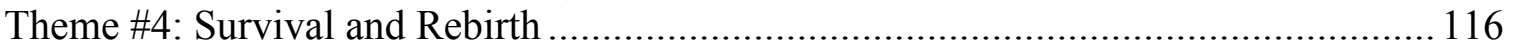

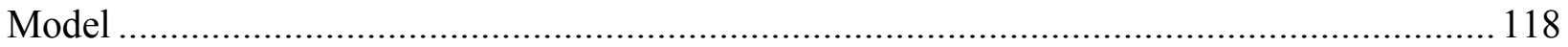

Conclusion Drawing and Verification .......................................................................... 119

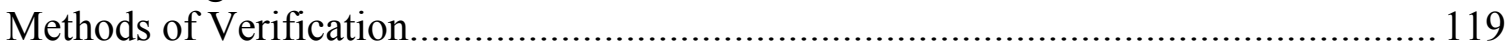


CHAPTER SIX: SUMMARY AND CONCLUSIONS ........................................... 126

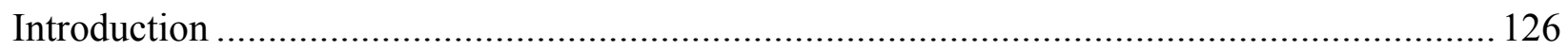

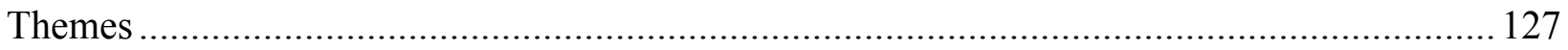

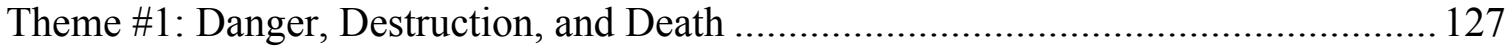

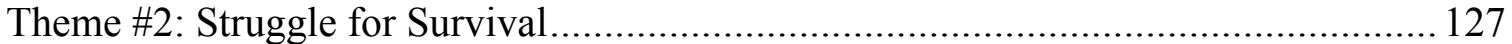

Theme \#3: Assistance Provided by Others ........................................................... 127

Theme \#4: Survival and Rebirth ..................................................................... 127

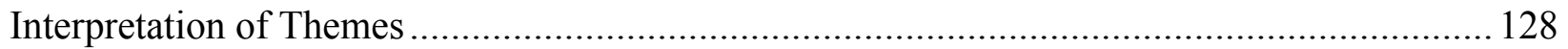

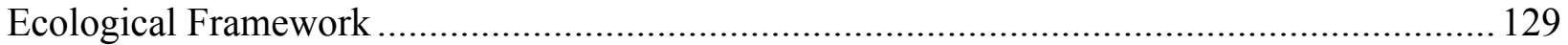

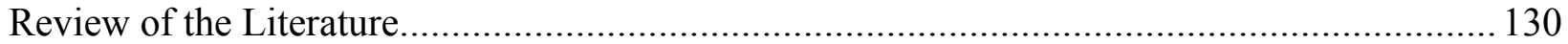

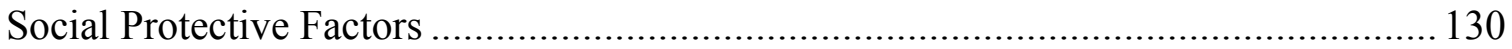

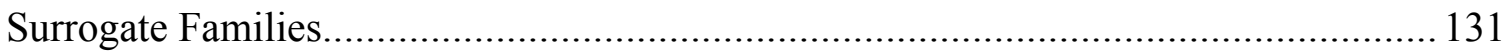

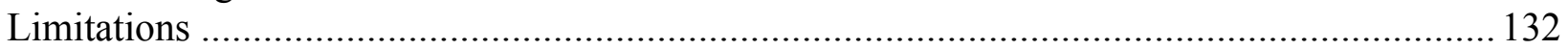

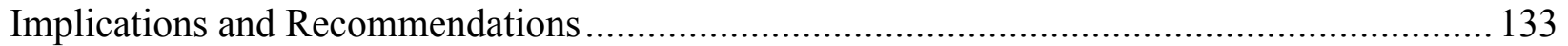

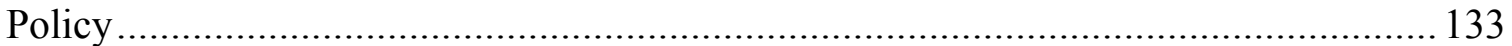

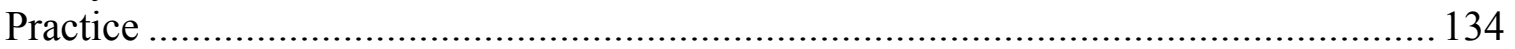

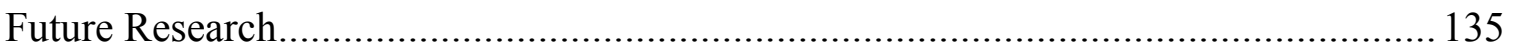

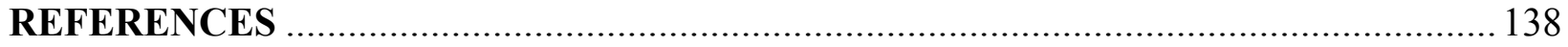

APPENDIX

A: LOUISIANA STATE UNIVERSITY, INSTITUTIONAL REVIEW BOARD, ACTION ON PROTOCOL APPROVAL REQUEST.

B: LOUISIANA STATE UNIVERSITY, INSTITUTIONAL REVIEW BOARD

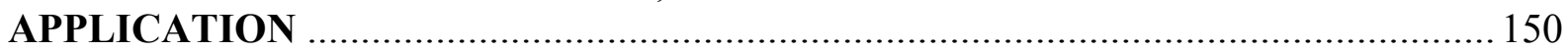

PRE-SCREENING INTERVIEW PROTOCOL ............................................... 151

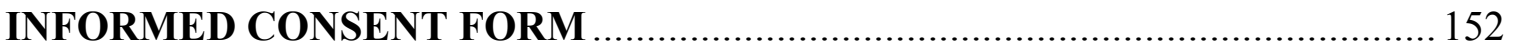

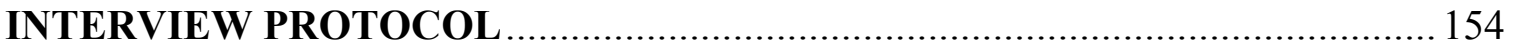

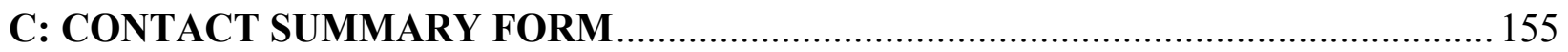

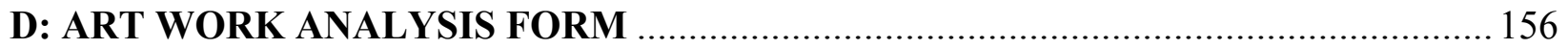

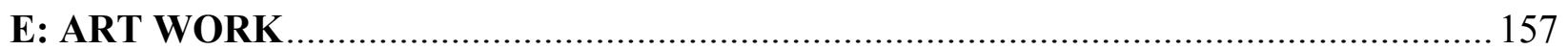

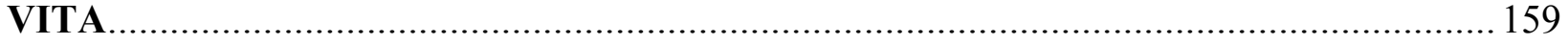




\section{LIST OF TABLES}

Page

3.1: Research Questions and Related Interview Questions................................55

5.1: Data Sources and Collection Procedures...........................................86

5.2: Initial List of Categories and Codes.............................................95

5.3: Revised List of Categories and Codes.......................................... 97

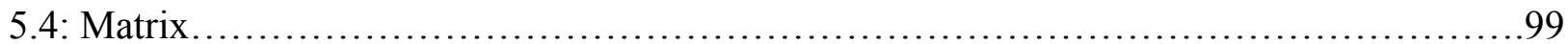




\section{LIST OF FIGURES}

Page

1.1: Map of the Sudan..............................................................

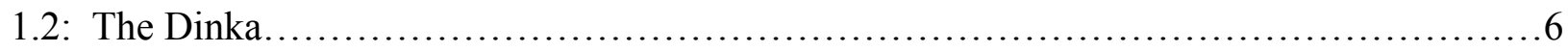

1.3: Cattle in the Sudan............................................................

1.4: John Garang................................................................ 11

1.5: Lt. General Omar Hassan al-Bashir................................................11

1.6: "Lost Boys" in Flight...................................................... 12

1.7: A "Lost Boy" .............................................................

1.8: Aerial View of Kakuma Refugee Camp....................................... 14

1.9: A "Lost Boy" Shopping in a Grocery Store in the United States.......................... 16

1.10: The Levels of the Ecological System.......................................... 18

2.1: Sudanese Child Soldier...................................................... 30

5.1: Thematic Model.................................................................. 118 


\section{ABBREVIATIONS}

IDP

NGO

PTSD

SPLA

SPLM

UNHCR

UNICEF

VOLAG

VOLOG
Internally Displaced Person

Non-Governmental Organization

Post-Traumatic Stress Disorder

Sudanese People's Liberation Army

Sudanese People's Liberation Movement

United Nation's High Commissioner for Refugees

United Nation's International Children's Fund

Voluntary Agency

Voluntary Organization 


\begin{abstract}
The purpose of this qualitative study was to explore the role of familial protective factors in moderating the relationship between risk and resilience in Sudanese refugee youth exposed to political violence. Interviews, direct observations, and physical artifacts were the sources of data. Eight "Lost Boys" participated in the study, providing narratives of their experiences of the Sudanese civil wars. They also answered questions posed about the role of familial protective factors in moderating the relationship between risk and resilience. The interviews were recorded on audiotape and then transcribed. Data consisted of the transcripts and field notes of processes and observations. The field notes also included the Contact Summary Form, and when a physical artifact was obtained, an Art Work Analysis Form. The transcripts and field notes were later analyzed and coded.
\end{abstract}

Eventually themes emerged. The results of the study indicate that familial protective factors play a role in moderating the relationship between risk and resilience in Sudanese refugee youth exposed to political violence. However, not all familial protective factors play a role nor those that do play a role do so equally. Some factors were more important than others as indicated by their frequency of being mentioned by the participants. Also, familial protective factors do not play a sole or primary role in moderating the relationship between risk and resilience. It appeared that initially familial protective factors were the sole protective mechanism. However, once the youth were separated from their families of origin and, given their extreme circumstances and need for protection and support, they quickly sought and developed other sources of support. Given the presence of their peers and little else as potential sources of support it seems natural that the peer group evolved as a surrogate family over a period of time. Eventually, the participants come to rely on their peers/surrogate family as their 
primary source of support. Finally, implications and recommendations for policy, practice, and future research were noted 


\section{CHAPTER ONE: INTRODUCTION}

This study explores how familial protective factors moderate the relationship between risk and resilience in Sudanese refugee youth exposed to political violence. This first chapter, an introduction, begins with a story that elucidates the genesis of my personal interest in the area of study. It continues with an overview of the Sudan, the historical and political backgrounds of its civil wars, an introduction to the "Lost Boys of the Sudan," the theoretical and conceptual frameworks in which the study is grounded, the purpose of the study and a brief description of its design, a list of terms and their meanings as used in the study, statements of delimitations and limitations, and finally a discussion of the assumptions of this researcher that undergird the study.

\section{A Story: The Genesis of My Personal Interest in the Area of Study}

I have practiced social work for over 20 years. During these years, I provided clinical services primarily to families and children. Most of my clients' difficulties involved some form of violence - usually familial, such as physical and sexual abuse and gross neglect. In addition, there were numerous instances where families and children had witnessed or were victims of communal violence. One memorable client was an 8-year-old female whose mother suffered from paranoid schizophrenia and an addiction to crack cocaine. According to the reports I received from the Office of Community Services, one evening, when my client was 2-years-old, her mother filled a bathtub with boiling water and placed her in it. She suffered severe burns over her hands, forearms, and her entire body below her waist. This child endured a grueling recovery and rehabilitation and although her physical scars were obvious her emotional ones were less so.

Despite the pervasive familial and communal violence and its effects, I would periodically see a family that was doing remarkably well, even thriving. My client and the family 
with whom she was living - her paternal grandmother, her father, and paternal aunt - were one of these families. Although her father, aunt, and grandmother worked full-time jobs, they worked shifts so someone was always at home with my client. They were also involved in the community and active in their church. As for my client, she had perfect attendance at school and was one of the best students in the second grade. She, was also very active in church, attending services, Sunday school and singing in the children's choir - an activity she particularly enjoyed. She was a warm, vibrant, joyful child.

I was intrigued by this family, as well as many others with whom I worked. I had more questions than what was appropriate to ask them. But the one question that I always asked was, “How did your family do it?" I got a myriad of answers and each one piqued my interest more. More questions came to me.

In 1992 I married my husband Ghazi, a native of Beirut, Lebanon. At that time my knowledge of Lebanon was fairly limited, confined mostly to their recent civil war and the Western, mostly American, hostages who were kidnapped and held for years by radical militias. Much of this information was obtained from watching reports on the civil war by the late Peter Jennings, one of The ABC Nightly News anchors then stationed in Beirut. Jennings often used the infamous Holiday Inn as a backdrop to his nightly broadcasts. As one of the tallest buildings in Beirut that offered a cityscape view, the Holiday Inn was a nexus for the violence because it had a critical vantage point for the militias. Interestingly, my husband grew up one-half block from this building.

My husband did not remember Peter Jennings reporting nightly, but he did vividly recall the violence. Despite spending much of his childhood and youth in communal violence, in a country consumed by a brutal civil war, my husband managed to do well. During the war he 
received a law degree from the Lebanese University, Faculty of Political Science and Law. Unbeknownst to him, his mother, terrified of her young adult son's deepening entanglement in the civil war, applied for a scholarship on his behalf to study in the United States. To his dismay he was awarded the scholarship and spent the next two years studying at Loyola University New Orleans and Tulane University Schools of Law, eventually receiving a Master's degree from Tulane University School of Law.

I always had many questions for Ghazi about his experiences in Beirut, but he was rather reluctant to engage with me in what usually degenerated into a question-and-answer drill. To the questions he chose to respond his answers were usually terse. When asked, "How did you and your family do it?" he merely replied, “Oh, I don't know, we just did." His reluctance and my dissatisfaction with his answers only heightened my curiosity more.

Several years ago, I was the Refugee Resettlement Coordinator at Catholic Charities of the Archdiocese of New Orleans. Every day I met families who had fled their home countries and were seeking refuge in the United States. Many were fleeing oppression and persecution. Others were survivors of genocide. All had witnessed horrific political violence. Yet, despite the violence, virtually all of the families were thriving. Again, I had more questions than was appropriate to ask these families. As a result, I decided to formally study my deepening area of interest. I took a qualitative research course in which, for one of the assignments, I interviewed adults who, as children with their families, had fled oppression, persecution, or political violence and became refugees. I felt so privileged that these individuals were sharing their life-narratives with me, and I was utterly captivated by them.

One of the academic benefits of the assignment was that I was forced to focus my interest. Eventually, it evolved into a succinct research question: what is the role of families in 
moderating the relationship between risk and resilience in refugee children and youth exposed to political violence? I wanted to expand that study and thought the dissertation research might be an opportunity to do so. However, a critical obstacle was the lack of a large group of refugee youth who had fled political conflict and violence. Then, one day I read an article in the Christian Science Monitor (Crawley, 2000) about a large group of Sudanese refugee youth, the "Lost Boys" of the Sudan, who had begun resettling in the United States. I realized that this group offered me the opportunity to pursue the dissertation study.

\section{Context}

\section{Overview of the Sudan}

The ancient Egyptians and Israelites referred to the land of present day Sudan as Cush, and later as Nubia and as Punt (Scroggins, 2002). The Greeks and Romans called it Ethiopia or "The Land of the Burnt-Faced Ones." The Arabs named it Bilad al Sudan "The Land of the Blacks" (Scroggins, 2002). It was not until the Middle Ages that it became known as simply "The Sudan" or "Sudan." The name originally referred to the broad belt of sub-Sahara Africa that stretches from the Red Sea to the Atlantic Ocean, but now applies to just the territory of the present day republic (Petterson, 1999).

Sudan (Figure 1.1) is the largest country in Africa occupying approximately 1 million square miles, which is approximately the size of the United States east of the Mississippi River. It shares borders with nine other countries including Egypt, Eritrea, Ethiopia, Kenya, Uganda, the Democratic Republic of the Congo, Central African Republic, Chad, and Libya. There are deserts in the north and a tropical terrain in the south. The Nile River and its tributaries dominate the country (Central Intelligence Agency, 2005; Scroggins, 2002; www.sudan.net., n.d.). 


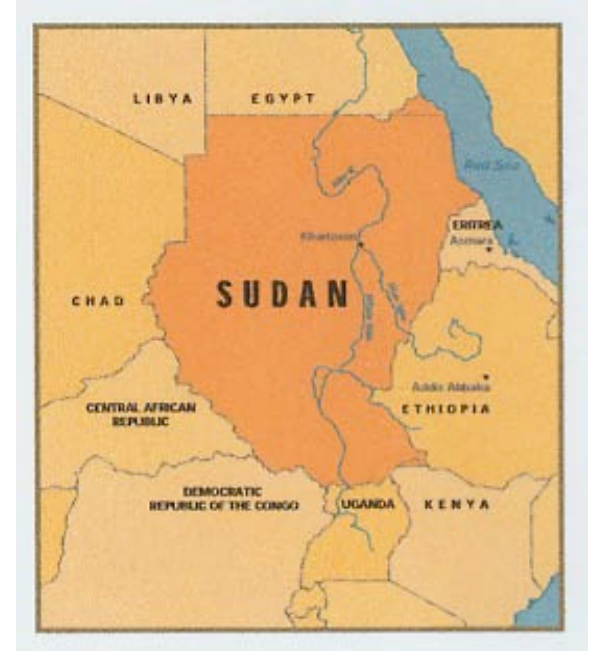

Figure 1.1: Map of the Sudan http://www.coping.org

With a population of approximately 30 million people, it is one of the most impoverished countries in the world. There are more than 450 ethnic groups who speak some 132 languages. Arabic, however, is the official language and is spoken by $51 \%$ of the population. Most Sudanese are multilingual by necessity (Central Intelligence Agency, 2005; Petterson, 1999). Almost all of the people of the north are Muslims, and Arabic is the first language learned by the majority. Most of the people in the south are Nilotes, who are either animists or Christian; they speak a variety of languages including Nubian, Ta Bedawie, dialects of the Nilotic languages, and English (Central Intelligence Agency, 2005; Deng, 1984; Petterson, 1999; www.sudan.net, n.d.). One of the largest groups of Nilotes is the Dinka.

\section{The Dinka}

The Dinka (Figure 1.2) number approximately 2 million people. They are divided into 20 to 25 or more tribal groups and further divided into subtribes each occupying a tract of land www.africana.com, 2003). The Dinka have lived on either side of the White Nile for centuries. 


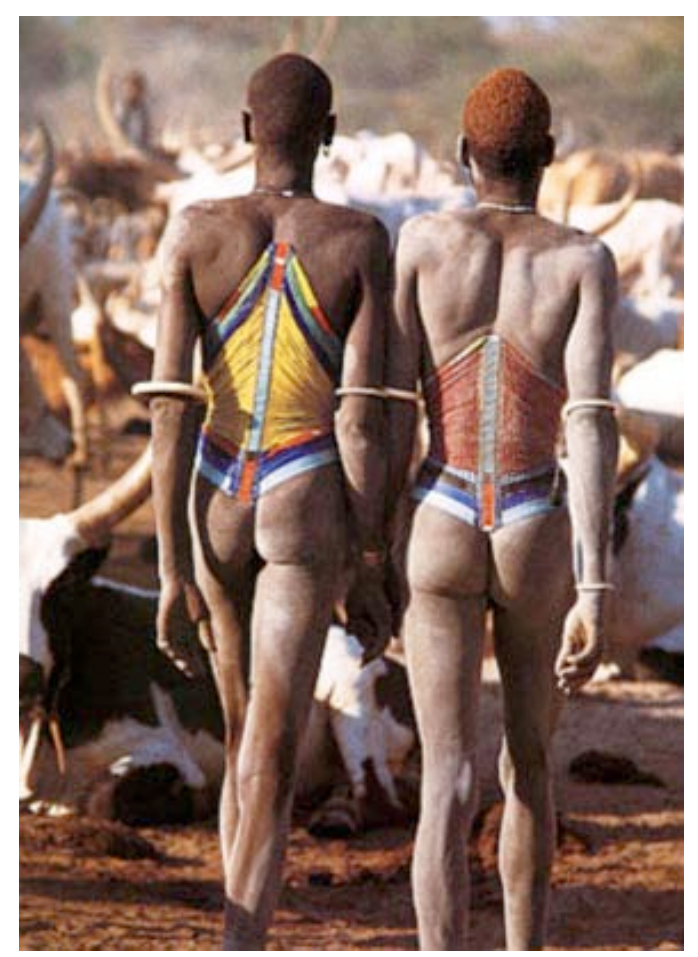

Figure 1. 2: The Dinka http://www.imagineafrica.co.uk, http://www.africanceremonies.com

They are pastoralists and cattle herders (Preston, 2003) and center their lives on their cattle (Deng, 1984). Families rely on cattle for many uses, i.e., for milk and its byproducts - butter and ghee, and urine for washing, dyeing hair, and tanning hides. The dung provides fuel for fires from which ash is used to clean the cattle and rid them of blood-sucking ticks. The ash is also used to decorate the Dinka and as a paste to clean their teeth. The horns and bones are used for a number of practical and aesthetic items (Bixler, 2005; Preston, 2003). Cattle are not killed for meat but, if one dies or is sacrificed to honor gods and ancestors, the meat is eaten. In addition, the cows are used as dowries to arrange marriages. The bridegroom's family gives cattle to the bride's family (Preston, 2003). This is the primary way by which wealth is acquired, with wealth being traditionally measured in terms of how many cattle one possesses (Deng, 1984; Preston, 2003). Cows (Figure 1.3) are also a source of self-esteem and delight for Dinka men (Deng, 1984; U. S. Committee for Refugees and Immigrants, 2001). 


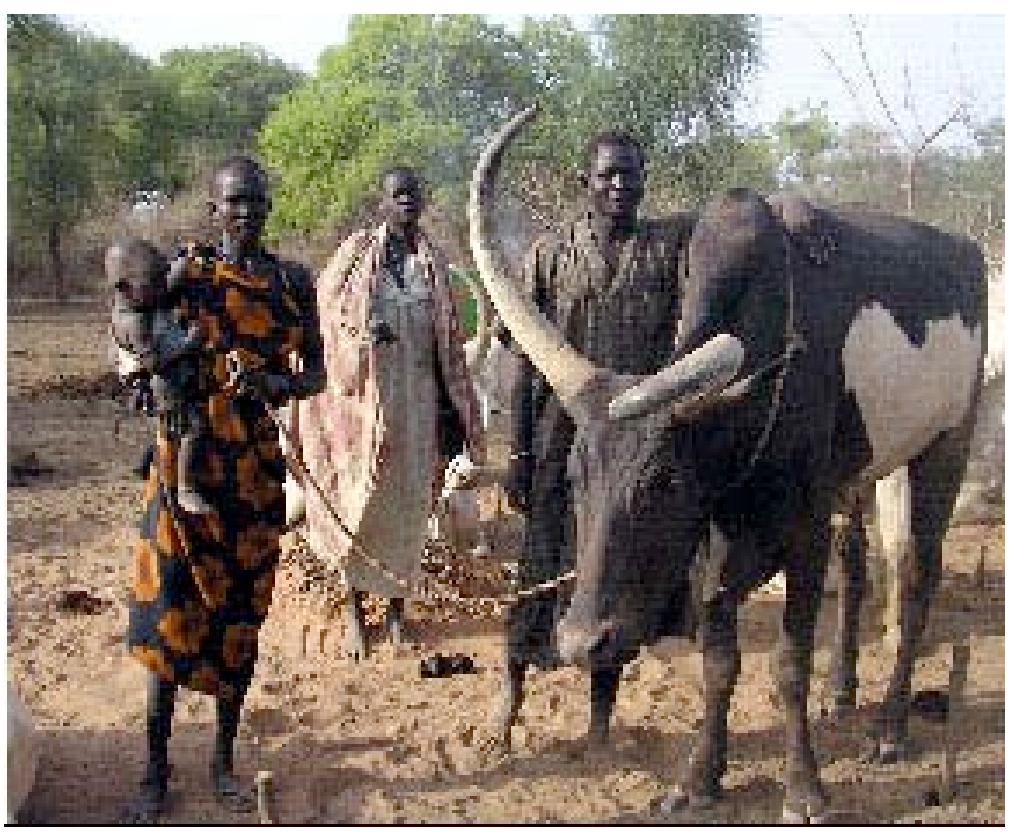

Figure 1.3: Cattle in the Sudan http://www.usaid.gov/our_work/crosscutting_programs/transition_initiatives/country/sudan/index.html

Dinka family members provide an essential support network to each other. In the homesteads, each family group lives in its own cluster of huts around a communal cooking hearth (Deng, 1984; Preston, 2003). The families' cattle are tethered around the cluster of huts. Blood links extend out to clan members, descendents of a single ancestor, and there is the assumption that blood relatives will unquestioningly support each other; the closer the blood line, the more automatic and greater the support (Preston, 2003).

\section{History of the Sudan}

In 1517, the Turks conquered Egypt and a part of northern Sudan and incorporated this territory into the Ottoman Empire. The area was divided into several provinces, each of which was placed under a Mamluk bey or viceroy and responsible to the pasha, but it was the Mamluk who held real power because the pasha's authority was tenuous (www.sudan.net, n.d.). In 1798, Napoleon and French forces, at the Battle of the Pyramids, altered the political situation by 
defeating the Mamluks. Then, in 1801, combined British and Ottoman forces ousted the French. For the next several years there was a period of chaos (www.sudan.net, n.d.). In 1805, the Ottomans sought to restore order by appointing Mohammed Ali as the pasha. In 1820, Mohammed Ali began a war of conquest in the Sudan (Johnson, 2003; Petterson, 1999; www.sudan.net, n.d.). However, administrative incompetence and the enslavement of southern Sudanese led to continuous unrest in the southern Sudan.

In 1881, Mohammed Ahmed bin Abdullah, a mystic and religious recluse, proclaimed himself the Mahdi, the second great prophet (Petterson, 1999). He raised an army and in 1882 annihilated the Ottomon empire proxies, the Egyptian army units, and took control of all of the Sudan except Khartoum. The British recognized that the Sudan could not be taken without a costly military intervention and ordered an Egyptian withdrawal from the Sudan. They then sent General Charles George Gordon, a former governor of northern Sudan, to supervise the evacuation of the Egyptian troops, British officials, and foreign nationals from the Sudan, particularly in the area around Khartoum where most resided (en.wikipedia.org, 2005; Johnson, 2003; Petterson, 1999; www.sudan.net, n.d). The Mahdi captured Khartoum in 1885 and in the process his forces killed General Gordon. Five months later, the Mahdi died of typhus in Khartoum (www.sudan.net, n.d.).

By 1896 , the British were contemplating a military campaign in the Sudan, in part because the British public strongly desired revenge for Gordon's death. In addition, the British government had two concerns that influenced their desire for the military campaign. Firstly, they feared the French were preparing to move into the Sudan. Secondly, they were anxious that Khalifa Abdullah, the Mahdi's successor, might attack Egypt and the Suez Canal (Johnson, 2003; Petterson, 1999; www.sudan.net, n.d.). An Anglo-Egyptian alliance quickly defeated the 
Khalifa's army and in 1899, an Anglo-Egyptian Condominium was established over the Sudan. Although Egypt and Britain had equal status over the Sudan, in actuality it was the British alone who administered the Sudan until it became independent in 1956 (Johnson, 2003; Petterson, 1999; www.sudan.net, n.d.).

During the British colonial era, interactions between the Arab north and the southern Sudan were restricted by policy. Sudan was administered as two separate entities - the north and the south. In the north, the British fostered the Arabs' Islamic values, helped promote modernization, and established an educational system that created an educated Sudanese elite. The southern Sudanese, however, were largely isolated from this progress and were provided with only minimal British resources, leaving them essentially underdeveloped (Bixler, 2005; Johnson, 2003; Petterson, 1999). Continuing neglect by the British and enslavement by the northerners led the southern Sudanese to become increasingly hostile and resistant to outside rule.

Even before Sudan became independent, southerners perceived the northern Sudanese as attempting to Arabize and Islamize the south such that hostilities often flared and resistance to northern domination increased. Eventually, full-scale war erupted in 1955. With the exception of a 10-year hiatus from 1972 until 1982, the politically complex civil wars have been an ongoing feature in the Sudan.

\section{Sudan's Civil Wars}

The Sudan's long, ongoing civil wars have resulted in nearly 2 million deaths from casualties, disease, and famine (Church World Service, n.d.; U. S. Committee for Refugees and Immigrants, 2001). At least one in five southern Sudanese has died as a result, and nearly 4 
million people of the southern Sudanese population have been forced to flee their homes and become internally displaced persons or refugees.

Although all sides have committed violence against civilians, the government and its allies bear the largest responsibility because civilian areas have been routinely bombed (Amnesty International, 2002; Bixler, 2005). As a result of the conflicts, the country has been left with virtually no infrastructure or institutions. Ninety percent of the people have no access to health care and the Sudanese government regularly blocks humanitarian relief (Reeves, 2002; www.committeeonconscience.org, n.d.). The conflict has also destroyed so many schools that an entire generation of Sudanese is illiterate.

One recent phase of the civil war began in 1983, pitting the main rebel army - the Sudanese People's Liberation Army (SPLA) and its allies - against the government's military and its allies. The Sudanese People's Liberation Movement (SPLM), the political wing of the SPLA, has stated that they are fighting for political autonomy within a united Sudan. Other southerners advocate secession from Sudan and the establishment of an independent country in the south (anonymous, personal communication, May 7, 2002; Petterson, 1999). The SPLA has drawn its support primarily from the black African, southern Sudanese. John Garang (Figure 1.4), who died in a helicopter accident in northern Uganda in July 2005 was the head of the SPLA. Sudan's current government is headed by Lt. General Omar Hassan al-Bashir (Figure 1.5), who staged a coup to gain power in 1989.

In January 2005 a comprehensive agreement was signed providing for peace between these two warring groups - for the first time in over 21 years - and formal recognition of southern Sudan autonomy (BBC News, 2005). The Sudanese government recently signed a peace agreement with the Eastern Front, another rebel group that had fought a low-intensity 


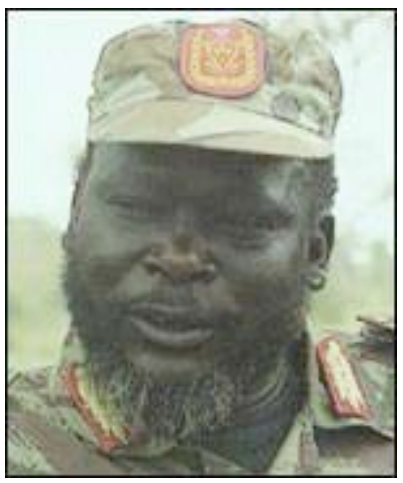

Figure 1.4: John Garang http://www.axisglobe.com/article.asp?article $=272$

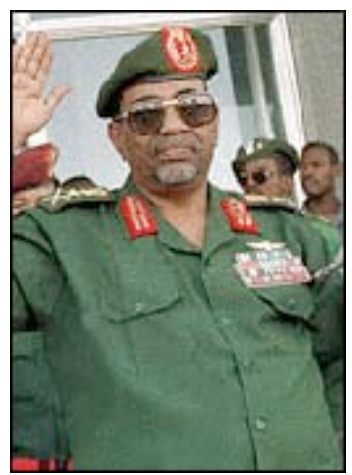

Figure1.5: Lt. General Omar Hassan al-Bashir http://www.axisglobe.com/article.asp?article $=272$

conflict in the eastern Sudan for over ten years. However, another conflict erupted in February 2003 in the Darfur region of western Sudan between groups loyal to and supported by the government - the janjaweed - and local rebels wanting greater autonomy for the region. Reports from 2006 say that some 200,000 people have been killed and up to 2.5 million displaced by the conflict. The mass media and the U.S. government have described the conflict as "ethnic cleansing" and "genocide." The United Nations has declined to do so. There have been claims that this conflict will result in the greatest humanitarian disaster of our time (Shirtliff, 2004).

\section{The "Lost Boys of the Sudan"}

Essentially, the wars in the Sudan are wars against civilians. Families are deliberately killed or purposely forced to flee for their lives (U. S. Committee for Refugees and Immigrants, 2001). In the chaos of the conflict, many children become separated from their parents and 
relatives, and many simply flee for fear of being abducted or recruited by force to join one of the armed militias. Also, in times of stress, families all over Africa send their children elsewhere for safety, schooling, work, or food (Deng, 1984).

Many boys traveled together (Figure 1.6), and still others traveled alone (Figure 1.7). thousands of them died along the trek, as prey for animals or from disease and hunger, while others disappeared in the wilderness. Most lost what few belongings they had en route. After several months they eventually reached Ethiopia where they remained for a couple of years. But, in 1991, after a change in the government of Ethiopia and increased sentiment against their presence, they had to flee again.

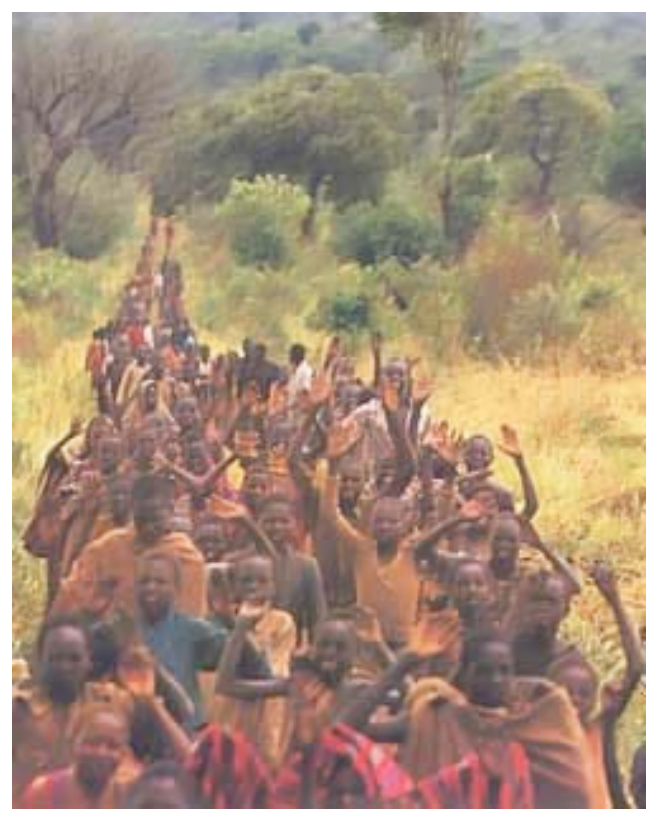

Figure 1.6: "Lost Boys" in Flight http://www.coping.org/wordauthors/lostboys/history.htm

They attempted to return to the Sudan and made their journey during the heavy rain season. As a result, many perished while crossing the swollen rivers or were attacked by crocodiles. They settled temporarily in southern Sudan but, by the end of 1991, fighting again erupted in the southern Sudan and the children were forced to flee yet again. Survivors are now in refugee camps in the Sudan, Kenya, and Uganda (United States Fund for UNICEF, n.d.). By 
this point the media had named them the "Lost Boys," an allusion to the group of orphans in J. M. Barrie's fairy tale "Peter Pan" who clung together to escape a hostile adult world.

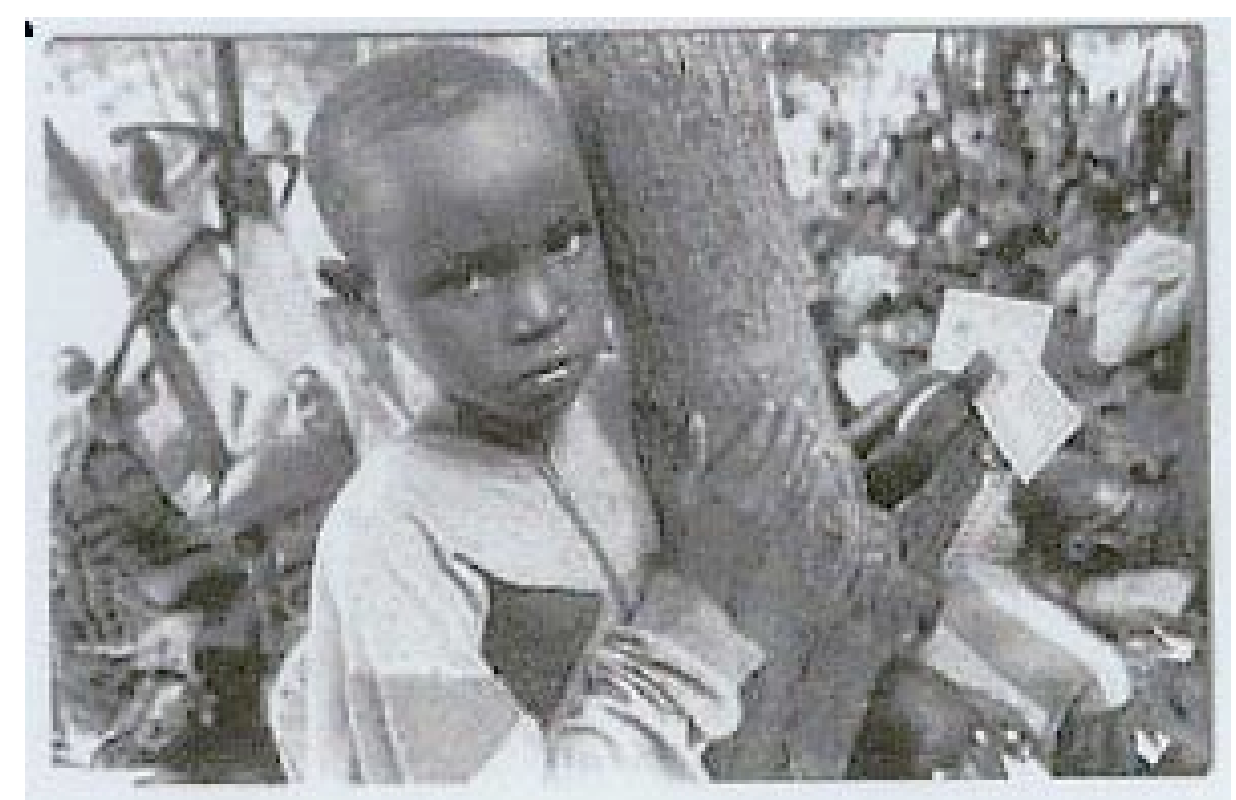

Figure 1.7: A "Lost Boy"

http://www.unicef.org/sowc96/closboys.htm

Kakuma Refugee Camp

The Kakuma Refugee Camp (Figure 1.8), located on the northwestern border of Kenya, has a population of 82,216, of which $82 \%$ are Sudanese. The camp was established in 1992 following the influx of some 20,000 Sudanese asylum-seekers who were fleeing the fighting. The Lutheran World Federation/World Service, as a partner with the United Nations High Commissioner for Refugees (UNHCR), is currently responsible for the management of the camp (www.sudanlostboys.com, 2001). At present, the refugee policy of the Kenyan government only provides for the encampment of refugees. This arrangement severely restricts these refugees, in that it forbids their movement, employment, or local integration. Thus, this policy renders the refugees solely dependent on non-governmental organizations (NGO) to provide assistance for their needs. 
Life in Kakuma was much like life in many other African villages where the youth live in traditional huts in clusters that serve a family-like function (Lorch, 2001). There was tremendous overcrowding, poverty, and squalor. Narrow dirt streets were covered with refuse and sometimes running with open sewerage. In short, life was a struggle. Each refugee had to guard his bimonthly United Nations food rations, which consisted of flour, lentils, sugar, and oil in quantities hardly enough for one meal per day. Sometimes there were riots over food and water distribution. Malaria and other diseases regularly swept through the camp (anonymous, personal communication, May 7, 2002; Harrell-Bond, 2001; www.sudanlostboys.com, 2001).

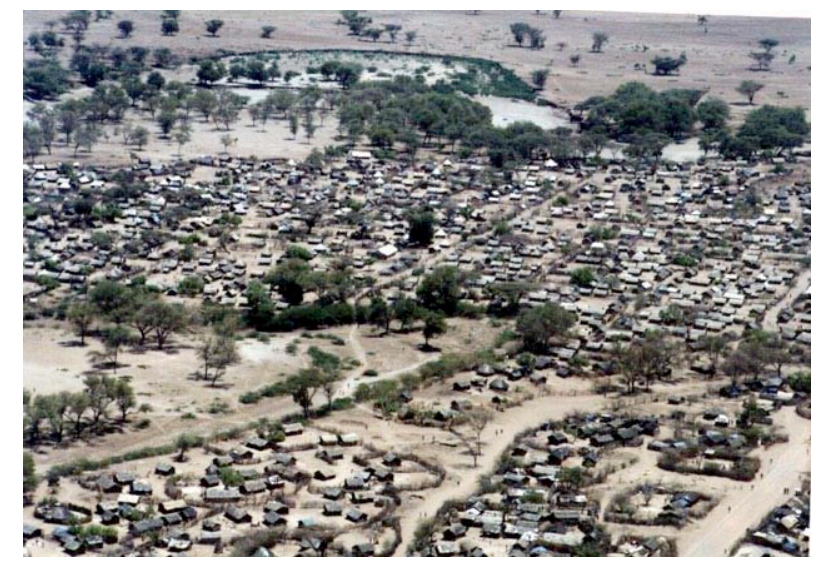

Figure 1.8: Aerial View of Kakuma Refugee Camp http://www.state.gov/g/prm/rls/27435.htm

Due to the limited educational facilities and teachers, most of the refugee children did not attend school consistently or even complete a primary education. In addition, no vocational training was made available.

Because conditions in the camp were volatile, safety and security were tenuous. Given the diverse backgrounds of the refugees, conflicts frequently erupted (U. S. Committee for Refugees and Immigrants, 2001). With guns prevalent in the camp, many of the conflicts ended in violence. In addition, armed robbery was frequent. 


\section{Search for a Durable Solution}

According to the 1951 United Nations Convention Relating to the Status of Refugees (Office of the United Nations High Commissioner for Refugees, 1992), a refugee is a person who "owing to a well-founded fear of being persecuted for reasons of race, religion, nationality, membership in a particular group, or political opinion, is outside the country of the nationality, and is unable to or, owing to such fear, is unwilling to avail himself of the protection of that country" (p. 58). The United Nations High Commissioner for Refugees (UNHCR) is mandated with protecting refugees and finding a durable solution to their situation.

Possible durable solutions include voluntary repatriation to home country, local integration to the country of first asylum, and resettlement in a third country. Voluntary repatriation is feasible when conditions prevail in the country from where the refugee fled that will allow return. This is considered to be the most beneficial solution for refugees as it enables them to resume their lives in a familiar setting under the protection and care of their home country. Local integration in the country of first asylum becomes feasible when the possibility of voluntary repatriation is not foreseeable. Resettlement in a third country is geared primarily to the special needs of refugees. These include refugees with legal and physical protection needs, refugees without local integration prospects, and children and youth (Office of the United Nations High Commission for Refugees, 1992). Cases of refugees in need of resettlement are usually submitted to one of ten principal resettlement countries, one of which is the United States. In 1999, the UNHCR referred over 3,000 youths to the United States for resettlement (Bixler, 2005; S. Weishar, personal communication, April 30, 2000). 


\section{Resettlement in the United States}

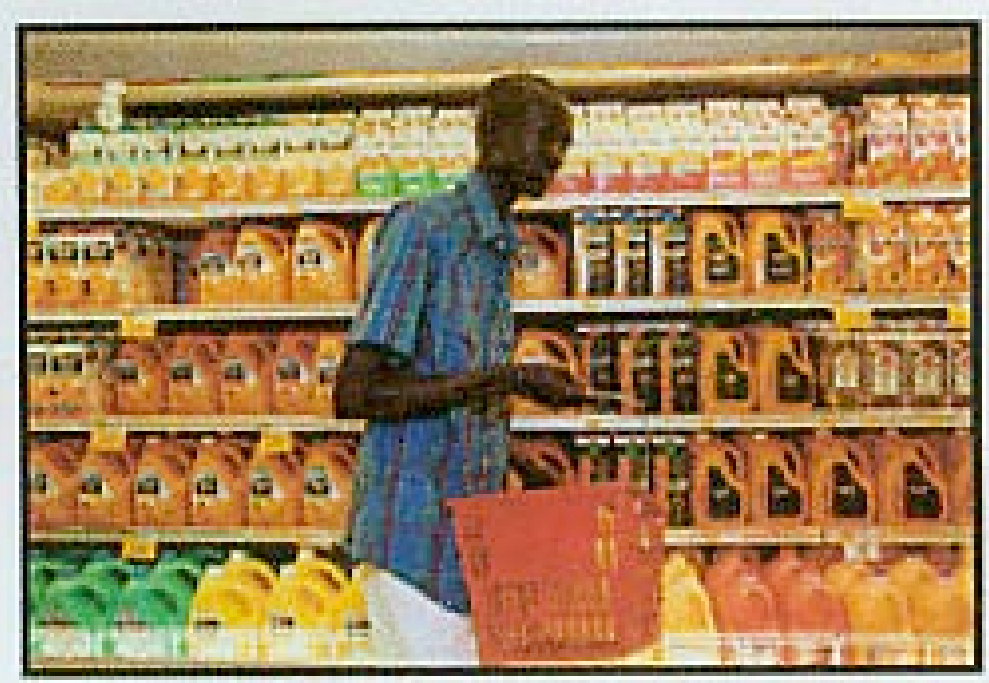

Figure 1.9: A "Lost Boy" Shopping in a Grocery Store in the United States http://gbgm-umc.org/umcor/updates/lostboys.stm

In the fall of 2000 and throughout 2001, approximately 3,600 Sudanese youth and young adults from Kakuma, of the 30,000 to 40,000 who originally fled from the Sudan, were resettled in the US (Figure 1.9). The youth were resettled by voluntary organizations' (VOLOGs) affiliated programs in cities scattered throughout the US. The largest VOLOG is the United States Conference of Catholic Bishops, Migration and Refugee Services.

\section{Theoretical Framework}

\section{Ecological Framework}

The theoretical framework in which this study is grounded is the Ecological Framework, specifically Bronfenbrenner (1979) and Garbarino's (1992) ecological model. The framework will be introduced and generally discussed; however, only concepts relevant to the study will be further elaborated. Furthermore, the concepts of resilience and protective factors will also be presented and discussed at length.

The ecological framework asserts that the family is an open system that functions in relation to its broader sociocultural context (Zastrow \& Kirst-Ashman, 1997). Critical concepts 
of the ecological framework are the ecosystem, boundary, and the environment. The ecosystem, depending on one's unit of analysis, consists of the individual or family in interaction with its environment (Bronfenbrenner, 1979; Whitchurch \& Constantine, 1993; Zastrow \& KirstAshman, 1997). A boundary defines the ecosystem and represents the interface or point of contact between the ecosystem and its environment (Whitchurch \& Constantine, 1993). The environment is everything external to the ecosystem but is in some way in direct or indirect interaction with it (Whitchurch \& Constantine, 1993). Individuals as well as families are dependent upon effective interactions with the environment in order to survive and thrive (Zastrow \& Kirst-Ashman, 1997).

Bronfenbrenner and Garbarino divide the environment into different levels, (Figure 1.10) which they describe these levels as being like a series of Russian eggs, with the largest one cut open to reveal a smaller egg, which when cut open reveals a still smaller egg (Bronfenbrenner, 1979). They suggest that the smallest egg is the microsystem level, then the mesosystem, the exosystem, and finally the macrosystem. The microsystem includes the individual and all persons and groups that incorporate the individual's day-to-day environment. This would also include the individual's intellectual capacities and emotional development, level of functioning, impact of life experiences, and connections and interactions between the individual and others in the environment (Zastrow \& Kirst-Ashman, 1997). The mesosystem involves the relationship between two microsystems that are linked by some individual who exists in both microsystems. The interactions in one microsystem influence the interactions of another (Zastrow \& KirstAshman, 1997). The exosystem includes community-level factors that may not relate directly to the individual but affect the way the individual functions. Finally, the macrosystem involves the 
sociopolitical, historical, economic, and environmental forces that influence... individuals (Barker, 2003).

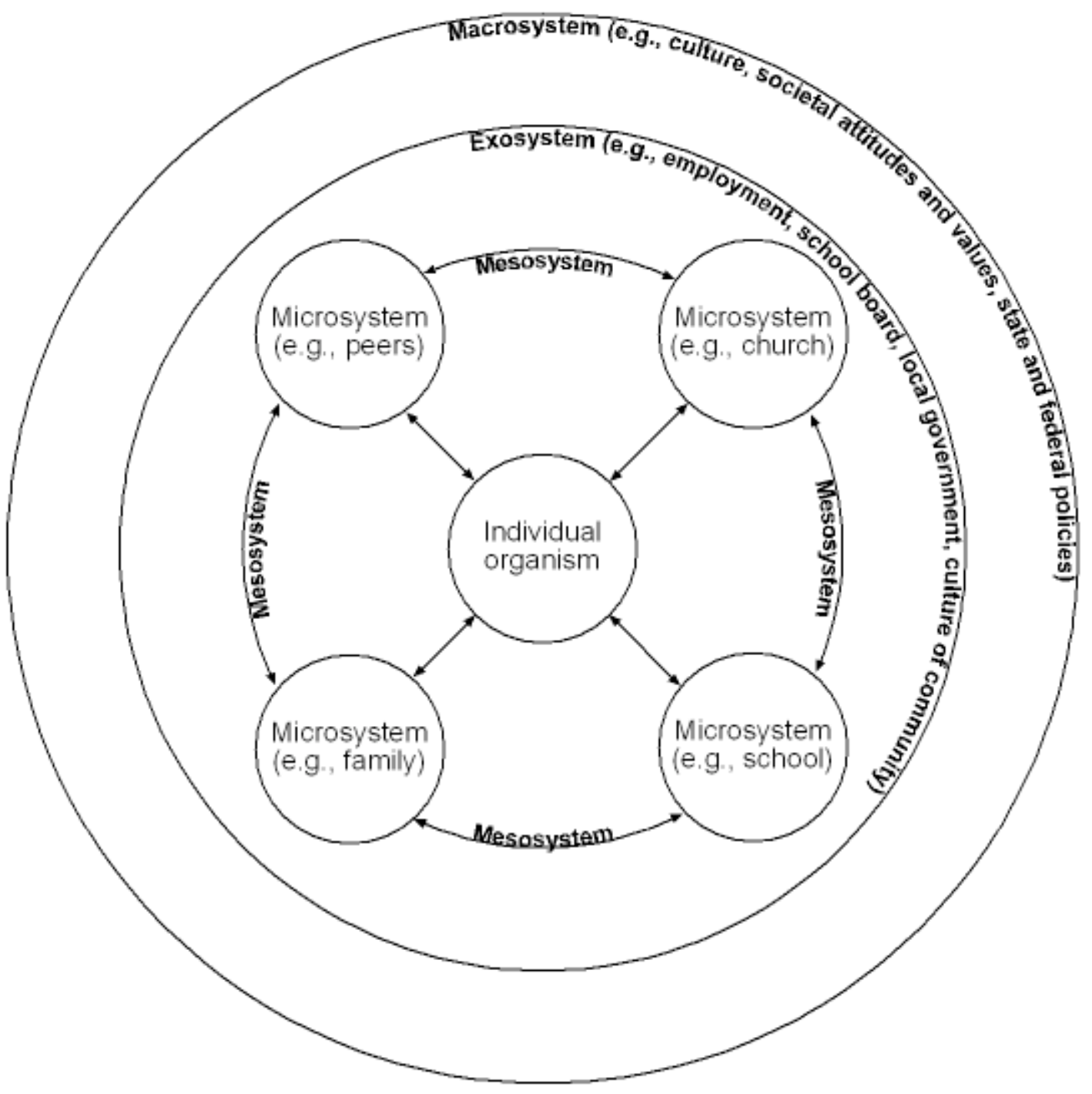

Figure 1.10: The Levels of the Ecological System

Garbarino, James. Children and Families in the Social Environment. $2^{\text {nd }}$ Edition. (New York: Aldine de Gruyter). Copyright @ 1992 Walter de Gruyter, Inc. New York. 
Pertinent to this study were the microsystem, mesosystem, and macrosystem levels. For example, the youth's family, as part of the microsystem, was the focus of the study. However, the impact of life experiences of war, flight, and resettlement on the youth was highlighted in this study as well. Since the purpose of the study was to explore the relationship, or specifically the transaction, between two microsystems - the individual youth and his family - the mesosystem level was an important focus of the study. The macrosystem of the long-term civil wars in the Sudan was prominent as well.

Similarly related concepts associated with the ecological framework are interaction and transaction. Interaction is a process whereby a change or action in one part induces a change in another part (Bubolz \& Sontag, 1993). Transaction, a process of interaction, occurs within families and between families and other systems in the environment. Again, the purpose of the study was to explore the transactions within the youth's families.

Another concept is interdependence, which is the mutual reliance of each person upon every other person (Bubolz \& Sontag, 1993). An individual is interdependent or reliant upon other individuals and groups of individuals in the social environment. Likewise, others are interdependent upon each other. A person cannot exist without other people - they need each other in order to survive (Zastrow \& Kirst-Ashman, 1997). For example, in the Dinka tribe, family members are mutually dependent on one another for provision of goods and services as well as emotional support.

An assumption of the ecological framework is that for an individual or family there are risks and opportunities at each level of the environment. Risks are defined as direct threats to healthy development or the absence of opportunities that facilitate healthy individual or familial development (Bubolz \& Sontag, 1993). Examples of risks are a civil war and flight from it. 
Opportunities encourage the individual or family to meet needs and facilitate healthy development (Bubolz \& Sontag, 1993).

An additional concept is adaptation, which refers to the capacity of an individual or family to adjust to surrounding environmental conditions. Adaptation implies change. An individual or family will change or adapt to new conditions or circumstances in order to continue functioning effectively. As individuals or families are constantly exposed to risks, it is important that they be flexible and capable of adaptation.

\section{$\underline{\text { Additional Concepts }}$}

A considerable number of studies indicate that most children exposed to risks do not go on to have negative outcomes and instead are resilient; that is, they are able to overcome adversity without negative outcomes. Resilience has been characterized in three ways: (1) recovery in the face of trauma or stressor; (2) coping; and (3) the presence of protective factors or processes that moderate the relationship between risk and resilience. Since this study focused on resilience the third definition was utilized - the presence of protective factors that moderate the relationship between risk and resilience. Rutter (1987) defines protective factors as influences that modify, ameliorate, or alter a person's responses to some stressor that predisposes to a negative outcome.

Interdisciplinary research has broadly confirmed the role of three domains of protective factors: (1) individual attributes; (2) family resources; and (3) support systems in the environment. Individual attributes include: (1) temperament; (2) intelligence; (3) social skills; (4) an ability to attract adults as protective agents; (5) sociability and humor as the child gets older; (6) psychological insight; (7) self-efficacy; (8) self-esteem; (9) religious beliefs; and (10) an ability to endow a situation with meaning (Rutter, 1987). Familial resources include: (1) 
attachment to at least one adult in early childhood; (2) constant and consistent nurturing by the primary caretaker during the first year of life with little separation; (3) presence of the father; (4) non-conflicted relationships in the family; (5) the presence of other adult caretakers; (6) four or fewer children in the family spaced no more than two years apart; (7) sibling caretakers or young companions with whom the child can confide; (8) appropriate parental management such as providing structure, rules, and assigning responsibilities; and (9) a network of kin who share similar values and beliefs and to whom the child can turn for advice and support (Rutter, 1987). Support systems in the environment include: (1) the presence of teachers; (2) the presence of other adults to whom the child can turn; (3) peers; (4) opportunities for the child to participate in conventional activities; and (5) supportive institutions (Rutter, 1987).

\section{Purpose of the Study}

The purpose of this qualitative study was to explore the role of familial protective factors in moderating the relationship between risk and resilience in Sudanese refugee youth exposed to political violence. It was anticipated that the study would result in rich, context-bound data and findings that would suggest patterns about the role of familial protective factors in moderating the relationship between risk and resilience in Sudanese refugee youth exposed to political violence.

\section{Rationale for and Design of the Study}

Due to the descriptive, exploratory nature of this study, qualitative methods were most appropriate for the conduct of this study. The research design used a case study methodology. Yin (1993) describes a case study as an empirical inquiry that investigates a contemporary phenomenon within its real-life context, especially when the boundaries between phenomenon 
and context are not clearly evident. A case study may be about singular or multiple cases. This study was a case study of multiple cases and thus was referred to as a collective case study.

Participants were selected by purposive or purposeful sampling utilizing a combination or mixed strategy. Combination or mixed purposeful sampling uses a number of different sampling strategies. These strategies included typical case, reputational, and snowball or chain sampling. All participants were Sudanese refugee youth who were resettled by a United States Conference of Catholic Bishops, Migration and Refugee Services affiliated program in a mid-sized city in the Midwest. Data were collected through interviews, direct observations, and physical artifacts.

\section{Definitions}

The following definitions apply to terms as they were used in this study:

Adaptation- the ability to adjust to surrounding environmental conditions.

Child- every human being below the age of 18 (Office of the United Nations High

Commissioner for Human Rights, 1989).

Childhood- period of life of every human being under the age of 18 (Office of the United Nations High Commissioner for Human Rights, 1989).

Internally Displaced Person- "persons or groups of persons who have been forced or obliged to flee or to leave their homes or places of habitual residence, in particular as a result of, or in order to avoid, the effects of armed conflict, situations of generalized violence, violations of human rights, or natural or human made disasters, and who have not crossed an internationally recognized state border" (United Nations Office for the Coordination of Humanitarian Affairs, n.d.).

Moderate- limited in scope or effect (Mish, 2004). 
Political Violence- violence perpetrated by one set or group of people on another set or group of people who were strangers to each other before the violence occurred (Cairns, 1996).

Process- a natural phenomenon marked by gradual changes that lead toward a particular result (Mish, 2004).

Protective Factors- influences that modify, ameliorate, or alter a person's responses to some stressor that predisposes to a negative outcome. There are three domains of protective factors: (1) individual attributes; (2) family resources; and (3) support systems in the environment (Rutter, 1987).

Refugee- "any person who, owing to a well-founded fear of being persecuted for reasons of race, religion, nationality, or membership of a particular group or political opinion, is outside the country of his nationality and is unable, or owing to such fear, is unwilling to avail himself of the protection of that country" (Office of the United Nations High Commissioner for Refugees, 1992).

Resilience- a dynamic process encompassing positive adaptation within the context of significant adversity (Coleman \& Ganong, 2002; Luthar, Cicchetti, \& Becker, 2000).

Resiliency- a personal attribute (Coleman \& Ganong, 2002; Luthar, et al. 2000).

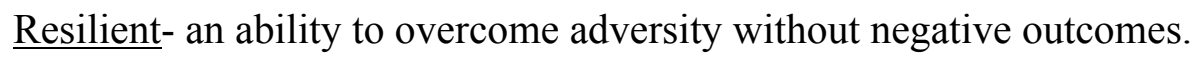

Risks- direct threats to healthy development or the absence of opportunities that facilitate healthy individual or family development (Rutter, 1987; Werner \& Smith, 1988).

Surrogate- one who takes the place of another (Mish, 2004).

Youth- period of life between childhood and maturity, a young man, and younger persons (Mish, 2004). 


\section{Statements of Delimitations and Limitations}

\section{$\underline{\text { Delimitations }}$}

Delimitations are how a study is narrowed in scope. There were a number of parameters that were established for this study. They were related to the participants, data collection, and findings. Participants were restricted to those who met the following criteria: male Sudanese nationals who as refugees from the UN administered Kakuma refugee camp in Kenya were resettled by a United States Conference of Catholic Bishops, Migration and Refugee Services affiliated program in a mid-sized city in the Midwest and were considered to be a Lost Boy. I utilized interviews, direct observations, and physical artifacts as my data collection sources. Thus, the data were restricted to what was verbally and nonverbally communicated as well as what was created during my interviews with the youths, my analytic impressions of the interview and observational experiences, and examination and analysis of physical artifacts. It was anticipated that the study would result in rich, context-bound data and findings that suggest patterns about the role of familial protective factors in moderating the relationship between risk and resilience in Sudanese refugee youth.

\section{$\underline{\text { Limitations }}$}

Limitations are potential weaknesses in the design of the study. Two foreseen weaknesses in the study were the design of the study and the type of participant. Typical of qualitative inquiry - as well as due to the number of participants - this study, as designed, made no claims regarding generalizability to other refugee groups or children exposed to political violence or war. In addition, the uniqueness of the study with the specific context makes it unlikely that it could be replicated exactly in another context. Those who participated in the study were those who were willing to participate. Thus the participants were limited to those motivated and 
willing to participate and who were verbal and insightful enough to be able to answer the questions posed. This may have restricted in some unforeseen manner the data obtained.

\section{Assumptions}

Based upon my life experiences and work with refugees, as well as my review of the literature on children and political violence, refugee children and resilience, I identified the following assumptions which undergird my thinking about the phenomenon of interest. They were as follows:

(1) All of the youth were exposed to tremendous stressors and risks as children;

(2) Some of the participants may have been negatively affected in some way by their experiences in the Sudanese civil war and subsequent flight;

(3) Individuals seek to restore order, balance, and harmony;

(4) Many, if not all, have been able to overcome the risks;

(5) Individuals benefit from and contribute to a network of relationships in their family and community particularly during times of crisis;

(6) An ability to overcome these risks is due to many factors but in particular, the influence of one's family;

(7) Familial protective factors and family processes moderate the recovery and resilience of family members; and

(8) Most of the Sudanese refugee youth are resilient.

\section{Organization of the Dissertation}

This dissertation is organized in the traditional format. This chapter, an introduction, provides pertinent information for understanding the genesis of my personal interest in the area of the study. It provides an overview of the Sudan, the historical and political backgrounds of its 
civil wars, and an introduction to the Lost Boys. This chapter also discusses the theoretical and conceptual frameworks in which the study is grounded, the purpose of the study and a brief description of its design, a list of terms and their meanings as used in the study, statements of delimitations and limitations, and finally a discussion of the assumptions of this researcher that undergird the study.

Chapter Two presents a summary of the literature relevant to the role of familial protective factors in moderating the relationship between risk and resilience in Sudanese refugee youth exposed to political violence. It consists of reviews of the literature on children and political violence, refugee children and unaccompanied refugee children. It also reviews the literature on risk factors, resilience, and protective factors.

Chapter Three presents the research questions, research design, assumptions of quantitative and qualitative paradigms, and rationale for using qualitative methodology for the study. It describes the research plan, sampling strategies, process of gaining entry, and the rights of the participants. It also describes case study methodology, the data sources, and data collection procedures.

Chapter Four introduces the participants of the study and presents summaries of their experiences of the Sudanese civil wars and their responses to the interview questions. It also provides a group summary of the participants.

Chapter Five provides a discussion of the data. It reviews the data sources and the associated data collection procedures. It discusses the data analysis procedures of data reduction, data display, drawing and verification of conclusions. It also introduces, discusses, and elaborates upon the themes or results; and reviews and answers the research questions. 
Finally, Chapter Six reviews the purpose of the study, summaries of the procedures used in the study and themes, and the interpretation of the themes. Also, limitations are noted and discussed. Finally, implications and recommendations for policy, practice, and future research are provided and discussed. 


\section{CHAPTER TWO: REVIEW OF THE LITERATURE \\ Introduction}

This chapter presents a summary of the literature relevant to the role of familial protective factors in moderating the relationship between risk and resilience in Sudanese refugee youth exposed to political violence. The review of the literature is arranged in four parts: the first part reviews the literature on children and political violence; the second part considers one of the consequences of political violence - migration, specifically migrating across an international boundary and, according to the United Nations, becoming a refugee. This second part also addresses a specific category of refugee - the unaccompanied child. The third part reviews the literature on risk factors in children. In doing so, it contrasts research on the subject which focuses on the role of various risk factors in the development of psychological symptoms and disorders, including Post-traumatic Stress Disorder with the literature that focuses on resilience. The final part explores resilience and protective factors.

\section{Children and Political Violence}

Children all over the world are witnessing, experiencing, and participating in acts of political violence perpetrated by one set of people upon another (Cairns, 1996; Jensen \& Shaw, 1993). The term child is difficult to define because the age at which childhood ceases differs by context. The definition provided by the United Nations Convention of the Rights of the Childthat is, every human being below the age of 18 (Office of the UN High Commissioner of Human Rights, 1989) - will be used.

Political violence is defined as violence perpetrated by one set or group of people on another set or group of people who were often strangers to each other before the violence occurred (Cairns, 1996). According to the United Nations International Children's Fund (n.d., 
1996), there have been over 150 major conflicts worldwide since 1945. Most are relatively shortlived while a few of the conflicts have existed for many years, such as in the Sudan where civil wars have raged for the past 30 years. Throughout history, political conflicts and war have exacted a horrific toll on civilians (Machel, 2001). Unfortunately, they have become increasingly devastating for civilians and in particular, children (Maksoud, Aber, \& Cohn, 1996; Onyango, 1998; Raundalen \& Melton, 1994; United Nations International Children's Fund, n.d.; War Child, n.d.). In World War II, $20 \%$ of the casualties were civilians; by the end of the 1980 s, however, between 80 and $90 \%$ of the causalities in conflicts have been civilians (Raundalen \& Melton, 1994; Richman, 1993; Suplido, 1997; War Child, n.d.). A staggering 2 million children have died in the last decade alone and, over 1 million children have been orphaned (Onyango, 1998).

Between 4 and 6 million children have become disabled. Small arms and light weapons maim and kill thousands of children in conflicts each year. In addition, landmines and unexploded ordnance - bombs, shells and grenades that fail to detonate on impact yet may eventually be set off years later - maim and kill not only in the midst of conflict, but for many years after the conflict has ended. African children live on the continent most plagued by landmines (Machel, 2001; Raundalen \& Melton, 1994).

Children have also become combatants (Onyanga, 1998). A child soldier (Figure 2.1) is defined as any child - boy or girl - under the age of 18 who is compulsorily, forcibly, or voluntarily recruited or used in hostilities by armed forces, paramilitaries, civil defense units, or other armed groups (Machel, 2001). Child soldiers are used as combatants, messengers, porters and cooks, as well as the forced provision of sexual services. Most are adolescents, though many are 10 years of age or younger. The majority are boys but a significant proportion overall are 
girls. Current estimates put the number of child soldiers at about 300,000 at any one time, but the cumulative total is much larger (Lustig et al., 2002; Machel, 2001). As children are killed or wounded or manage to grow to adulthood, their places are taken by new children.

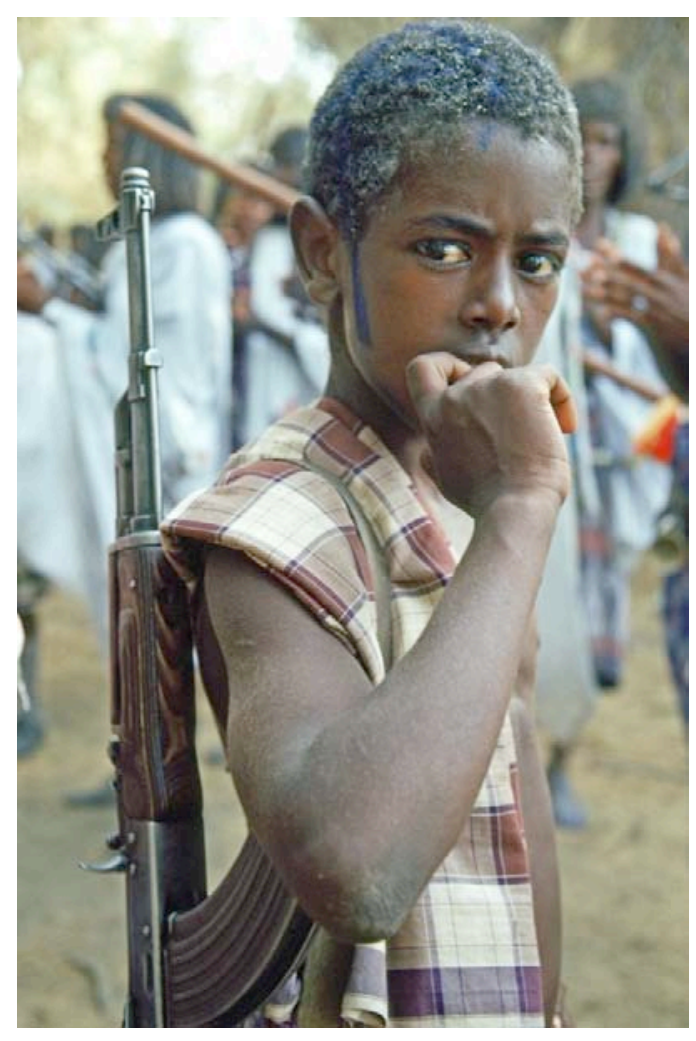

Figure 2.1: Sudanese Child Soldier http://www.child-soldier.org

It is estimated that 10 million children have been psychologically traumatized by these events. The prevalence of psychological trauma has been estimated to be from 10 to $90 \%$. This trauma is manifested as anxiety, depression, unresolved grief reactions, disruptive behaviors, somatic symptoms, and Post-traumatic Stress Disorder (PTSD) (Allwood, Bell-Dolan, \& Husain, 2002; Eth \& Pynoos, 1985; Goodwin, 1988; Herman, 1992; Thabet \& Vostanis, 1999).

Conflicts all over the world force people to flee and seek places of safety elsewhere. Some people seek to move to new places within their country and are referred to by the UN as internally displaced persons (IDPs), while others cross international borders and become 
refugees. Current estimates are that there are 30 million IDPs and 27.4 million refugees globally (United Nations High Commissioner for Refugees, 2005). It is estimated that 25 million children have been forced to flee their home communities, either as IDPs or refugees (United Nations High Commissioner for Refugees, n.d.; United States Fund for UNICEF, n.d.). More than 5 million children are living in refugee camps (Raundalen \& Melton, 1994). Many more have become street children. Although such forced movement occurs throughout the world, Africa and Asia have been most affected. In the chaos of a conflict many children are separated from their parents or relatives and are forced to journey alone. In southern Sudan, some 20,000 unaccompanied children from 7 to 17 years of age trekked between Sudan, Ethiopia, back to the Sudan, and finally to Kenya between 1983 and 1991 (Bixler, 2005; Crawley, 2000; Refugees International, 1998).

Large numbers of the displaced and refugees end up in camps, many of which are overcrowded and lack adequate sanitation, clean water, and food. Fights between various groups are continuously breaking out. The camps are often raided by rebels seeking recruits, as well as by government soldiers who believe that the camp residents are sympathetic to rebel movements.

According to recent estimates by the UNHCR, the number of refugees globally had reached 27 million people, half of whom are believed to be children (United Nations High Commissioner for Refugees, 2005). The 1951 UN Convention Relating to the Status of Refugees defines a refugee as any person "who owing to a well-founded fear of being persecuted for reasons of race, religion, nationality, or membership of a particular group or political opinion, is outside the country of his nationality and is unable, or owing to such fear, is unwilling to avail himself of the protection of that country." Refugees are those individuals who are forced to leave their country to avoid persecution, armed conflict, or other forms of violence. 


\section{Refugee Children}

Children who flee their homes as refugees face a broad range of challenges. Young children have especially high mortality rates during and immediately following exile (Jablensky, Marsella, Ekblad, Jansson, Levi, \& Bornemann, 1994; United Nations International Children's Fund, 1996). They are often at high risk of physical injury and illness due to conditions of the

journey (e.g., difficult terrain, lack of food, water and shelter), as well as their ongoing exposure to aerial bombings, landmines, confrontations with military or militias, and sniper fire. The deprivations and exertions of flight also render a significant number of refugee children with a poor nutritional status (Ahern, Loughry, \& Ager, 1999). In addition, mass population movements, close proximity, and poor sanitation facilities create the conditions for transmission of infectious diseases.

In general, refugees are at high risk for mental health problems, and refugee children and adolescents are particularly vulnerable (Rousseau, 1995). The literature on refugee children reports a wide range of symptoms: anxiety, recurring nightmares, insomnia, secondary enuresis, introversion, depressive symptoms, behavioral problems, academic difficulties, and somatic problems (Allodi, 1980; Arroyo \& Eth, 1985; Athey \& Ahearn, 1991; Boothby, 1992; Kinzie \& Sack, 1991; Kinzie, Sack, Angell, Clarke, \& Ben, 1989; Kinzie, Sack, Angell, Manson \& Rath, 1986; Westermeyer \& Wahmanholm, 1996).

\section{Unaccompanied Refugee Children}

In the chaos of conflict many refugee children become separated from their parents and relatives and are then forced to go into exile unaccompanied by any adult responsible for their well-being (Miller, 1998). This category of refugee child is referred to as an unaccompanied child. Although precise data regarding the number of unaccompanied children in the world today 
are not available, Ressler, Boothby, and Steinbock (1988) have suggested that the total number may well be in the hundreds of thousands.

Among refugee children, those who are unaccompanied refugee children are considered to be in the highest risk group for psychological trauma among refugee children (Ressler et al., 1988; Sourander, 1998). This is based on the recognition of the extreme nature of their experiences - loss of family, deprivation of emotional relationships, loss of a familiar environment, and considerable traumas related to armed conflict or war in their country of origin, as well as during their flight. Studies have shown that unaccompanied children have more emotional distress and poorer adjustment than children who faced the refugee experience with their families (Masser, 1992; Melville \& Lykes, 1992; Ressler et al., 1988). Several studies indicate a high incidence of behavioral problems, somatic problems, depression, suicide attempts, and transitory psychotic episodes (Charron \& Ness, 1981; Looney, Rahe, Harding, Ward, \& Liu, 1979; Pask \& Jayne, 1984; Rahe, Looney, \& Ward, 1978; Ressler et al., 1988).

\section{Risk Factors}

Garmezy and Rutter (1983) have defined risk factors as those circumstances that increase the likelihood of a negative outcome. Risk factors include characteristics of individuals and families, social contexts, or the interactions between persons and the environment. Single risk factors rarely determine later outcomes. Evidence suggests that it is the accumulation of risk factors that increases vulnerability to adverse outcomes.

The effects of risk factors on various groups have been studied over the years. The first group studied were child victims and evacuees of the Nazi bombing of London during World War II (Freud \& Burlingham, 1943). Shortly thereafter, Hill (1949) studied the stress of military family members who were separated due to the war. Years later numerous studies were done on 
Vietnam War veterans and the development of symptoms associated with Post-traumatic Stress Disorder. Shortly thereafter, the research was expanded to include victims of domestic violence and rape, and children who were victims of physical and sexual abuse (Burgess \& Holmstrom, 1979; Goodwin, 1988; Russell, 1975). In recent years the effects of violence on various aspects of child development has been the focus of study. The subjects have included children from war zones, refugee children, unaccompanied refugee children, and children from communities beset with violence (Garbarino, Kostelny, \& Dubrow, 1991; Kinzie et al., 1986; Rayhida, Shaya, \& Armenian, 1986; Sack, Angell, Kinzie, \& Rath, 1986).

The results of these studies have indicated that risk factors can influence children in a number of ways. Here, I will only discuss the psychological and social effects. A whole spectrum of psychological symptoms have been mentioned in the literature: anxiety, depression; fear, grief, guilt, panic, and worry (Eth \& Pynoos, 1985; Gold, Goodwin, \& Chrousos, 1988; Herman, 1992; Pynoos, 1992; Pynoos, Frederick, Nader, Arroyo, Steinberg, \& Eth, 1987; Richman, 1993). Other symptoms that have been noted are aggression; an excessive demand for affection and security from parents and/or other adults; enuresis; encopresis; learning difficulties; loss of appetite; nightmares; psychosomatic disorders such as migraines, stomach pains, asthma, and allergies; regressive behavior; PTSD; school refusal; sleep problems; and stammering (Fraser, 1977; Ronstrom, 1989; Toner, 1994).

The vast majority of these studies have focused on the role of risk factors in the development of psychological symptoms and disorders. However, the results of these and other studies have indicated that most children exposed to risk factors do not go on to have a negative outcomes and instead are resilient (Garmzey \& Masten, 1991; Rutter, 1983, 1985, 1987; and Werner \& Smith, 1981). 


\section{Resilience}

There has been growing scholarly attention in the past three decades to the concept of resilience. It represents a departure from an intense focus on risk factors and their relation to the development of psychological symptoms and disorders (Conrad \& Hammen, 1993; Cowen, Kerley, Work, \& Wyman, 1993; Fergusson, Horwood, \& Lynskey, 1996; Luthar \& Zigler, 1991; Radke-Yarrow \& Brown, 1993).

The concept of resilience has been defined in many ways over the years. However, most researchers have defined it as a dynamic process encompassing positive adaptation within the context of significant adversity (Coleman \& Ganong, 2002; Ganong \& Coleman, 2002; Masten, Best, \& Garmezy, 1990). Implicit in this notion has been two critical conditions: (1) exposure to significant threat or severe adversity; and (2) the achievement of positive adaptation despite adverse and challenging circumstances (Luthar, Cicchetti, \& Becker, 2000).

Resilience has been characterized in three ways: (1) it has been equated with coping which is defined as efforts to restore or maintain internal or external equilibrium under significant threat by means of human activities including thoughts and actions (Masten et al., 1990); (2) it has been viewed as recovery in the face of trauma such as abuse or injury; and (3) it has been characterized as the presence of protective factors or processes that moderate the relationship between stress and risk, on the one hand, and coping and competence on the other.

Initially, researchers found increasing evidence that the same adversity could result in different outcomes. In early, groundbreaking studies, such as the Kauai Longitudinal Study, Werner and colleagues (Werner \& Smith, 1981, 1988; Werner, 1992) followed the progress of over 200 high-risk children born in Kauai, Hawaii for a period of 32 years. In the Minnesota Project Competence, Garmezy and colleagues (1984) studied over 200 children from urban areas 
in Minnesota as well as children with physical disabilities. Likewise, Rutter (1987) studied the effects of numerous risk factors on children in the British National Child Development Study. The conclusions of these studies was that not all children and youth subjected to high levels of risk factors experience poor outcomes. Most children were resilient, that is, they were able to overcome adversity without apparent negative outcomes. There was evidence to indicate that considerable recovery from early trauma is not merely possible, but common (Anthony, 1987; Garmezy \& Rutter, 1983, 1985; Werner \& Smith, 1981). The fact that most children were resilient led to a search for factors which differentiated those children who escaped the more severe forms of stress from those who did not.

Initial studies focused on personal traits associated with resilience reflecting the dominant cultural ethos of the "rugged individual." Resilience was viewed as inborn or acquired on one's own, as in the "invulnerable child" thought to be impervious to stress because of inner fortitude (Anthony, 1987). Current research views resilience in terms of the interplay of risk and protective processes over time, involving individual, family, and larger sociocultural influences (Garmezy \& Masten, 1991; Masten, Best, \& Garmezy, 1990; Rutter, 1987).

Resilience in children has since been examined in response to many adverse circumstances, for example poverty (Cowen, Wyman, \& Work, 1988; Garmezy \& Masten, 1991); abuse and neglect (Cicchetti \& Rogosch, 1997; Heller, Larrieu, D’Imperio, \& Boris, 1999); divorce (Pedro-Carroll, Sutton, \& Wyman, 1999), and parental mental illness (Beardslee, 1989; Radke-Yarrow, Nottelmann, Martinez, Fox, \& Belmont, 1992).

\section{Protective Factors}

Rutter (1987) has defined protective factors as influences that modify, ameliorate or alter a person's response to some environmental hazard that predisposes to a negative outcome. Thus, protective factors come into play once risk is established and then moderate the likelihood of 
developing symptoms or problems. Interdisciplinary research has indicated that there are three domains of protective or moderating influences: (1) individual attributes of the child or adolescent; (2) family resources; and (3) support systems in the environment (Rutter, 1987). Protective factors have been hypothesized to exert their beneficial influences in either of two ways. For example, a protective factor can have an equally beneficial effect across an individual's risk status (Garmezy et al., 1984). This type of effect is indicated by a negative main effect of the protective factor (e.g., intelligence) on the maladaptive outcome of interest (e.g., aggression.) Alternatively, the protective factor may have a particularly beneficial effect on highrisk individuals relative to low-risk individuals. This type of effect is indicated by an interaction between the protective factor and the risk factor (Brook, Momura, \& Cohen, 1989 as cited in Freitas \& Downey, 1998; Zimmerman \& Arunkumar as cited in Freitas \& Downey, 1998). Evidence has indicated that particular factors rarely serve exclusively risk or protective functions (Freitas \& Downey, 1998).

Individual Attributes or Individual Protective Factors

The results of several longitudinal studies (Garmezy et al., 1984; Rutter, 1983, 1985, 1987; Werner \& Smith, 1981) have identified specific individual attributes or protective factors that distinguish resilient children. These include: (1) an active, evocative approach toward problem-solving, enabling the individual to negotiate an array of emotionally hazardous experiences; (2) an ability from infancy on to gain others' positive attention; (3) an optimistic view of the experience even in the midst of suffering; (4) an ability to maintain a positive vision of a meaningful life; (5) an ability to be alert and autonomous; (6) a tendency to seek novel experience; and (7) a proactive perspective. 
In subsequent studies researchers have identified additional protective factors. These include: (1) temperament (Rutter, 1987); (2) intelligence (Rutter, 1987); (3) sociability and a sense of humor as the child gets older (Rutter, 1987); (4) a high activity level (Rutter, 1987); (5) an ability to interact positively with others (Cowen \& Work, 1988); (7) self-reliance and an ability to think and act independently (Masten, 2001; Masten et al., 1990; Rutter, 1987); (8) high self-esteem and self-concept (Rutter, 1987); (9) an ability to self-reflect (Garmezy \& Masten, 1991; Rutter, 1987); (10) an ability to endow a situation with meaning (Rutter, 1987); (11) an ability to find meaning in one's life (Parry \& Shapiro, 1986); and (11) religious beliefs (Rutter, 1987).

\section{Family Resources or Familial Protective Factors}

Along with individual factors researchers have found an array of family resources or familial protective factors that moderate risk. Specific family resources or familial protective factors include: (1) attachment to at least one adult in early childhood; (2) constant and consistent nurturing by the primary caretaker during the first year of life with little separation; (3) presence of the father; (4) non-conflicted relationships in the family; (5) the presence of other adult caretakers; (6) four or fewer children in the family spaced no more than two years apart; (7) sibling caretakers or young companions with whom the child can confide; (8) appropriate parental management such as providing structure, rules, and assigning responsibilities; and (9) a network of kin who share similar values and beliefs and to whom the child can turn for advice and support (Garmezy et al., 1984; Rutter, 1983, 1985, 1987; Werner, 1984; Werner \& Smith, 1981).

Other familial protective factors that have been noted by researchers in later studies include: (1) the presence of at least one stable emotional relationship with a parent who can 
provide a supportive climate for constructive coping with conflicts, and (2) the ability of parents to provide support and guidance (Garbarino et al., 1991; Bliesener \& Losel, 1992).

Studies identifying factors that help support resiliency in children have noted often that it is the parents that make a difference. While it is true that parents, especially the mother, can play such a role, the circumstances in which the child's family can serve to protect the child psychologically are now seen to be more limited than earlier claims would have led one to expect (Coleman \& Ganong, 2002).

\section{$\underline{\text { Support System or Social Protective Factors }}$}

Along with individual or familial protective factors researchers have found an array of support system or social protective factors that moderate risk. Support system or social protective factors include: (1) the presence of other adults to whom the child can turn, such as teachers; (2) peers; (3) opportunities for the child to participate in conventional activities; and (4) the presence of supportive institutions, such as schools (Garbarino, 1991; Losel \& Bliesener, 1992; Rutter, 1987).

Social protective factors are of two types: supportive people and supportive institutions. One of Werner \& Smith's $(1981,1988)$ most significant contributions was identifying supportive people or role models as protective factors. Examples of supportive people include individual teachers, school counselors, coaches, supervisors of after-school programs, mental health workers, workers in community centers, clergy, and close neighbors.

Resilient children often have a number of mentors throughout their development. These people provide: (1) esteem support, or indications that the child is a person of value; (2) informational support, or helpful problem-solving advice; (3) instrumental support, or providing or connecting to specific resources or services that may be of assistance; and (4) companionship 
support, or opportunities to engage in activities with others. Finally, these people provide connections with peers and activities that are socially rewarding and that also foster social values and connectedness. This typically takes place in supportive environments that offer numerous chances to connect with conventional opportunities and institutions.

Although a considerable amount of research has been conducted on the experiences of adult refugees, there has been much less research on the experiences of child refugees. Most of the studies that have been conducted on these two groups of refugees have focused on their psychological distress and pathology. Many researchers have criticized this focus stating it is exaggerated because of a lack of racial and cultural understanding and sensitivity. They have argued that these are normal responses to abnormal situations that are misconstrued as abnormal states (Hodes, 2000; Richman, 1993). Others have questioned the application of Western and biomedical views of psychiatric classification in a culturally diverse world.

There have been a large number of studies in the area of resilience. However, most of these studies have been conducted with adult subjects in the West. Few studies have focused on resilience and adult refugees from non-Western, African, or Asian backgrounds and even fewer on child refugees. I was not able to find any studies on refugees that considered the role of protective factors and resilience. Yet, Werner in 1989 suggested that the study of protective factors was a promising concept in connection with the studies of refugees. In addition, some researchers are of the opinion that qualitative material simply does a better job of explaining the problems faced by those who live in areas dogged by community strife (Garbarino et al., 1991). Thus, this qualitative research study was designed in consideration of these recommendations for future research. 
The following is a summary of relevant findings from a review of the literature as discussed in this chapter. Political violence is prevalent throughout the world and devastating to civilians, particularly children. There are an estimated 27 million refugees, half of whom are children. The effects of risk factors have been studied on groups over the years. An example of a specific risk factor that has been studied is political violence. Some of the groups that have been studied include children from war zones and refugee children. Exposure to risk factors has various outcomes. Most studies have indicated that children are resilient. Protective factors have shown to play a role in moderating risks with the various groups that have been studied. The mechanisms or processes that are involved is unknown. 


\section{CHAPTER THREE: METHODOLOGY}

\section{Introduction}

This chapter presents the research questions, research design, assumptions of quantitative and qualitative paradigms, and the rationale for using qualitative methodology for the study. Then, the research plan, sampling strategies, process of gaining entry, and rights of the participants are introduced. Finally, case study methodology, the data sources and collection procedures are discussed.

\section{Research Questions}

The global research question that was the focus of this study is: "What is the role of familial protective factors and processes in moderating the relationship between risk and resilience in Sudanese refugee youth exposed to political violence?" Subquestions designed to support this question are: (a) "Do these protective factors actually moderate the relationship between risk and resilience in the group in question?"; (b) "If they do, then how do familial protective factors moderate the relationship between risk and resilience?"; (c) "How are familial protective factors organized in order to initiate the processes that moderate the relationship between risk and resilience?"; (d) "If familial protective factors do not moderate the relationship, then what factors do?"; (e) and "Does the separation of the youth from their family of origin affect the moderating relationship of the familial protective factors?"

The purpose of the study was to explore the role of familial protective factors in moderating the relationship between risk and resilience in Sudanese refugee youth exposed to political violence utilizing a case study design. It was anticipated that the study would result in rich, context-bound data and findings that would suggest patterns about the role of these factors in moderating the relationship between risk and resilience in Sudanese refugee youth. 


\section{Research Design}

Philosophers of science and methodologists have been engaged in a long-standing debate about how best to conduct research (Patton, 1990). This debate has centered on two fundamentally different and competing paradigms: positivism and post-positivism. Positivism uses experimental or quantitative methodology and usually refers to the collection and analysis of numerical data (Marshall \& Rossman, 1999). Post-positivism uses naturalistic or qualitative methodology and tends to refer to forms of data collection and analysis that rely on understanding, with an emphasis on meanings (Marshall \& Rossman, 1999).

\section{Assumptions of the Paradigms}

Each paradigm has assumptions based on ontological, epistemological, axiological,

rhetorical, and methodological considerations (Creswell, 1994; Denzin \& Lincoln, 2000; Patton, 1990). These considerations influence the values, thinking, and the manner in which one approaches research (Patton, 1990). The ontological assumption concerns the nature of reality. The quantitative researcher views reality as objective, singular, and apart from the researcher. This view differs significantly from the qualitative researcher's view of reality, which regards reality as including the subjective and multiple perceptions of participants in the study (Creswell, 1994).

The epistemological assumption concerns the relationship of the researcher to that which is being researched. The quantitative researcher's approach is that the researcher should remain distant and independent from that being researched. In contrast, the qualitative researcher's approach is that the researcher interacts with that being researched (Creswell, 1994). 
The axiological assumption concerns the role of values in a study. The quantitative researcher is value-free and unbiased. This is impossible according to the qualitative researcher, who is value-laden and biased (Creswell, 1994).

The methodological assumption concerns the process of research. Quantitative methodology uses a deductive form of logic wherein hypotheses and theories are tested in a cause-and-effect order. Concepts, variables, and hypotheses are chosen before the study begins and remain fixed throughout the study. The goal of a study is to develop generalizations that contribute to theory and thus enable one to better predict, explain, and understand some phenomenon. These generalizations are enhanced if the information and instruments used are valid and reliable (Creswell, 1994; Patton, 1990). By contrast, qualitative methodology uses inductive logic. Categories emerge from informants, rather than being identified a priori by the researcher. This results in rich, context-bound information that may lead to patterns or theories capable of explaining a phenomenon. The question about the accuracy of the information may not surface in a study but, if it does, the researcher takes steps to verify the information with informants or by triangulating, that is, by using several, different sources of information (Creswell, 1994).

The rhetorical assumption concerns the language of research. According to the quantitative researcher, the language should be kept formal and impersonal. For the qualitative researcher the language used is informal and personal (Creswell, 1994).

\section{The Qualitative Approach}

\section{Characteristics of and Rationale for the Qualitative Approach}

In that the qualitative approach was used in this study, the following six characteristics are particularly worthy of note: the use of a naturalistic inquiry; personal contact and insight with 
empathic neutrality; context sensitivity; a unique case orientation; attention to dynamic systems; and qualitative data with inductive analysis (Merriam, 1988; Patton, 1990). These characteristics are defined below.

A naturalistic inquiry involves the researcher going to the informants or the setting in which they cluster to interview or observe. For this study I traveled to a resettlement site where a large number of Sudanese refugee youth resided. There, I interviewed the youth either at the administrative office of the resettlement agency or in their homes. Most of the observations that I made occurred in the youths' homes, although some were done at a community college and a restaurant.

In my study personal contact and insight are indicative of the researcher's direct contact and close works with the informants, situation, or phenomenon that is being studied. In addition, the researcher's personal experiences and insights are an important part of the inquiry and critical to understanding the phenomenon (Patton, 1990). Nonetheless, the researcher maintains a neutral, nonjudgmental stance toward whatever content may emerge (Patton, 1990). Herein, I have provided a great deal of personal information and revealed my assumptions concerning this inquiry. However, I believe I have taken a nonjudgmental stance concerning the content that emerged from the interviews, observations, and physical artifacts.

Context sensitivity refers to placing the findings in a social, historical, and temporal context (Patton, 1990). The findings from this study are inextricably linked to the context of Sudanese refugee youths who: (1) experienced aspects of the world's longest ongoing civil wars; (2) fled for safety to surrounding countries and in the process became refugees; (3) lived in a refugee camp; and (4) later resettled in the United States. 
Unique case orientation assumes that each case is special. The researcher can best demonstrate this assumption by carefully interviewing and capturing the details of each case. To meet this criterion, I assumed that each case was unique and special and I carefully considered the interview questions in my preparation for each interview. After many years of experience interviewing clients, I believe that my listening skills enabled me to capture the details of each unique case.

The concept of dynamic systems presupposes that attention is given to processes. Given the nature of my research question, "What is the role of familial protective factors in moderating the relationship between risk and resilience?" and that the goal was to identify which familial protective factors were utilized by the Sudanese refugee youth and explore how they were organized in order to initiate processes that moderate the relationship between risk and resilience, a considerable portion of this study is focused on process.

The final concept is qualitative data with inductive analysis. It is through in-depth inquiry that a detailed, "thick description" of the phenomenon can be obtained (Geertz, 1973). It is common for direct quotations to be used so as to capture the informants' experiences and perspectives (Patton, 1990). The analysis is inductive in that from the details the researcher builds abstractions, concepts, hypotheses, and theories.

This particular study is well suited to the qualitative approach. According to the literature, a need exists to explore the phenomena of familial protective factors and processes in relation to their role in moderating the relationship between risk and resilience in refugees (Werner, 1992). 


\section{Research Plan}

\section{The Person of the Researcher}

Because qualitative research is interpretive research, my experiences will shape the interpretation of this report. Thus, I have included information about my experiences that provides familiarity with the context, phenomena of study, and the informants. I have practiced social work for over 20 years. During these years I have provided clinical services primarily to families and children. Most of my clients' difficulties involved some form of violence - usually familial, such as physical and sexual abuse - and gross neglect. In addition, there were numerous instances where families and children were victims of, or had witnessed, communal violence.

Despite the hardships, many of my clients functioned exceedingly well. Similarly, my husband Ghazi, who, despite spending much of his childhood in communal violence, in a country consumed by a brutal civil war, managed to do well.

One of the settings in which I worked as a social worker was a United States Conference of Catholic Bishops' refugee resettlement program affiliated with Catholic Charities of the Archdiocese of New Orleans. Initially I provided mental health services to families and children who had fled Kosovo for their safety and had either witnessed or been victims of political violence. Later, I was the Refugee Resettlement Coordinator and assisted in resettling refugees

from all over the world in New Orleans. The vast majority of these clients had also witnessed or been victims of violence. I was impressed by the many refugee families who were doing remarkably well given what they had been through. These experiences certainly shaped my interpretation of the data.

One of my initial tasks with all clients was to conduct a psychosocial interview. Later sessions involved therapeutic interviewing. One of the essential skills of a good interviewer is 
listening. In my tenure, I became particularly skilled at interviewing people from diverse backgrounds on a range of sensitive topics and developed keen listening skills. In addition, the reports and notes required for each session made me adept at putting together the life narratives of numerous clients.

\section{$\underline{\text { Sampling }}$}

The two basic types of sampling are probability and nonprobability. Probability sampling allows the researcher to generalize the results of the study from the sample to the population from which it was drawn. Probability sampling is not necessary, or even justifiable, in qualitative research because generalization is not the goal of qualitative research (Merriam, 2001). Thus, nonprobability sampling is the method utilized for qualitative research and used in this study.

The most common strategy of nonprobability sampling is referred to as purposive (Chein, 1981) or purposeful (Patton, 1990). This type of sampling is based on the assumption that because the researcher wants to discover, understand, and gain insight, he or she must select a sample from which the most can be learned (Chein, 1981). Patton (1990) states that the logic and power of purposeful sampling lies in selecting information-rich cases for in-depth study. Information-rich cases are those from which one can discern a great deal about issues of importance to the purpose of the research (Kuzel, 1992; Miles \& Huberman, 1994; Morse, 1991).

There are many different types of sampling strategies (Merriam, 2001; Miles \& Huberman, 1994; Patton, 1990). I used what is referred to as a "combination" or "mixed purposeful" sampling. Combination or mixed purposeful sampling uses a number of different sampling strategies with each strategy serving a different purpose. The strategies utilized in this study were typical case, reputational case, and snowball or chain sampling. 
In utilizing typical case sampling, I requested that the director of the refugee resettlement agency refer typical, average, or normal cases. In addition, I requested that they be good interview subjects, which Kvale (1996) describes as being knowledgeable, eloquent, motivated, cooperative, and truthful. This also means that they would be able to provide coherent accounts and concise and precise answers.

The director suggested that I start with those who were the leaders among the refugees. Thus, reputational case strategy, that is, selection based on the recommendation of an expert or key informant was utilized from the beginning. The director also included some typical cases. He explained that the leaders would use their reputation and influence to encourage others to partake in the process. In addition, they could provide the names of other Sudanese refugees. Thus, snowball or chain sampling was also used.

\section{Identifying Participants}

There was considerable anticipation about resettling the Lost Boys while I was the Refugee Resettlement Coordinator. An article in the Christian Science Monitor announced that the "Lost Boys of the Sudan" would be resettled in various communities throughout the United States (Crawley, 2000). The article related that the refugees would be resettled through Lutheran Immigration and Refugee Services and the United States Conference of Catholic Bishops, Migration and Refugee Services, which are recognized by the Department of State Office of Refugee Resettlement as VOLAGS that are capable of resettling young refugees unaccompanied by their families. I contacted the administrators of these VOLAGs.

\section{Gaining Entry}

After speaking with the administrators and several of the resettlement directors of the two VOLAGS, I chose to conduct the research at a particular site - Catholic Social Services, 
Immigration and Refugee Services' in the diocese of a mid-sized city in the Midwest. I chose this site primarily because it was a large resettlement agency, resettling over 400 people annually, and one of the largest sites for resettling Sudanese refugees. It also had the reputation of being a well-administered program that was successful at resettling refugees. The director was approachable, open, and agreeable to my doing the study. The refugees were also agreeable.

\section{Rights of Participants and Confidentiality}

An application, research protocol and consent form were submitted to, and eventually approved by, the Louisiana State University Institutional Review Board for Human Subjects (see Appendixes A and B). Issues of consent, protection from harm, privacy, confidentiality, and anonymity were specifically addressed in the protocol and safeguarded throughout the study. The consent form summarized the purpose of the study and the rights of the participants. It used simple, everyday language that was free of jargon.

Voluntary informed consent was requested from each participant. Voluntary means that consent was given by the participant without threat or undue duress (Sieber, 1992). Informed means knowing what a reasonable person in the same situation would want to know before giving consent. In most cases people just want to know what they are likely to experience. Consent means that there is an explicit agreement to participate in the study, although it also means that the informant is free to terminate his or her participation in the study at any time without consequence.

I briefed each participant before the interview, describing the situation, the purpose of the interview, and the use of the tape recorder. I also asked each participant if he was comfortable with proceeding and if he had any questions prior to beginning the interview. Each participant was then debriefed after the interview. This involved reviewing the interview process, expressing 
appreciation, and offering the youth the opportunity to ask questions or make comments on the research.

Protection from harm is related to the ethical principle of beneficence, which means that the risk of harm to a participant should be the least possible. The sum of potential benefits to a participant and the importance of the knowledge gained should outweigh the risk of harm to the informant. Privacy refers to a person's interest in controlling other's access to information about themselves (Sieber, 1992). Confidentiality concerns the data obtained and an agreement as to how the data are to be handled in keeping with the participant's interests in controlling others' access to information about themselves. Confidentiality was discussed in detail with each participant. The consent form also included a confidentiality agreement indicating acceptance of the plans for the data. I utilized adequate safeguards of confidentiality which were described in specific terms in the consent form. The data were gathered anonymously, without linking any unique identifiers such as the informant's name or social security number to the data.

\section{Case Study}

A case study design was utilized in this study. A case study is defined as both the process of learning about a particular case and the product of that learning (Stake, 1995). Yin (1993) describes a case study as an empirical inquiry that investigates a contemporary phenomenon with its real-life context, especially when the boundaries between phenomenon and context are not clearly evident. A qualitative case study is characterized by the researcher spending substantial time, on-site and personally in contact with activities and operations of the case, reflecting, and revising meanings of what is going on (Stake, 1994). In this study, the case was a Sudanese refugee youth. 
This design was chosen because of its advantages. One advantage, as Bromley (1986) suggests, is that a case study permits getting as close to the phenomenon of interest as possible. A second advantage is that a case study is a particularly suitable design if the phenomenon of interest is the process. Finally, a case study may be selected for its uniqueness with regard to what it can reveal about a given phenomenon (Merriam, 2001).

Although a case study may be about singular or multiple cases, a case study of multiple cases is often referred to as a collective case study (Stake, 1995). The benefit of a collective case study is that it strengthens or broadens analytic generalizations which illustrate, represent, or generalize to a theory (Yin, 1993). They may be strengthened or broadened as a result of the multiple cases designed to replicate each other, thus producing corroboratory evidence from two or more cases. The ability to design and conduct 6 to 10 case studies is considered analogous to the ability to conduct 6 to 10 experiments on a related topic (Yin, 1993).

Case studies are not a new form of research. The disciplines of sociology and anthropology are credited with the primary shaping of this form of research. However, case study research has drawn from a number of other areas as well: the clinical methods of physicians and psychologists, the casework technique of social workers, and the methods of historians. The sociologist most closely identified with the case study method was Robert Park at the University of Chicago. The "Chicago School" was preeminent in the field of sociology and the source of a great deal of the research. During the 1930s, criticism denigrating the case study method from competing schools that championed the "scientific method" led to a decline in its use. However, in the 1960s researchers became disenchanted with quantitative methodologies and this lead to renewed interest and a resurgence in the use of the case study method. 
A case study may be based on six different sources of evidence: documentation; archival records; interviews; direct observations; participant-observation; and physical artifacts (Yin, 1989). This case study was based on three of these evidential sources: interviews; direct observations; and physical artifacts.

\section{$\underline{\text { Interviews }}$}

One important source of case study evidence is the interview. An interview is a social interaction that results in a transfer of information from the interviewee to an interviewer or researcher (Marshall \& Rossman, 1999). The purpose of an interview is to enter into the other person's perspective (Patton, 1990). Qualitative interviewing begins with the assumption that the perspective of others is meaningful, knowable, and capable of being made explicit.

Interviews have particular strengths. They are a useful way of getting a large amount of data quickly and they also provide greater breadth. In addition, they allow for immediate followup and clarification (Marshall \& Rossman, 1999; Yin, 1993).

There are three basic approaches to collecting qualitative data through open-ended interviews: the informal conversational interview; the general interview guide approach; and the standardized open-ended interview (Patton, 1990). The general interview guide involves outlining a set of issues that are to be explored with each participant. This guide assumes that there is common information that should be obtained from each person interviewed. However, the interviewer is expected to adapt both the wording and the sequence of questions to specific participants in the context of the actual interview. The interview guide provides topics or subject areas within which the interviewer is free to explore, probe, and ask questions that will elucidate and illuminate that particular subject (Patton, 1990). Thus, the interviewer is free to build a conversation within a particular subject area, wording questions spontaneously and establishing a 
conversational style, yet also maintaining a focus on a predetermined topic (Patton, 1990). The following questions were posed to the participants:

(1) Could you tell me about the events that led to you coming to the United States?

(2) Could you tell me about the Sudanese civil wars?

(3) Could you tell me about your experiences in the civil wars?

(4) How did the civil wars affect you?

(5) You have experienced events in your life that many people might describe as difficult or stressful. How did you (do you) deal with or cope with these events?

(6) Many people might describe someone who dealt with or coped well with these events as strong or resilient. What helped you in being (becoming) strong or resilient?

(7) In what ways did your relationship with your family help you in coping?

(8) Could you give me an example?

(9) How do you think your family or your relationship with your family was able to help you even though you were separated from them and did not know their status?

(10) Could you give me an example? Then? Now?

(11) Is there anything else that you would like to add?

This is set up as Table 3.1 matching research questions with interview questions.

Since the purpose of an interview is to record the particular interviewee's perspective as fully and fairly as possible, a tape recorder was used to increase the accuracy of data collection and to facilitate greater attention to the participant during the interview. There was also a need to take notes. Notes serve two purposes. First, they allow the interviewer to formulate new questions as the interview moves along, particularly when it may be appropriate to investigate what was said earlier. Second, they facilitate later analysis (Kvale, 1996). Field notes were 
written about the interviews immediately following each interview. Taped interviews were then transcribed verbatim.

Table 3.1: Research Questions and Related Interview Questions

\begin{tabular}{|c|c|}
\hline Research Questions & Interview Questions \\
\hline \multicolumn{2}{|l|}{ Global Research Question } \\
\hline \multirow[t]{4}{*}{$\begin{array}{l}\text { 1) What is the role of familial protective } \\
\text { factors and processes in moderating the } \\
\text { relationship between risk and resilience } \\
\text { in Sudanese refugee youth exposed to } \\
\text { political violence? }\end{array}$} & $\begin{array}{l}\text { 1) Could you tell me about the events that } \\
\text { led you to come to the United States? }\end{array}$ \\
\hline & $\begin{array}{l}\text { 2) Could you tell me about the Sudanese } \\
\text { civil wars? }\end{array}$ \\
\hline & $\begin{array}{l}\text { 3) Could you tell me about your } \\
\text { experiences in the civil wars? }\end{array}$ \\
\hline & 4) How did the civil wars affect you? \\
\hline \multicolumn{2}{|l|}{ Subquestions } \\
\hline \multirow[t]{2}{*}{$\begin{array}{l}\text { a) Do these protective factors actually } \\
\text { moderate the relationship between risk } \\
\text { and resilience in the group in question? }\end{array}$} & $\begin{array}{l}\text { 5) You have experienced events in your life } \\
\text { that many people might describe as } \\
\text { difficult or stressful. How did you (do } \\
\text { you) deal with or cope with these } \\
\text { events? }\end{array}$ \\
\hline & $\begin{array}{l}\text { 6) Many people might describe someone } \\
\text { who dealt with or coped well with these } \\
\text { events as strong or resilient. What } \\
\text { helped you in becoming (being) strong } \\
\text { or resilient? }\end{array}$ \\
\hline \multirow[t]{2}{*}{$\begin{array}{l}\text { b) If they do, then how do familial } \\
\text { protective factors moderate the } \\
\text { relationship between risk and } \\
\text { resilience? }\end{array}$} & $\begin{array}{l}\text { 7) In what ways did your relationship with } \\
\text { your family help you in coping? }\end{array}$ \\
\hline & 8) Could you give me an example? \\
\hline \multirow[t]{2}{*}{$\begin{array}{l}\text { c) How are familial protective factors } \\
\text { organized in order to initiate the } \\
\text { processes that moderate the relationship } \\
\text { between risk and resilience? }\end{array}$} & $\begin{array}{l}\text { 7) In what ways did your relationship with } \\
\text { your family help you in coping? }\end{array}$ \\
\hline & 8) Could you give me an example? \\
\hline
\end{tabular}


(Table 3.1 cont.)

\begin{tabular}{|l|l|}
\hline Research Questions & Interview Questions \\
\hline $\begin{array}{l}\text { d) If familial protective factors do not } \\
\text { moderate the relationship, then what }\end{array}$ & $\begin{array}{c}\text { 5) You have experienced events in your life } \\
\text { that many people might describe as } \\
\text { difficult or stressful. How did you (do } \\
\text { you) deal with or cope with these } \\
\text { events? }\end{array}$ \\
& $\begin{array}{l}\text { 6) Many people might describe someone } \\
\text { who dealt with or coped well with these } \\
\text { events as strong or resilient. What } \\
\text { helped you in becoming (being) strong } \\
\text { or resilient? }\end{array}$ \\
$\begin{array}{ll}\text { e) Does the separation of the youth from } \\
\text { their family of origin affect the } \\
\text { moderating relationship of the familial } \\
\text { protective factors? }\end{array}$ & $\begin{array}{l}\text { How do you think your family or your } \\
\text { relationship with your family was able } \\
\text { separated from them and did not know } \\
\text { their status? }\end{array}$ \\
\hline & $\begin{array}{l}\text { 10) Could you give me an example? Then? } \\
\text { Now? }\end{array}$ \\
\hline
\end{tabular}

\section{$\underline{\text { Direct Observations }}$}

Observation, which is one of the earliest and most basic forms of research, is often used in conjunction with others sources of data collection. Morris (1973, as cited in Adler, 1994) offers a broad explanation of observation and defines it as the act of noting a phenomenon, often with instruments, and recording it for scientific or other purposes. Observational data allows one to describe the observed setting, the activities that took place there, the people who participated in those activities, and the meanings of what was observed from the perspective of those being observed.

Observation can occur in any setting where activity occurs. In Gold's (1958, as cited in Adler \& Adler, 1994) classic typology of roles, he outlined four modes through which observers may gather data: (1) the complete participant; (2) the participant as observer; (3) the observer as participant; and (4) the complete observer. My role was that of observer as participant.

According to Gold (1958, as cited in Adler \& Adler, 1994), this role describes researchers as 
primarily observing their subjects for brief periods of time as they attempt to conduct structured interviews. A full explanation of the real purpose of my observations was provided to all participants prior to the time I made overt observations.

There are a number of strengths to utilizing observation (Adler \& Adler, 1994; Lofland \& Lofland, 1995). One strength lies in the ease through which researchers can gain entrance to settings. Observational methods also embody the least potential for generating observer effects. Another strength associated with observational research is that it is especially valuable as an alternate source of data for triangulation (Denzin, 1989) against information gathered through other means. Finally, observation produces especially great rigor when combined with other methods. Yin (1989) notes that another strength of observation is that it covers events in real time as well as the context of the event. I made multiple observations of limited duration for about two weeks. It was not possible to observe and record everything, so I had to limit what I observed. In addition, I had to determine what types of observations were pertinent to the study. I decided that during interviews I would focus on nonverbal and verbal behaviors, at what point significant behaviors occurred during the interview, and any contradictions between nonverbal and verbal behaviors. During observations at the agency office, the apartments, a community college, and a restaurant I noted the setting, activities that took place, and the people who participated in these activities. I specifically focused on the interactions between the refugees. Examples of several types of interactions that I was interested in included: who interacted the most, and the least; who interacted with whom; the types of interactions; and the topics of conversations. I made extensive field notes of each observation. 


\section{Physical Artifacts}

A physical artifact is some sort of physical evidence such as a work of art. Drawings have advantages as a source of evidence because they provide insight into an individual or culture (Yin, 1989). Drawings were requested from each participant at the beginning of the initial interview.

The following is a summary of the methodology used in the study as discussed in this chapter. The global research question that was the focus of the study is: "What is the role of familial protective factors in moderating the relationship between risk and resilience in Sudanese refugee youth exposed to political violence?" The purpose of the study was to explore the role of familial protective factors in moderating the relationship between risk and resilience in Sudanese refugee youth exposed to political violence. Due to the discriptive, exploratory nature of the study, a qualitative approach was most appropriate. A case study design was utilized. Since the study was of multiple cases, it is referred to as a collective case study. Combination or mixed purposive sampling with strategies of typical case, reputational, or snowball or chain sampling was utilized. Data were collected through interviews, direct observations, and physical artifacts. 


\section{CHAPTER FOUR: PRESENTATION OF THE PARTICIPANTS}

\section{Introduction}

This chapter introduces the participants of the study presenting their individual experiences during the Sudanese civil wars and their responses to the interview questions. The individual summaries are then followed by a group summary of the participants.

\section{The Individual Participants}

\section{$\underline{\text { Participant \#1 }}$}

Participant \#1 arrived early at the offices of the refugee resettlement agency. He was warm and engaging. He was relaxed and sat comfortably in the chair. He did not know his age but assumed that he was in his early twenties. He was enthusiastic about telling of his experiences of the Sudanese civil war.

I introduced myself. I asked the participant if he was comfortable with the setting - the office, chair, or temperature - and offered him snacks and refreshments. I then explained the nature and purpose of the study. Assurances were given that he would remain anonymous. I ensured confidentiality and briefed him on the steps that would be taken to protect his privacy. I indicated that he might find some of the questions difficult to answer and that he could refuse to answer one or more of the questions. I told him he could request to stop the interview at any point. I also told him that he could interrupt and ask questions about any aspect of the interview. I requested permission to tape record the interview and explained why I wanted to do so. I told the participant that his views were important to me and for this study because of what might be learned. I also requested that he draw a picture of some aspect of Dinka life or of his experiences of the Sudanese civil war. He declined politely. He gave the excuse that he "didn't draw good." 
Finally, I requested to observe him at some point. He agreed and said it could be done at any time, at my convenience.

The participant noticed an Arabic version of Welcome to the United States: A Guide for Refugees, a booklet containing essential information to assist refugees in adjusting to life in the United States. The participant immediately reacted and demanded, "Is this yours?" I responded, "No." I explained that it belonged to the refugee resettlement agency and that copies are given to all refugees prior to their coming to the United States. I stated that he, too, should have received a similar version.

I then explained the purpose of the booklet, and that copies were written in the languages of the current flows of refugees. I told him that this copy was written in Arabic because it was intended for someone literate in Arabic. I then reiterated that it did not belong to me, but to the agency. The participant seemed satisfied with my explanation, so we commenced with the interview.

The participant said he "was born in war [and] grew up in war." He described how his area of the Sudan had been under heavy bombardment from government forces for several years. Then, in 1987, the fighting got closer to his village. During one "heavy attack by Arabs," he and his family were forced to "run to the forest" and "tried to hide there."

The attacks grew "worse." During one attack his father was killed and "Arabs" [sic] captured his youngest sibling, a brother. He then ran in "one direction" while his "mother, together with some of [his] brothers and sisters, ran in a different direction." Other villagers were running as well.

He joined a group of boys who were fleeing. The conditions of their flight were extremely difficult. There was no food or water. He stated that they had to forage for food, and 
"people used their own urine to drink as water because you could not find any water."

Sometimes the "only thing edible was the leaves on the trees. Many people died of hunger and thirst."

Eventually, the refugees streamed into Ethiopia, where the participant first had contact with the UN. The UN provided shelter and food and, he claimed, set up schools. It was there that the participant "first started school" and learned "how to write and read." He spent four years in Ethiopia. During that time "life was normal and everything was going well."

In 1990, however, a civil war broke out in Ethiopia and the Sudanese refugees were forced to flee Ethiopia and return to the Sudan. On the way they came to the Gilo River. People "settled there for some time because ... the river was full" and then waited "for the river to go down." But a firefight broke out between Ethiopian governmental forces and their militias and Sudanese rebels. To escape many of the boys jumped in the river where many drowned and some were attacked and killed by crocodiles. Many lives were lost. Eventually they reached Pachala, Sudan and spent some months there before the "Arabs" captured it. More people were killed.

He then walked with his group to Buma and from there to Kapoeta, both towns in southern Sudan. However, the "natives" of Kapoeta did not want them in the village. They then walked to the next village - Nairus - but the "Arabs" advanced and attacked Kapoeta. They were forced to flee over the border to Kenya to a town called Lokichiogio. The UN was present when they arrived in Lokichiogio, and provided water, food, and shelter. The UN eventually transported them to the Kakuma Refugee Camp.

According to the participant, the native people of the area, the Turkana, resented the assistance, particularly the rations the Lost Boys were receiving from the UN. The villagers 
made frequent incursions into the camp at night to rob the inhabitants, even though by any standard the food rations were barely subsistence.

Finally, according to the participant, their situation was "heard by some people ... in the United States whereby the American people especially the government think that if the situation of these boys is very worse than this we can try to help them and give them a place to settle." Thus, he was resettled in the United States in 2001 and has since resided in a mid-sized city in the Midwest.

He has had contact with his mother. She is safe and in good health and residing further north in Sudan. His siblings are alive as well, although one of his brothers who lived in Khartoum died there recently. Participant \#1 is currently employed in a meat processing plant.

The interview ended after 1_ hours. After the participant was debriefed, I thanked him for sharing his experiences and his involvement with the study. Unfortunately, I was not able to reach the participant at the telephone numbers he had given me and could not set up a time for me to observe him.

\section{$\underline{\text { Participant \#2 }}$}

Participant \#2 was interviewed in an isolated office in the refugee resettlement agency. He was somewhat shorter than the other Dinka I had recently met. I noticed he had two horizontal scars across his forehead. I wondered if they were the result of the scarification ritual that all young Dinka males participate. He did not know his age but assumed he was in his early twenties. He was very willing to participate and seemed to want to please the interviewer. He appeared to be relaxed and sat comfortably in the chair.

I introduced myself. I asked the participant if he was comfortable with the setting - the office, chair, or temperature - and offered him snacks and refreshments. I then explained the 
nature and purpose of the study. Assurances were given that he would remain anonymous. I ensured confidentiality and briefed him on the steps that would be taken to protect his privacy. I indicated that he might find some of the questions difficult to answer and that he could refuse to answer one or more of the questions. I told him he could request to stop the interview at any point. I also told him that he could interrupt and ask questions about any aspect of the interview. I requested permission to tape record the interview and explained why I wanted to do so. I told the participant that his views were important to me and for this study because of what might be learned.

I also requested that he provide a drawing of some aspect of Dinka life or of his experiences of the Sudanese civil wars. After some encouragement he agreed to do so. Finally, I requested to observe him at some point. He agreed to do so at my convenience.

The participant was from southern Sudan and a member of the Dinka tribe. In 1987 he was driven from his "homeland, from ... mother and father." He traveled to Ethiopia and resided there until 1990. At that time he was forced to flee Ethiopia and reluctantly returned to the Sudan. He said he was "faced with a lot of problems - I seen people died ... seen people drown with water."

He eventually made it to Kenya, where he "started over as a refugee." He stayed in Kenya for over nine years. Then, the “American government say that 'enough is enough' ... it's better for them to come to the United States and they can start a new life." He was resettled in the United States in 2001 and has since resided in a mid-sized city in the Midwest. He has had no contact with his family since he was separated from them. He does not know if they are alive or dead. He is currently employed in a meat processing plant. 
The interview ended shortly after one hour. I debriefed the participant, and thanked him for sharing his experiences and being involved in the study. I observed the informant twiceboth times at the apartment he shares with several other Lost Boys. The observations lasted for approximately one hour each.

\section{Participant \#3}

Participant \#3 was interviewed in an isolated office of the refugee resettlement agency. He was a short, stout man. He rarely smiled and made minimal eye contact. He seemed somewhat anxious during our initial encounter, although this may have been attributable to shyness. He did not know his age but assumed that he was in his early twenties. He was willing to participate. He spoke haltingly and at times stuttered. His speech was heavily accented. He did not exhibit the same comfort with the English language that the other refugees did.

I introduced myself. I asked the participant if he was comfortable with the setting - the office, chair, or temperature - and offered him snacks and refreshments. I then explained the nature and purpose of the study. Assurances were given that he would remain anonymous. I ensured confidentiality and briefed him on the steps that would be taken to protect his privacy. I indicated that he might find some of the questions difficult to answer and that he could refuse to answer one or more of the questions. I told him he could request to stop the interview at any point. I also told him that he could interrupt and ask questions about any aspect of the interview. I requested permission to tape record the interview and explained why I wanted to do so. I told the participant that his views were important to me and for this study because of what might be learned.

I also requested that he provide a drawing of some aspect of Dinka life or of his experiences of the Sudanese civil wars. Finally, I requested to observe him at some point. He 
seemed disinterested so I did not pursue the issue any further. Later, however, he was willing to be observed in the apartment he shared with a group of Lost Boys.

He seemed to want to tell his story and was very focused on doing so. When I would interrupt him to seek clarification he seemed somewhat irritated and quickly returned to his story. Despite revealing some horrific experiences, he tended to show little emotion and seemed somewhat detached. He was very serious. He sat slightly hunched over in the chair. He saw the conflicts in the Sudan in strictly religious terms. He strongly identified with being Christian. $\mathrm{He}$ spoke in very general terms. The interviewer had to interrupt several times in order to get specific information. He provided more detail with continued probes.

He told me that in the late 1980s "Arabs from the north" attacked the village in which he and his family lived. The "Arabs" ransacked and looted family huts, destroyed possessions and property, and eventually burned the entire village. The villagers fled on foot, traveling southeast toward Ethiopia and Kenya. While fleeing he became separated from his family.

He stayed in Ethiopia for four years until the Ethiopian civil war erupted in the area where he was encamped. He fled again - this time back toward Sudan. During this flight Ethiopian militias continuously attacked him and the other refugees, forcing them to the banks of the Gilo River. According to the participant, "many, many people were pulled ... in River Gilo, drowning in the water." The abundance of dead bodies attracted carnivorous animals, such as lions, which ate the remains.

He eventually reached Pachala, Sudan in June 1991. He faced "very bad hunger" and many people "died of starvation" until "the Red Cross arrived and provided water and food." $\mathrm{He}$ stayed in Pachala for about eight months, until "Arabs" again attacked the town. 
They fled to "Magose, another small town, another village in Sudan," where they spent several days. Because of the frequent night attacks from natives of the area, he and his group moved on to Kapoeta. He spent several days there.

They then moved on to Nairus, where they intended to stay. However, Kapoeta was captured by "Arabs" and, because the "Arabs" were so close, they decided to move on to avoid any more conflict. They moved again, heading toward Lokichiogio in Kenya. He "spent at least some two months there and then they [Red Cross] took us ... to a place called Kakuma." He lived at this UN sponsored camp for nine years. After several years he became a "team leader" with responsibilities that involved assisting in the preparation of Lost Boys for their eventual resettlement in the United States.

He has had no contact with his parents since the attack on his village. He thought it was possible that his parents were dead, although he had heard that they were alive. His brother died during the conflict, but his four sisters were alive and have since married. He claimed he was currently attending school. He was looking forward to starting a new life and becoming an American citizen.

The interview ended after one hour. After debriefing the participant, I thanked him for sharing his experiences and his involvement with the study. I observed the informant at the apartment he shares with several other Lost Boys. The observation lasted for approximately one hour.

\section{Participant \#4}

I met the participant in the office of the refugee resettlement agency. He was exceptionally tall, even by Dinka standards. He was neatly dressed, attired in a football jersey, jeans, and tennis shoes. The participant was very warm and engaging. He was unsure of his age, 
but assumed he was in his early twenties. He was very eager to participate in the interview and wanted to do so to help the interviewer and possibly others. He hoped that by participating he could bring some awareness to "the situation in the Sudan" and the "suffering of [his] people." During the interview he was relaxed and sat comfortably in the chair.

I introduced myself. I asked the participant if he was comfortable with the setting - the office, chair, or temperature - and offered him snacks and refreshments. I then explained the nature of and purpose of the study. Assurances were given that he would remain anonymous. I ensured confidentiality and briefed him on the steps that would be taken to protect his privacy. I indicated that he might find some of the questions difficult to answer and that he could refuse to answer one or more of the questions. I told him he could request to stop the interview at any point. I also told him that he could interrupt and ask questions about any aspect of the interview. I requested permission to tape record the interview and explained why I wanted to do so. I told the participant that his views were important to me and for this study because of what might be learned.

I requested a drawing of some aspect of Dinka life or of his experiences during the civil wars in the Sudan. He smiled and quickly agreed to do so. I then asked to observe him, to which he enthusiastically agreed as well.

Participant \#4 saw the war in Sudan "as being fought ... about freedom." The "rules" of the country are based "on a religion," he said, and Christians and Muslims are fighting the "religion war" because Christians want their "freedom."

The participant lived in "southern Sudan, in a rural area, a village area" where he and his family "cultivated sorghum and tended cattle." When his village was attacked, everything was either destroyed or killed. He fled. He does not know what happened to his family - his mother, 
father, several brothers or sisters. He just fled "to save my life." He eventually "met three guys in the forest" who "directed" him and showed him the way to Ethiopia. They advised him, when there was a lack of water, to drink his urine. They also helped him forage for food - particularly fruits. The participant stated that on this trek to Ethiopia he saw "thousands of people die."

He settled in Ethiopia and lived there for three to four years, until the Ethiopian civil war broke out and conflicts erupted near his encampment. He was forced to flee again in the direction of Sudan, as well as cross the swollen Gilo River during rainy season. He did not know how to swim but "luckily, luckily, I didn’t know even I was in the river. Somebody hold my hand. I don't know whether it's God or what ... I don't know. A lot of people lost their life in that river - thousands." However, the Sudanese civil war was still raging. He fled to Kenya. There, he was placed under the care of the UNHCR and lived in the Kakuma Refugee Camp. He stated that he "spend [his] life there" and started his education.

Yet, in Kakuma "the suffering" continued. There was continuous harassment by the Kenyan police, as well as tensions and sometimes conflicts with the natives of the area, the Turkana. They frequent attacked the refugees at night and stole their meager rations and few belongings. The refugees lived in poorly constructed shelters that were little more than sticks and canvas and provided little protection from the elements or animals. The rations were hardly enough on which to survive, and amounted to "one cup of maize a week." Many people "died of hunger in the camp."

The participant was resettled in the United States in 2001. He resided in a mid-sized city in the Midwest. He "[does] not know where [my] family, where they are right now, whether they are alive or not." He was attending a community college where he was taking classes in international relations. He was "very happy to get [an] education in the United States." He hoped 
to complete his education "and try, if God wishes me to do, to make some peace that was happening in my country if God allows me to do that." He was "very happy" with his life. He said, "my life is really, really good in the USA." The interview lasted slightly less than two hours. I debriefed the participant and thanked him for sharing his experiences and his involvement with the study. We then made arrangements for me to observe the participant at a later time.

Two days later, we met at an intersection between the agency offices and his apartment. I followed him in his car out to the edge of town to where the community college was located. I spent the day with him and another Lost Boy. I followed him around the school and observed his activities.

I observed him in his classes - one on English language and another on English composition. Then we ate lunch and afterwards he and the other refugee played basketball with some fellow students.

Later, I observed him in meetings with his financial aid and academic advisors to plan for the next semester. These observations lasted for approximately three hours. The next day I met with him, again along with several other Lost Boys, for lunch at a local Italian chain restaurant. This observation lasted for approximately two hours.

\section{Participant \#5}

I met Participant \#5 at the apartment he shared with several other Lost Boys in a residential area not far from the agency offices. It was located in a quiet middle-class neighborhood of single homes and small duplexes - an idyllic setting with well-kept homes and manicured lawns. He lived in a duplex in which one of the other apartments house several Lost Boys. The duplex had the largest concentration of Lost Boys in the city. 
He was smaller than the other Dinka that I had met and was rather disheveled in his appearance: his hair was uncombed and his wrinkled clothes were too large for him. He was exceptionally quiet and seemed passive. He had fleeting eye contact. He only smiled occasionally.

When I arrived at the apartment, he quickly volunteered to do the first interview. I interviewed him in the largest bedroom, at the desk of one of his roommates. This setting was quiet but once or twice noise from visitors arriving at the apartment interfered with the tape recording and muffled some of the responses. Otherwise it was a completely uneventful interview. He was somewhat relaxed as he sat and sometimes reclined on the bed in his room. He did not know his age but assumed he was in his early twenties.

I introduced myself and explained the nature of and purpose of the study. Assurances were given that he would remain anonymous. I ensured confidentiality and briefed him on the steps that would be taken to protect his privacy. I indicated that he might find some of the questions difficult to answer and that he could refuse to answer one or more of the questions. I told him he could request to stop the interview at any point. I also told him that he could interrupt and ask questions about any aspect of the interview. I requested permission to tape record the interview and explained why I wanted to do so. I told the participant that his views were important to me and for this study because of what might be learned.

The participant is from a province in southern Sudan. In 1989 fighting broke out for the first time near his village. He and his family attempted to escape the fighting and fled for safety. It seems as if his parents were deeply concerned for his safety, as it was well known that children were being recruited or captured by the Sudanese government and forced to serve as child soldiers. According to the participant, his parents sent him off with other people because of their 
concern for his safety. Eventually he made his way into a group of similarly aged boys that was guided by some older boys or, possibly, adults. There were large numbers of boys and they were initially grouped and kept together by a sort of kinship bond. He stated, "We were high in number, and people who are related to each other, it could be like a clan or something like that."

He and the group kept walking, continuing on toward wherever they thought they could find food. Whenever possible, they would try to walk close to a source of water such as a river. However, there was very little food available and they "were suffering" because there was also no water. He was forced to eat various fruits and leaves from the trees. It took over a month of walking to reach Ethiopia.

Eventually he made his way there and sought refuge. He stayed in Ethiopia for three years, under the protection and care of the UN. In 1991 a civil war broke out in Ethiopia, forcing him to move again to the border of Sudan. Because the war was continuing in the Sudan, he then went to a camp in Kenya.

There were continuous tensions and skirmishes with the natives of the area around the camp. Because the area is very arid, little food is produced. The participant stated that the "natives thought we were getting some little food from the UN so they said you have to share it." The natives frequently raided the camps at night, stealing whatever they could. Neither the Kenyan police nor the UN was capable of providing security.

He lived in the Kakuma Refugee Camp for over nine years until he was resettled in the United States in 2001. He worked briefly at a meat processing plant. It is unclear why he left the job, but it is possible he was let go. He claimed it was very difficult work. Thus, he was dependent on others in the apartment to provide him with shelter, food, and clothing. He claimed he was looking for a job, but had not done anything to do so. 
The interview lasted slightly less than one hour. I debriefed the participant and thanked him for sharing his experiences and his involvement with the study. I later observed the participant in the apartment. On one occasion the participant was primarily socializing with his peers and assisting in the preparation of dinner. On another occasion he was socializing with his peers during an arranged get-together. Each observation lasted approximately one hour. At the time of the interview the participant had recently discovered the whereabouts of his family: they were living in southern Sudan near the Ugandan border in an area called Darfur.

\section{$\underline{\text { Participant \#6 }}$}

I also met and interviewed Participant \#6 at his apartment in a duplex in a residential area not far from the agency offices. He shared the apartment with several other Lost Boys. He was tall and striking, well-dressed and seemed quite educated. He had a wealth of information about the conflict and provided tremendous detail. He also seemed to understand the complexities of the civil wars in Sudan, the various factions, and their political motivations. He spoke with a slight British accent.

He obviously was a leader among the Lost Boys in this city. Prior to the commencement of the interview and during observations he was continuously receiving telephone calls seeking information or advice on some issue. He seemed to enjoy being sought out, but at times felt burdened by the responsibility of the expectation of always being available and able to provide some assistance. As with the other Dinka he did not know his age but assumed he was in his early to mid-twenties. His spoke of his experiences in terms of, or in relation to, his educational struggles and accomplishments.

I introduced myself and explained the nature of and purpose of the study. Assurances were given that he would remain anonymous. I ensured confidentiality and briefed him on the 
steps that would be taken to protect his privacy. I indicated that he might find some of the questions difficult to answer and that he could refuse to answer one or more of the questions. I told him he could request to stop the interview at any point, as well as that he could interrupt and ask questions about any aspect of the interview. I requested permission to tape record the interview and explained why I wanted to do so. I told the participant that his views were important to me and for this study because of what might be learned.

I requested that the participant provide me with a drawing of some aspect of Dinka culture or of his experiences of the Sudanese civil wars. He agreed to do so but, when he was actually prompted to do so, put off the task. No drawing was provided. I also asked to observe the participant. He agreed to this and offered me the opportunity to do so then and there, which I accepted. I requested that he ask others in the apartment if they were agreeable to this arrangement. He did so and everyone agreed.

In the late 1980s, conflicts between "Arabs," natives of the area, and the SPLA were increasing in frequency and ferocity. His father told him "that we had to leave the area because it was becoming a war zone." The family left for a more rural area, further south in Sudan, where they lived in the bush for almost a month. "Life was becoming hard" for the family. There was no money and little food or water. And, the fighting was moving south as well.

One day during an attack the family became separated. The participant went in one direction, away from his family. He eventually trekked further south along the border of Sudan and Ethiopia. He "encountered many things." Most were deeply disturbing and he has tried to forget many of these experiences. At one point he was "about to be attacked by a lion, but fortunately someone grabbed" him. His trek took over 90 days and he went through many towns prior to reaching Ethiopia, where the $\mathrm{UN}$ assisted him. 
The relief workers divided the boys into groups. He stayed in Ethiopia, living in two different refugee camps, for four years. In May 1991 the opposition toppled the Ethiopian government. When it was rumored that all Sudanese refugees would be ordered to leave Ethiopia, he immediately left the area.

They were fired upon by one of several possible groups - either the SPLA or the Ethiopians. They attempted to hasten the boys' departure. However, they were stopped at the swollen Gilo River. In an attempt to escape the fighting and cross the river, "many people lost their lives." He said, "about 3,000 Lost Boys drowned." He also felt he was about to lose his life as well but, "due to God's involvement," he survived. SPLA fighters assisted him across the Gilo. A week later, they arrived in Pachala.

Unfortunately, no food was available and there was tremendous hunger. They foraged for food, but there was none. There was also no shelter. Eventually the Red Cross intervened and small amounts of food was distributed to the various groups of boys.

They stayed in Pachala for seven months. His life began to take on some organization that would remain until this day. The boys were divided into groups, then subdivided. They were sheltered by groups and food was distributed to each of the groups. Duties and activities were assigned to each boy in each group. Their life began to stabilize. However, the native peoples of the area, the Nuba, would attempt, and often succeed, in raiding their camp and stealing whatever was available. Eventually, the fighting reached Pachala and the boys were forced to flee yet again.

They left Pachala, hoping to reach Kapoeta. They passed and stopped momentarily in Buma. Although the International Committee of the Red Cross (ICRC) provided some transportation, the fighting was following closely. When they eventually reached Kapoeta, the 
fighting continued to come closer, so they moved on to Nairus. Then, when Kapoeta was captured, they immediately left for Kenya.

They reached a border town in Kenya called Lokichiogio, where they were received by the various NGOs working in the area. They stayed there for approximately one month and were then transported to a more permanent living arrangement at the Kakuma Refugee Camp. He stayed in Kenya for many years.

Schools were constructed and he was able to complete his secondary education while in Kenya. However, "life was also not okay in Kakuma." Water was difficult to obtain from the wells available to them. Rations were limited and "people still died" of hunger in the camp.

Eventually the UN gave permission for the Lost Boys to be resettled in the United States. Participant \#6 waited several years before he finally left for and resettled in the United States in 2001. He was residing in a mid-sized city in the Midwest. He was working at a meat processing plant. He often worked split shifts. He did not particularly like his work.

He also provided transportation for several other Lost Boys to and from their home, work sites, or school. He complained that all of these responsibilities were taking "over ten hours a day." He was seen as a leader among the Lost Boys. He was continuously being called on his landline and cell phones for advice, information, or intervention. He also felt somewhat burdened by having to be financially responsible for a couple of other Lost Boys who were unemployed. He wanted to continue his education but realized that "school will not go together with work."

He said that his parents were alive and living in Khartoum. He was in fairly frequent contact with them. He stated they also needed some financial assistance.

The interview lasted over three hours. I debriefed the participant and thanked him for sharing his experiences and his involvement with the study. I later observed the participant in the 
apartment. One time the participant was primarily socializing with his peers and assisting in the preparation of dinner. Another time he was socializing with his peers during an arranged gettogether. Each observation lasted for approximately one hour.

\section{$\underline{\text { Participant \#7 }}$}

I met Participant \#7 at the apartment he shared with several other Lost Boys in a residential area not far from the agency offices. It was located in a solidly middle class neighborhood of mixed single homes and small duplexes. It was an idyllic setting of well-kept homes and manicured lawns. He lived in a duplex in which one of the other apartments housed several Lost Boys as well. It had the largest concentration of Lost Boys in the city. The lawn and walkways of the duplex were poorly maintained by the residents. Fast food and junk food wrappers and cigarette butts were strewn all over the sidewalks. Despite the appearance of the outside of the apartment, the inside was exceptionally clean and tidy. The bedrooms were clean but somewhat cluttered.

Participant \#7 was in his twenties. He was neatly dressed. He was very warm and engaging. He was quite willing to participate in the interview. During the interview he was relaxed and sat comfortably in the chair in his bedroom.

I introduced myself. I explained the nature of and purpose of the study. Assurances were given that he would remain anonymous. I ensured confidentiality and briefed him on the steps that would be taken to protect his privacy. I indicated that he might find some of the questions difficult to answer, but that he could interrupt and question some aspect of the interview at any point. I also told him that he could refuse to answer one or more of the questions. Or, he could request to stop the interview at any point. I requested permission to tape record the interview and 
indicated why I wanted to do so. I told the participant that his views were important to me and for this study because of what might be learned.

I requested that the participant provide me with a drawing of some aspect of Dinka culture or of his experiences of the Sudanese civil wars. He declined. I also asked to observe the participant. He agreed to do so and offered me the opportunity to attend classes with him the next day or any other day. I immediately accepted the offer to observe him at the local community college.

The participant was living in southern Sudan with his parents in the late 1980s. In 1987 war "broke out" in Sudan. An attack occurred on his village and he fled. Apparently his parents "moved in different directions." He "then moved from Sudan to Ethiopia." There were "really terrible conditions." On the way to Ethiopia there was "no water as there is a desert" through the area in which he was crossing. "Also there was a shortage of food." He survived by "eating wild fruit plants and different vegetables stuck under the ground." He also survived by begging for water and food from people he met along the way.

Approximately two weeks later he arrived in Ethiopia, where he spent four years.

However, another "political disagreement" in Ethiopia forced him to move again - this time back to Sudan. Once he arrived at the River Gilo he was "attacked by the Ethiopian militia." He and many other children "jumped into the river but some drown down. A lot of people lost their lives, a lot of people, thousands, lost their lives there." He then crossed the Sudanese border and stayed in a town called Pachala for approximately eight months. There he suffered from a "very, very severe hunger again." But, in 1991, "again due to war, [he] moved again following secure corridors out of there between the border of Kenya and Sudan." He spent three months on the 
border of Kenya and Sudan before being moved to a UN sponsored refugee camp - Kakuma. He lived for nine years in Kakuma.

In 1997 he started the process of immigrating to the United States. He eventually resettled in the United States in 2001. He resided in a mid-sized city in the Midwest where he was enrolled at the local community college. He was taking English as a Second Language as well as general studies classes. He was unsure of what he wanted to study in the future but was interested in international business.

The interview lasted approximately one hour. I debriefed the participant and thanked him for sharing his experiences and his involvement with the study. I observed him at the local community college he attended with several other Lost Boys. I followed him around the school and observed his activities. I observed him in his classes - one on English language and another on English composition. We then ate lunch and afterwards he and one of the other Lost Boys played basketball with some fellow students. Later, I observed as he met with financial aid and academic advisors to plan for his next semester. These observations lasted for approximately three hours. The next day I met with him again when we met for lunch at a local Italian chain restaurant with several other Lost Boys. This observation lasted for approximately two hours.

\section{Participant \#8}

I interviewed participant \#8 at his apartment which was part of a semi-detached house in a middle-class neighborhood in a mid-sized city in the Midwest. The apartment was not particularly well maintained. However, it was immaculate inside. There were seven other Lost Boys who resided in the four-bedroom apartment. He was very welcoming and exceptionally polite. He offered me refreshments. He was very interested in the interview. 
I introduced myself. I explained the nature of and purpose of the study. Assurances were given that he would remain anonymous. I ensured confidentiality and briefed him on the steps that would be taken to protect his privacy. I indicated that he might find some of the questions difficult to answer, and that he could refuse to answer one or more of the questions. I also told him that he could interrupt and question some aspect of the interview at any point. And, if he wanted, he could request to stop the interview at any point. I asked permission to tape record the interview and explained why I wanted to do so. I told the participant that his views were important to me and for this study because of what might be learned. I requested that he provide me with a picture of some aspect of Dinka culture or of his experiences of the Sudanese civil wars. He politely declined. I requested to observe him which he agreed to do so at my convenience.

The participant said he left the Sudan "because of a civil war in [the] country." His village was attacked and he "ran from the scene." He fled the Sudan and went to Ethiopia. Fortunately he "met with some people who were older and started walking with them." These people were instrumental in assisting him in staying alive. These people told him "which is bad and which is good." These people encouraged him to do things that he might not have done otherwise in order to survive, such as drinking his urine.

He spent "two or three years" in Ethiopia. He then came back to the Sudan, but "the civil war still existed there." He then went to Kenya and lived there for over nine years. The participant resettled in the United States in 2001. At the time of the interview he resided in a mid-sized city in the Midwest and was enrolled at the local community college. He had no recent contact with his family. He was not sure if they were alive or dead. 
The interview lasted approximately one hour. I debriefed the participant. I then thanked him for sharing his experiences and his involvement with the study. I later observed the participant while he was attending classes at the local community college and while he was socializing with peers while having lunch at an Italian chain restaurant.

\section{Group Summary}

The following is a group summary of the experiences of the Lost Boys of the Sudan. After a brief hiatus, the civil wars in the Sudan resumed in 1983. Sudanese government forces and militias repeatedly attacked civilian areas, bombing, looting and burning villages and capturing people. They would steal grain and cattle. The government also caused the starvation deaths of hundreds of thousands of people because it restricted the movement of food provided by international relief organizations and $\mathrm{UN}$ agencies.

Thousands of terrorized and starving people fled their villages. In the chaos, many family members became separated from each other. Also fleeing were young boys, who were tending cattle away from home, as is the custom for boys that age in the Dinka culture.

Many said they were unable to return home to their families and started streaming from southern Sudan toward Ethiopia. Most of the boys just followed the crowds eventually forming groups. Many of the participants reported that older boys in the groups lead the groups toward camps in Ethiopia. The SPLA operated the camps in Ethiopia with the backing of the Ethiopian dictator Mengitsu Haile Mariam and used them to launch attacks against government forces inside Sudan.

Many aid workers and diplomats said some boys were encouraged to walk toward Ethiopia by the SPLA (Bixler, 2005). Because few opportunities existed for formal schooling in southern Sudan, the SPLA promised that the children could get an education in the camps. Word 
spread in parts of southern Sudan and many parents sent their children unaccompanied or with some representative of the SPLA to Ethiopia because of the promise of education. Human rights groups would later accuse the SPLA of luring boys to the camps not only for education but also for military training (Bixler, 2005).

Some boys left the Sudan with a few belongings and small amounts of water and food. Others left with nothing. They walked for weeks through forests and marshes and, at night, slept in the bush. When the food ran out, along the way, they ate grass and leaves and drank water from holes in the ground. When they came upon villages, they begged for food.

Eventually they entered a desert that would take several days to cross. There was no water or food. As a result many drank their own urine. They eventually reached a town near the Ethiopian border. Once in Ethiopia they registered as refugees with the UNHCR. Many ended up in a camp in Panyido, Ethiopia.

Diplomats in Addis Ababa, the Ethiopian capital, estimated that almost eight thousand boys died in the months-long journey from the Sudan. An aid worker who visited one of the camps in 1987 recalled "only naked bodies, very thin, of boys, as far as the eyes could see" (Bixler, 2005).

In May 1991 the Ethiopian dictator was on the verge of being overthrown, and the rebels ousting him were hostile to the southern Sudanese refugees in the camps. This caused the boys and nearly 250,000 other Sudanese refugees at Panyido and other Ethiopian camps to flee in a panicked evacuation.

In a day or so the boys reached the swollen Gilo River. The river was teeming with crocodiles. Ethiopian rebels were firing at SPLA soldiers hiding among the refugees as well as at 
the boys who they considered to be SPLA child recruits. Many of the boys leaped into the river only to be sucked under by the current or eaten by crocodiles. Thousand died (Bixler, 2005).

The surviving children walked to a town called Pachala. It took three days by foot. But, there was no water and food and this resulted in tremendous hunger. The children lived under these conditions for about two months, until the ICRC intervened and set up water tanks and provided some food. Medical stations were also set up.

The fighting continued, however, and in early 1992 the boys evacuated Pachala in advance of an attack by the Sudanese government. Human Right Watch/Africa noted that some relief workers suspected that part of the government's motivation for the Pachala attack was to kill or capture large groups of the minors, whom the Sudanese government viewed as combatants or at least a military reserve force (Human Rights Watch, 1995).

The boys pushed further south toward the Kenyan border, moving through the towns of Buma, Magose, and Kapoeta. At some point the Red Cross began providing transportation and the boys eventually reached Nairus. However, when they heard militias had captured Kapoeta, and that fighting was intensifying and getting closer, they were forced to flee again.

Thus they decided to cross the border to Kenya to the town of Lokichiogio. However, because the UN thought that the boys were so close to the border they would be subject to further attacks, they were taken further from the border. They wound up at the Kakuma Refugee Camp, where they lived in tents and mud huts with floors of dirt and roofs of plastic sheets. Usually the boys ate just one meal a day - consisting of corn or sorghum or maize.

In 1999 they were interviewed by officers of the Immigration and Naturalization Service to determine who might qualify for refugee status in the US. Eventually over 3,000 Lost Boys were resettled in the United States by various agencies. The participants in the study were all 
resettled by a refugee resettlement office affiliated with the National Conference of Catholic Bishops in a mid-sized city in the Midwest in 2001.

They have much hope for the future. One desire was to obtain an education and acquire a job so that they may be able to contribute to the betterment of their family members, the Dinka people, and Sudan. But most of all they hope for peace in their country. 


\section{CHAPTER FIVE: DISCUSSION OF THE DATA}

\section{Introduction}

This chapter provides a discussion of the data. It consists of four sections. The first reviews data sources of interviews, direct observation, and physical artifacts and the associated data collection procedures. The second section discusses the data analysis procedures used in this study which included data reduction, data display, drawing and verification of the conclusions (Miles \& Huberman, 1994). In the third section, the themes or results will be introduced, discussed, and elaborated upon. Finally, the research questions will be reviewed and answered.

\section{Data Sources and Collection Procedures}

\section{$\underline{\text { Interviews }}$}

An interview is a social interaction that results in a transfer of information from the interviewee to an interviewer or researcher (Marshall \& Rossman, 1999). The purpose of an interview is to enter into the other person's perspective (Patton, 1990). Qualitative interviewing begins with the assumption that the perspective of others is meaningful, knowable, and capable of being made explicit.

I utilized the general interview guide approach to collecting qualitative data (Patton, 1990). The general interview guide involves outlining a set of issues that are to be explored with each participant. This guide assumes that there is common information that should be obtained from each person interviewed. However, the interviewer is expected to adapt both the wording and the sequence of questions to specific participants in the context of the actual interview. The interview guide provides topics or subject areas within which the interviewer is free to explore, probe, and ask questions that will elucidate and illuminate that particular subject (Patton, 1990). Thus, the interviewer is free to build a conversation within a particular subject area, wording 
questions spontaneously and establishing a conversational style, yet maintaining a focus on a predetermined topic (Patton, 1990).

Since the purpose of an interview is to record the particular interviewee's perspective as fully and fairly as possible, a tape recorder was used to increase the accuracy of data collection and to facilitate greater attention to the participant during the interview. It was also necessary to take notes. Notes serve two purposes: (1) they allow the interviewer to formulate new questions as the interview moves along, particularly when it may be appropriate to investigate what was said earlier; and (2) they facilitate later analysis (Kvale, 1996).

The following questions were posed to the participants:

(1) Could you tell me about the events that led to you coming to the United States?

(2) Could you tell me about the Sudanese civil wars?

(3) Could you tell me about your experiences in the civil wars?

(4) How did the civil wars affect you?

(5) You have experienced events in your life that many people might describe as difficult or stressful. How did you (do you) deal with or cope with these events?

(6) Many people might describe someone who dealt with or coped well with these events as strong or resilient. What helped you in being (becoming) strong or resilient?

(7) In what ways did your relationship with your family help you in coping?

(8) Could you give me an example?

(9) How do you think your family or your relationship with your family was able to help you even though you were separated from them and did not know their status?

(10) Could you give me an example? Then? Now?

(11) Is there anything else that you would like to add? 
Field notes in the form of a Contact Summary Form (Appendix C) were written about the interview immediately following each interview.

\section{Direct Observations}

Observation is often used in conjunction with others sources of data collection.

Observation can occur in any setting where activity occurs.

In Gold's (1958, as cited in Adler \& Adler, 1994) classic typology of roles, my role was that of observer as participant. According to Gold (1958, as cited in Adler \& Adler, 1994), this role describes researchers as primarily observing their subjects for brief periods of time as they attempt to conduct structured interviews. A full explanation of the real purpose for my observations was provided to all participants prior to the time I made overt observations. I made multiple observations of limited duration for about two weeks. I observed the participants during the interviews at the agency office, their apartments, a community college, and restaurant. It was not possible to observe and record everything, so I had to limit what I observed. In addition, I had to determine what types of observations were pertinent to the study. I decided that during interviews I would focus on nonverbal and verbal behaviors, at what point significant behaviors occurred during the interview, and any contradictions between nonverbal and verbal behaviors. During observations at the agency office, their apartments, a community college and a restaurant I also focused on the interactions between the refugees. The particulars of these interactions that interested me included: who interacted the most, and the least; who interacted with whom; the types of interactions; and the topics of conversations. I made extensive field notes of each observation. 


\section{Physical Artifacts}

A physical artifact is some form of physical evidence such as a work of art. At the beginning of the initial interview, I requested from each participant a drawing of some aspect of Dinka culture or of his experiences of the Sudanese civil wars. Ultimately two drawings were obtained. They drawings were scanned and are included in Appendix E. Field notes in the form of the Art Work Analysis Form (Appendix D) were written for each physical artifact produced. Thus, my data consisted of transcribed tape recordings of the interviews, my field notes that were notes of my working processes and observations, and contacts with the participants. Table 5.1 displays the participants, the data source, the location where the data were obtained, and the length of the contact with the participant.

Table 5.1: Data Sources and Collection Procedures

\begin{tabular}{|c|l|l|c|}
\hline Participant & \multicolumn{1}{|c|}{ Interviews } & \multicolumn{1}{|c|}{ Observations } & $\begin{array}{c}\text { Physical } \\
\text { Artifacts }\end{array}$ \\
\hline 1 & In office - 1.5 hours & Unable to contact & Declined \\
\hline 2 & In office - 1 hour & Apartment - 1 hour & Yes \\
\hline 3 & In office - 1 hour & Apartment - 1 hour & Declined \\
\hline 4 & $\begin{array}{l}\text { In office - about 2 } \\
\text { hours }\end{array}$ & $\begin{array}{l}\text { Community college - 3 hours } \\
\text { Restaurant - 2 hours }\end{array}$ & Yes \\
\hline 5 & $\begin{array}{l}\text { At apartment - less } \\
\text { than 1 hour }\end{array}$ & Apartment - 2 times, 1 hour each & Declined \\
\hline 6 & At apartment & Apartment - 2 times, 1 hour each & Declined \\
\hline 7 & At apartment & $\begin{array}{l}\text { Apartment }-1 \text { hour } \\
\text { Restaurant }-2 \text { hour }\end{array}$ & Declined \\
\hline 8 & At apartment & $\begin{array}{l}\text { Community college - 3 hours } \\
\text { Restaurant - 2 hours }\end{array}$ & Declined \\
\hline
\end{tabular}




\section{Data Analysis}

\section{Preparation of Raw Data - Data Cleaning}

Initially the raw data were prepared for analysis. The tape recordings were transcribed by a professional transcriptionist. Since the transcriptionist had difficulty discerning some of the words or phrases used by the refugees, I listened to the tape recordings three times. Corrections to and gaps of words or phrases were added to the transcript. Yet, there were still gaps that were simply inaudible. I consulted a former Sudanese refugee who resided and was employed in Baton Rouge, Louisiana to assist me in clarifying some of the words and towns that were frequently mentioned. Every word of each interview was transcribed. Ample margins were left so I would have an area to write any memos or codes. Each transcript was numbered, each page numbered, and each line of the text was numbered to assist with cutting and sorting later.

Finally, I was comfortable that virtually all that was spoken was captured. The transcripts were then deemed ready for analysis. Multiple copies were made of each transcript onto a particular color of paper. Again, this was done to assist with cutting and sorting later. My field notes were notes of my working processes and observations and contacts with the participants. They also included the Contact Summary Form and a document summary form (Miles \& Huberman, 1994). The Contact Summary Form is a single sheet with focusing or summarizing questions (Appendix C). Each question was answered briefly to summarize the main points of the contact. I utilized the Contact Summary Form after any contact that I had with the participants.

I used another, similar type of contact form, a document summary form, when I obtained physical artifacts. However, I designated this form as an Art Work Analysis Form (Appendix D). It was completed and attached to each drawing produced. This form puts the art work in context, 
explains its significance, and gives a brief summary. Field notes and both forms were later coded and used in the analysis.

Drawing is recognized as one of the most important ways in which children and youth express themselves. In my clinical work with child and youth refugees, my experiences had been that most of them were keenly interested in art-making, particularly drawing. I found the use of art to be a highly effective tool in engaging with the client, putting them at ease, and assisting in communication. And, I hoped it would be so for the participants as well.

In the past when I would request a drawing, my clients were often quite anxious and initially reluctant, but with some encouragement would begin the process of art-making. A few clients - perhaps, two or three out of hundreds - refused to participate in drawing. However, those that did were adolescent or young adult males about the same ages as the Lost Boys. Nonetheless, I was quite surprised when most of the participants were reluctant and even declined to draw. Ultimately only two drawings were obtained.

Malchiodi (1998) has cited two possible reasons for reluctance or refusal: (1) an unfamiliarity with art materials and how to proceed; and (2) anxiety. To these I would add two of my own observations about the participants reluctance. First, I may have been mistaken in thinking that the participants needed this tool to facilitate communication. Despite some difficulties with grammar, they all communicated quite well. This is understandable as the Dinka have a strong oral tradition. In addition, the participants seemed to not want to be distracted by this exercise; most wanted to start in immediately and tell me of their experiences. Another possible reason for their refusal was that the participants may have attributed an ability to draw as evidence of an education or training. They were very self-conscious about their lack of 
education and may have refused to draw because they believed they lacked this training and ability.

In analyzing the two drawings that were obtained, I followed Malchiodi's (1998) phenomenological approach. The first step involves taking a stance of "not knowing" - that is, being open to the many possibilities of the drawings. The second step is to consider participant characteristics such as developmental maturity, cognitive ability, emotional development, and interpersonal skills. It is also important to acknowledge that children through their art expressions link their inner self with the outside world and their experiences in that world. Another consideration is to accept and expect that each individual has a different way of approaching art, with an individual style of drawing and particular likes and dislikes for color, form, and composition. Finally, although this approach is advantageous to understanding children's and youth's drawings, one must also consider some of the more reliable information relating specific content in drawings to certain meanings, experiences, and difficulties (Malchiodi, 1998).

After some encouragement, Participant \#2 agreed to draw a picture of some aspect of his experiences. He was hesitant and tentative throughout his art-making. He chose to use only a pencil. There are minimal markings on the paper and virtually no color. He drew a picture of a cow. Again, with considerable hesitation, he described his picture (Appendix E). He said it was a cow and explained the importance of the cow to the Dinka. He said little else despite encouragement to do so.

Participant \#4 quickly agreed to draw a picture of some aspect of his experiences in the Sudan. He undertook the task with considerable enthusiasm. He also willingly discussed it after it was completed. The drawing is entitled, "Cattle Camp." It depicts a cow and a male Dinka. 
The cow is the focus of the picture (Appendix E). The picture covers the entire space and the figures are somewhat large. There is some detail. He initially used a lead pencil. Later he used colored pencils and thus there is considerable color in his drawing. The participant explained the importance of the cow in Dinka culture. Interestingly, he noted that the cow is symbolic of manhood. He added "it is everything."

I later analyzed the drawings. I then summarized on the Art Work Analysis Form my analysis and notes of the discussion that I had with the participants of their drawings. They were then coded and categorized.

\section{Analytic Approach}

I used a general inductive approach in analyzing the data. The general inductive approach is a systematic procedure for analyzing qualitative data. According to Thomas (2003), the primary purpose of the inductive approach is to allow research findings to emerge from the frequent, dominant, or significant themes inherent in the raw data. Other purposes include:

(1) to condense extensive and varied raw data into a brief, summary format;

(2) to establish clear links between the research goals, questions, and the findings and to ensure that these links are both transparent (demonstrable to others) and defensible (justifiable given the objectives of the research); and

(3) to develop a model or theory about the underlying structure of experiences or processes which are evident in the raw data.

There are several assumptions underlying the use of the general inductive approach to data analysis (Thomas, 2003).

(1) Data analysis is determined by both the research goals and multiple readings and interpretations of the raw data. Thus, the findings are derived from both the research 
goals put forth and detailed by the researcher but also by the findings arising directly from the analysis of the raw data.

(2) The primary strategy of analysis is the development of categories from the raw data into a framework that captures key themes and processes judged to be important by the researcher.

(3) The research findings result from multiple interpretations made from the raw data by the researcher who codes the data. Inevitably, the findings are shaped by the assumptions and experiences of the researcher conducting the research and doing the data analysis.

(4) Different researchers are likely to produce findings which are not identical and which have non-overlapping components.

(5) Finally, the "trustworthiness" of the findings can be assessed by a range of techniques, such as: (i) independent replication of the research; (ii) comparison of findings from previous research; (iii) triangulation within the study; (iv) feedback from participants in the research; and (v) feedback from users of the research findings.

\section{$\underline{\text { Analytic Process and Procedures }}$}

Discussed below are the data analysis procedures. They are data reduction, data display, and conclusion drawing and verification.

\section{Data Reduction}

The first component of data analysis is data reduction. Data reduction refers to the process of selecting, focusing, simplifying, abstracting, and transforming the data that appear in written-up field notes or transcriptions. 
I began by closely reading the text of my interviews - line by line - while considering the multiple meanings that were inherent in the text. Text segments or "chunks" - words, phrases, sentences, or whole paragraphs of significance - that had meaning were identified. This is often referred to as "chunking." Further readings of the text were done until all chunks were identified. Then, beside or below each paragraph, the category was noted, the chunk was assigned, and a code was created. Codes are tags or labels for assigning units of meaning to information compiled during the study (Miles \& Huberman, 1994). Codes were then given clear operational definitions.

I initially followed this procedure but quickly realized that the vast numbers of categories was cumbersome. So, to provide structure to the process, I utilized Lofland's (1971, as cited in Miles \& Huberman, 1994) scheme. It is a general accounting scheme for codes that are not content-specific but point to the general domains in which codes can be developed intuitively. I found this scheme quite helpful. Lofland's scheme suggests that any study can deal with the following sorts of phenomena:

(1) Acts - action in a situation that is temporally brief, consuming only a few seconds, minutes, or hours;

(2) Activities - actions in a setting of more major duration - days, weeks, months - constituting significant elements of people's involvements;

(3) Meanings - the verbal production of participants that define and direct action;

(4) Participation - people's holistic involvement in or adaptation to a situation or setting under study;

(5) Relationships - interrelationships among several persons considered simultaneously; and

(6) Settings - the entire setting under study conceived as the unit of analysis. 
I reread the text until I identified all text segments and assigned them to a class of phenomena. Then, the categories were noted and coded with each code given a clear operational definition. Through the process of cutting and sorting, additional text segments were then assigned to the categories. Some chunks of text were assigned to more than one category. For example, the text segment 6-18.19 - "I had to survive, I had to survive" - was assigned to the category "Survival" but also to "War." Some portions of the text were not assigned to any category.

Ideally, at the conclusion of an initial coding procedure, between 30 to 40 categories should be created. After my initial coding procedure for this study, 35 categories were created. See Table 5.2 for the initial list of the categories and codes.

Categories may change as the analysis proceeds because analysis is an iterative process. Thus, virtually every definition of the codes was adjusted. As well new categories were identified so as to accommodate data that did not fit the existing codes. For example, the category "Experiencing Through Senses" was created to accommodate seemingly disparate or unrelated text segments. Similarly, text segment 4-16.21 to 25 , "very happy to get an education," was assigned to "Education" as well as "United States."

Still other categories were partitioned into subcategories. For example, the category "Groups" was partitioned into more specific categories. They became "Teachers' linked to groups" and "Peer Groups." Even more categories emerged later in the analysis, such as "Suffering," which was one of the last to emerge in the analysis.

For within category analysis, I was careful to notice similarities and differences between the participants. For example, in the category "Separation from Family and Parent," almost all of the participants had similar stories as to how they became separated from their parents and 
Table 5.2: Initial List of Categories and Codes

\begin{tabular}{|l|r|}
\hline Category & Code \\
\hline Acts, avoiding & ACT, A \\
\hline Acts, in reaction to war & ACT, R \\
\hline Africa & AFR \\
\hline Arabs vs. Dinka & AVD \\
\hline Coping & COP \\
\hline Departure/flight/journey & DFJ \\
\hline Dinka & DIN \\
\hline Education & EDU \\
\hline Ethiopia & ETH \\
\hline $\begin{array}{l}\text { Experiencing war through } \\
\text { senses }\end{array}$ & SEN \\
\hline Family/parents & F/P \\
\hline Peer groups & PG \\
\hline God & IUR \\
\hline Groups with whom initial fled \\
\hline Events in Kapoeta, Sudan \\
\hline
\end{tabular}

\begin{tabular}{|l|r|}
\hline Category & Code \\
\hline Events in Magose, Sudan & MAG \\
\hline Muslim vs. Christian & MVC \\
\hline Events in Nairus, Sudan & NAI \\
\hline New life/future & FUT \\
\hline North vs. South & NVS \\
\hline "Teachers" linked to groups & TEA \\
\hline Other ethnic groups vs. Dinka & EVD \\
\hline Events in Pachala, Sudan & PAC \\
\hline Refugee/'Lost Boys" & BOY \\
\hline Southern Sudan & SSU \\
\hline Sudan & SUS \\
\hline Suffering & SUF \\
\hline Survivor guilt & PSS \\
\hline Survival - physical & \\
\hline Survival - psychological & \\
\hline Survival - spiritual & \\
\hline United States & SPS \\
\hline
\end{tabular}


family. Participant \#6, however, had a different story. He explained that his father "sent me away" as "Sudan was becoming a war zone." And for my between category analysis I began to notice patterns or connections developing. For example, the categories "Survival - physical", "Survival - psychological", and "Survival - spiritual" referred to different dimensions of survival and yet were connected.

Through the continuing process of cutting and sorting the categories I was able to further reduce overlay and redundancy. Ideally, at this part in the analysis the number of categories should be no more than $15-20$. I reduced the number of categories to 15 . See Table 5.3 for a revised list of categories and codes.

Strauss (1987) and Lincoln and Guba (1985) (as cited in Miles \& Huberman, 1994) suggest that coding and recoding are finished when the analysis itself appears to have run its course, i.e., when all of the incidents can be readily classified, categories are "saturated," and sufficient numbers of regularities emerge. I began to see patterns and connections both within and between the categories.

The 15 categories were then further reduced to the three to four categories that emerged as the themes. These themes will be identified and further discussed in a later section.

\section{Data Display}

The second component of analysis activity is data display (Miles \& Huberman, 1994). A display is an organized, compressed assembly of information. Data displays allow the analyst to discern and/or verify patterns or themes that emerge from the data.

Other benefits of a display are: (1) it presents all of the relevant responses of all informants on one sheet; (2) it allows an initial comparison between participants and their 
Table 5.3: Revised List of Categories and Codes

\begin{tabular}{|l|r|}
\hline Category & Code \\
\hline Coping & COP \\
\hline Departure/flight/journey & DFJ \\
\hline Family/parents & PSF \\
\hline $\begin{array}{l}\text { Peer Groups that Evolved Into } \\
\text { Surrogate Families }\end{array}$ & GOD \\
\hline God & AFF \\
\hline $\begin{array}{l}\text { How affect by various } \\
\text { circumstances }\end{array}$ & FUT \\
\hline New life/future & SUF \\
\hline Suffering & PHS \\
\hline Survival, physical & PSS \\
\hline Survival, psychological & SPS \\
\hline Survival, spiritual & SUG \\
\hline Survivor guilt & TEA \\
\hline Teachers & USA \\
\hline United States & WAR \\
\hline War & \\
\hline
\end{tabular}

responses on one sheet; and (3) for multicase studies such as this collective case study, it lends itself easily to cross-case analysis.

Displays are of two types: (1) matrices, with defined rows and columns; and (2) networks, with a series of "nodes" with links between them (Miles \& Huberman, 1994). A matrix is recommended for studies that include several research questions. Quite often the 
researcher can become confused or overwhelmed during the analysis and lose sight of the research and interview questions and the connection between the two. I chose to build a matrix because it clusters research and interview questions so that meaning can be generated more clearly.

The format is a simple participant-by-question matrix. The matrix, Table 5.4, includes the participants, the research and related interview questions, and selected participants' responses to the interview questions. The data are multiform: coded categories; direct quotes; or summary phrases. The codes set up the presence of patterns and comparisons between participants. The quotes or summary phrases attach meaning to the code, thus making it more easily extracted for use in later analysis.

Ideally, the format should: (1) display all of the relevant responses of the participants on one sheet; (2) allow an initial comparison between participants and responses; and (3) allow the researcher to see how the data can be analyzed further (Miles \& Huberman, 1994).

After constructing the display, I made a quick scan across the rows and down the columns to note what was obvious. Then, I verified, revised, or disconfirmed my initial impressions through a more careful review. Reading across the rows provided me with a profile of each participant, as well as an initial test of the relationship between responses to the different questions. Reading down the columns uses the tactic of making comparisons between the responses of the different participants. Thus, I found that it verified the themes that emerged from the initial analysis. However, I was concerned with the seemingly lack of responses to interview questions \#7 and \#8. So, I returned to the transcripts and carefully read them several more times. 
Table 5.4: Matrix

\section{Global Research Question}

What is the role of familial protective factors and processes in moderating the relationship between risk and resilience in Sudanese refugee youth exposed to political violence?

\section{Subquestions}

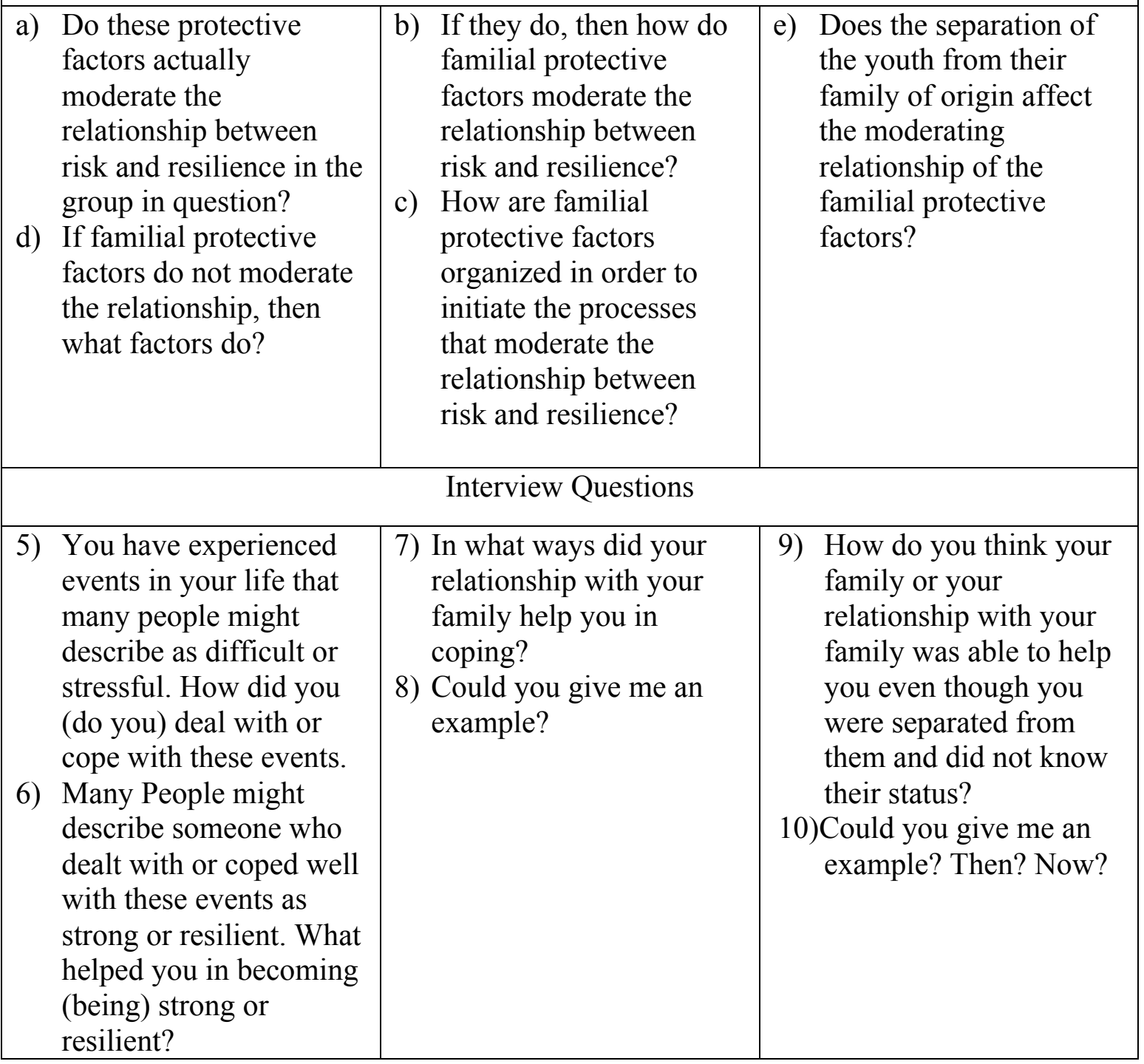


(Table 5.4 cont.)

\begin{tabular}{|c|c|c|c|}
\hline & $\begin{array}{l}\text { GOD, PSF, TEA, } \\
\text { "I did not have enough } \\
\text { time with my parents to } \\
\text { experience that kind of } \\
\text { help from them." } \\
\text { "I found more people } \\
\text { who had also running } \\
\text { and I joined them and I } \\
\text { went together with that } \\
\text { group of people. They } \\
\text { were having some who } \\
\text { were taking care of us } \\
\text {.. Teachers, You." } \\
\text { "Those teachers were } \\
\text { the ones who took care } \\
\text { of us." } \\
\text { "These were the people } \\
\text { who were taking care of } \\
\text { us and then they } \\
\text { managed to make us to } \\
\text { cope, to cope with the } \\
\text { situation." } \\
\text { "They were eager to } \\
\text { keep us alive." } \\
\text { "God will help." }\end{array}$ & $\begin{array}{l}\text { "I did not have enough time } \\
\text { with my parents to } \\
\text { experience that kind of help } \\
\text { from them." } \\
\text { "I did not get any help from } \\
\text { them." }\end{array}$ & $\begin{array}{l}\text { "I did not have enough time } \\
\text { with my parents to } \\
\text { experience that kind of help } \\
\text { from them." }\end{array}$ \\
\hline 2) & $\begin{array}{l}\text { GOD } \\
\text { "I didn't think about it } \\
\text {... I don't put it in my } \\
\text { mind." }\end{array}$ & & \\
\hline 3) & $\begin{array}{l}\text { EDU, F/P, FUT } \\
\text { "You go on and look to } \\
\text { future." } \\
\text { "... Go on and look at } \\
\text { school and study } \\
\text { properly." } \\
\text { "It was our parents } \\
\text { telling us like that." }\end{array}$ & $\begin{array}{l}\text { "You go on and look to the } \\
\text { future." }\end{array}$ & \\
\hline
\end{tabular}


(Table 5.4 cont.)

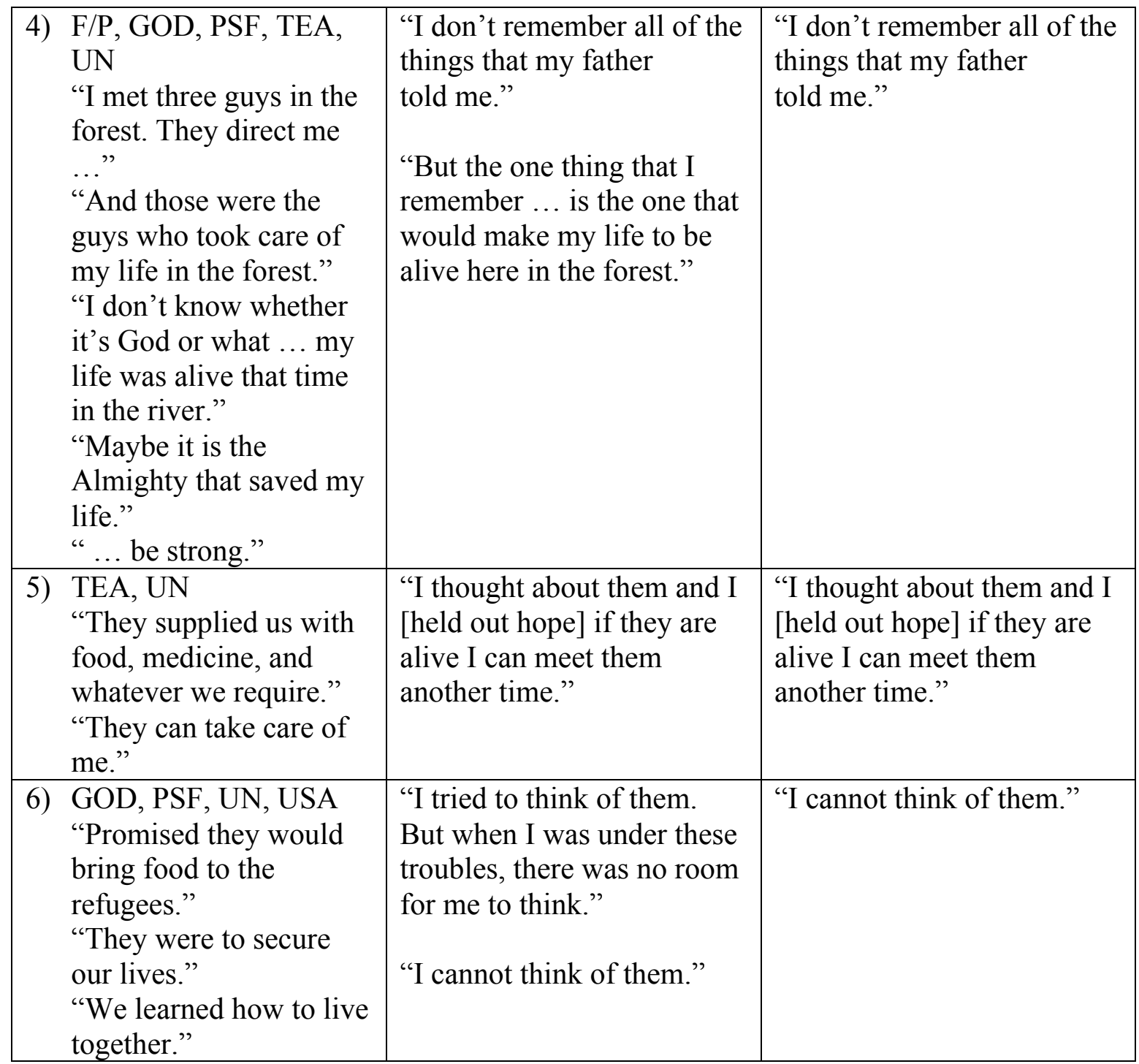


(Table 5.4 cont.)

\begin{tabular}{|c|c|c|c|}
\hline & $\begin{array}{l}\text { GOD, PSF, TEA } \\
\text { "Those guys helped me } \\
\text { to survive." } \\
\text { "And God got me out of } \\
\text { there." } \\
\text { " ... Due to God's } \\
\text { power." } \\
\text { "I met with other guys } \\
\text { and I came together } \\
\text { with them ... that's how } \\
\text { I survive." } \\
\text { "We have been together } \\
\text { for almost } 16 \text { or } 17 \\
\text { years. Now we are like a } \\
\text { family." }\end{array}$ & $\begin{array}{l}\text { "You know now I've been } \\
\text { away from them for almost } \\
\text { a decade. I never have so } \\
\text { called 'parental love.' You } \\
\text { know I don't know anything } \\
\text { about that ... its been long } \\
\text { time for me from them." }\end{array}$ & $\begin{array}{l}\text { "You know now I've been } \\
\text { away from them for almost } \\
\text { a decade. I never have so } \\
\text { called 'parental love.' You } \\
\text { know I don't know anything } \\
\text { about that ... its been long } \\
\text { time for me from them." }\end{array}$ \\
\hline 8) & $\begin{array}{l}\text { PSF, TEA } \\
\text { "I run one night and I } \\
\text { came and met with } \\
\text { some people and then I } \\
\text { start walking with } \\
\text { them." } \\
\text { "... Who were elder } \\
\text { than us." } \\
\text { "They told us which is } \\
\text { bad, which is good." }\end{array}$ & & \\
\hline
\end{tabular}

What was particularly striking was that the participants were initially at a loss when I questioned them about their parents' role in their survival. Perhaps because they had been separated from their parents so early in their lives, it was difficult for the young men to recognize the role their parents might have played in their survival. Indeed, the only fact they readily acknowledged was that their parents attempted to protect them from a very dangerous situation. Participant \#6 stated that his parents "told me to leave" as southern Sudan was "becoming a war zone."

Still, their answers were quite revealing. Their parents were seen as providing the basics for them in their early years - safety, food and shelter, love and affection. Apparently there was 
also a great deal of communication between the parents and the boys, much of which consisted of giving advice.

Some of the boys admitted that they "can't remember all of the things that they [his parents] taught me." Others said that some of the advice given by their parents was to simply "ignore or overlook the bad," "go on," and "look toward the future." Still others stated that their parents emphasized the importance of obtaining an education, advising them to "look at school and study properly."

Thus, even though it was not readily apparent to the boys, their parents provided them with some advice, coping skills and, despite dire circumstances, a sense of hope or optimism for the future, with the goal of obtaining an education and ultimately having a better life.

At this point in the analysis, ideally between three to eight themes should be noted. I had four themes. Through the initial analysis and the analysis of the data display, the following themes or results emerged.

\section{Themes}

\section{Theme \#1: Danger, Destruction, and Death}

The first theme - danger, destruction, and death - was the most striking given its prominence in the narratives of the participants. Every participant discussed the danger they encountered, the destruction, and the deaths resulting from the conflicts. Participant \#6 mournfully stated: "[S]o we lived under that condition, the war - too worse to imagine." In general the boys spoke, as noted by Participant \#5, of a "continuous struggle."

Their narratives chronicled three time periods: (1) the initial raid or bombardment of their village, which resulted in separation from their family, flight, and eventual arrival in Ethiopia; 
(2) their departure from Ethiopia and brief return to Sudan, followed by the journey to and arrival in Kenya; and (3) their life in the Kakuma refugee camp in Kenya.

\section{$\underline{\text { Initial Raid }}$}

The plight of the Lost Boys began when their villages were either attacked by aerial bombardment or raided by government forces or their militias. Often the villages were destroyed. Grain and livestock were stolen and what could not be taken was burned. Participant \#3's story began when "[T]hey attack our village. They attack us, they attack us, burning of everything, destroying everything, taking our properties. During these raids many people were killed or captured.” According to Participant \#4, “[T]hey would try to kill us even.” Many of the Lost Boys lost their family members, like Participant \#1, who stated that his "father was killed and last-born brother was captured." He reported that "they also captured young people, especially young ladies and young men. And what they do with these people that they take, they go and use these young ladies as their wife."

Most of the participants claimed that they were tending cattle - an activity common for boys of that age in the Dinka culture - when their villages were attacked. The attacks prevented them from returning to their villages and their families. The participants were very young when they became separated from their families. As Participant \#4 remarked: "I was separated; I can say I was really very, very young, about 11 , or seven - seven, probably seven years. Seven years of life was really very young."

So they ran with the fleeing crowds. Participant \#6 stated: "I found people running, so I run with them." Eventually the boys came together and formed groups. Sometimes young men assisted them and led the group, or one or more boys in the group asserted themselves and became leaders of the group. In the groups, the boys continued fleeing south as they followed 
sources of water. Their flight led them, according to Participants \#3 and \#6, “ $\ldots$ out of the southern part, to a border country, called Ethiopia."

Their journey on foot took them through difficult and dangerous terrain and forced them to live in terrible conditions. Many boys died of hunger and dehydration; others of diseases. Initially, they lived in the bush, eating whatever food was available, and otherwise foraging for anything that was edible. When they were lucky, they found bits of fruit, vegetables, or the roots of trees. Later, they survived on the leaves and bark of trees. Clean water was unavailable and what water they could find came from puddles on the ground. After a point, out of necessity, the boys were forced to drink their urine.

Participant \#1 recalled: "[S]o many people died on the way to Ethiopia." Other participants spoke of the horror of seeing people dying, and of the revulsion of "smelling people dying." Participant \#2 tearfully recalled: "I faced a lot of problems and have seen many people dead." According to Participant \#4: "[E]ven my roommate was killed on the road - shot by some ... an Arab - beside me yet I was alive.”

Still, the boys kept slightly ahead of the militias that were trying to attack and kill them. Their trek was made even more harrowing by natives of the area they were passing through. The natives frequently attacked the boys and stole their belongings. Participant \#1 reported:

It took us three months to go to Ethiopia and on our way we faced a lot of problems. Like hunger and thirst, and how we survived on the way to Ethiopia. People used their own urine to drink as water because you could not find any water. And, the thing we used for food if we cannot find anything that is edible, we can use any leaves from the tree.

According to Participant \#7,

It was really a terrible condition. On my way to Ethiopia there was no water. Also, there was a shortage of food. We only survived by eating wild fruit plants, different vegetables stuck under the ground. It was a very horrible hunger. It was really terrible conditions. 
There were numerous instances where boys were mauled by lions or attacked by crocodiles and killed. As Participant \#6 horrifically recounted: "I was about to be taken by a lion. While I was walking [by] the lion, fortunately somebody grabbed me off the mouth of the lion.”

The Lost Boys officially became refugees when they crossed an international boundary the border with Ethiopia - and registered with the United Nations High Commissioner for Refugees.

Departure from Ethiopia

Eventually the Lost Boys, now young men, would be uprooted again and forced to return to Sudan. As Participant \#1 reported:

... so we spent four years in Ethiopia. Everything was going well with us and our life was normal. But, in 1990, civil war of Ethiopia broke out. And that was the reason why we ran out ...

Their departure was dangerous and many of the boys died. One of the more horrific experiences was when the boys reached the River Gilo, at the border with Sudan. It was the rainy season and the river was swollen. Most of the boys did not know how to swim, so they planned to wait until the water subsided. However, a fire-fight broke out between the Sudanese militias and Ethiopian forces, and the Lost Boys were caught in between. To escape, the boys jumped into the river.

According to Participant \#7, "But at that place we were attacked by Ethiopian militia. [We] jumped into the river, but some drown down." Participant \#4 added: "That Gilo - a lot of people lost their life in the Gilo because they don't know how to swim. A lot of people lost their life in that river - thousands." Participant \#6 stated: "So almost 3,000 Lost Boys, boys like me, lost their lives because they don't know how to swim." 
Those who survived continued on and briefly returned to the Sudan. However, the situation there remained unchanged, and the boys' lives continued to be fraught with unimaginable difficulties. Participant \#7 explained, “Again, we moved from [Ethiopia] back to Sudan, at a place called Pachala. We spent eight months in Pachala. But we fell into a very, very severe hunger again." Participant \#6 remembered:

[T] here was so much cold. And ... there it came to the time that all of the food is already over, and we spent almost one and one-half months without any kind of food. So we were about to be wild human beings ...

Eventually, according to Participant \#7, the boys “ ... move again from Sudan, following the secure corridors up to the border of Kenya and Sudan. We spent three months at the border of Kenya and Sudan. Then we moved to Kenya, Kakuma.”

\section{$\underline{\text { Kakuma Refugee Camp, Kenya }}$}

The Kakuma refugee camp area, where the Lost Boys settled in Kenya, was fraught with difficulty. Participant \#5 described life in camp as "an endless struggle." Participant \#1 said, "Yeah, in fact, when we came to Kenya, our life was still not okay."

They had to build their own shelter, often with few supplies or very little assistance from nongovernmental organizations. Their shelters provided minimal protection from the elements, animals, and natives of the surrounding area. The young men said they never felt safe. "There was no protection." Participant \#1 stated,

There was a local people in the place where we were located in Kenya too. Those local people, they staying with us was not all right. Some of them, they just come at night with guns and kill some of us. Always some people are killed; every night you find that some ... one of people are killed.

The participants stated that when they ventured outside of the camp they were harassed by natives as well as the police. Participant \#4 recalled: “They don't like you because of refugee 
status ... we are Sudanese and we don't have, ah, we leave our country. They just give us some mistreating."

The refugees were given meager food rations by the U.N. Participant \#4 reported: “ ... people really suffering in Kakuma camp 'cause one, in one week, in one week, one week they, somebody having one cup of maize.” Others reported: “They don’t even have meat and they don't have any nutritional foods." At some point the rations were cut back, “[F]oods were reducing, everything were reducing." To add to their difficulties, natives of the area often attacked them and stole their rations. As Participant \#5 angrily recalled: “ ... so they came at night and shoot at us and take our rations."

Hunger was constant, water was scarce and difficult to obtain, and diseases were rampant. Thus, as many of the participants stated: "a lot of people die ... in that camp."

The manner in which different participants expressed this theme varied considerably. Some were controlled and emotionally detached when discussing the danger, destruction, and death they encountered. Certainly this could be an attempt to control overwhelming feelings associated with their experiences. Yet others displayed a range of emotions appropriate to what they were discussing. Still others, and one in particular, simply raged about their experiences. Even so, despite the differences in expressiveness, these experiences still seem to be omnipresent in their daily lives - and probably always will be.

\section{Theme \#2: Struggle for Survival}

The second theme that emerged was the Lost Boys' struggle for survival. As with the previous theme of "Danger, Destruction, and Death," every participant spoke of the struggle for survival, but did so with greater detail and emotional intensity. Each spoke of different aspects physical as well as psychological - to their struggle for survival. It seems as if attention to both 
was necessary for their survival. Not only did one need to physically undertake certain activities to survive, one also needed the psychological determination - or will - to survive.

\section{$\underline{\text { Physical }}$}

The most basic act of survival that the participants spoke of was physically escaping or fleeing potentially deadly events, such as bombings, firefights, or attacks by animals. Participant \#1 recalled: "[S]o there was a heavy attack made to the area where I was living - by Arabs themselves. They made a heavy attack ... We ran to the forest and hide." Participant \#2 said: "I have seen people fighting and have heard the guns and bombs with my naked eye. That's why I do all the running to go where I can get safe, or get help."

In describing their attempt to cross the Gilo River, Participant \#3 said: "You will be shot over the river ... so we escaped there.” Participant \#1 stated: "I survived because I was able to swim." And, in recalling an incident of an attack by an animal, yet another participant said: "[S]o they, so they [lions] just ate people there. Then there were the place that we escape there."

Because food was scarce, another aspect of their effort to survive was to cultivate or forage for food. As one participant described it: “[W]e cultivate our own food so when we had problems, we put [the food] in a small bag and run away ..." Other times, "we had to go into the forest and maybe find out what we shall eat." Participant \#7 recalled how he ate "wild fruit plants, different vegetables stuck under the ground." But, as Participant \#1 related, "[I]f we cannot find anything that is edible, we can use any leaves from the tree."

Water was also scarce. Participant \#1 explained that, out of desperation, "people used their own urine to drink as water because you could not find any water."

In spite of their exhaustion and constant pain from walking long distances and being exposed to the elements, the Lost Boys continued on, and struggled to survive. Later, when they 
settled in Kenya, the rations from the UN staff were meager and water was still scarce, causing the boys to suffer from extreme hunger and dehydration. Nonetheless, the boys had to learn how to prepare their own meals from the rations. Despite there being few building supplies available and very little assistance from the various NGOs, the boys had to build their own shelter. Psychological

Just as important as the boys' physical efforts to survive was their psychological determination or "will" to survive. Many spoke explicitly of being "determined to survive." Participant \#6 said: "I had to survive ... I had to survive." Some mentioned the importance of not thinking about one's difficulties or circumstances, of "putting them out of mind," while other young men mentioned the need to "focus on living and going on." Still others believed in the importance of hope. As Participant \#2 said: "[W]hen you hope, you cannot die; when you lose hope ... somebody can just die."

Another psychological aspect of their struggle to survive was their realization that ultimately their fate - whether as an individual or as a member of the group - would be a matter of self-reliance. The young men repeatedly spoke of "[having] to handle things on our own," "taking care of ourselves," "saving ourselves," "supporting ourselves," "defending for our own" - and this "without family or parents." "We don't have somebody." There was a strong sense among the participants that they were alone.

\section{Theme \#3: Assistance Provided by Others}

All of the participants spoke of other people or entities that assisted them in their struggle for survival. These included their family and parents, teachers, peer groups that evolved into surrogate families, staff of nongovernmental organizations, and God. 


\section{$\underline{\text { Family and Parents }}$}

What was particularly striking was that the participants were initially at a loss when I questioned them about their parents' role in their survival. After the participants considered the question for a while, however, most gave a thoughtful response to the question. Perhaps because they had been separated from their parents so early in their lives, it was difficult for the young men to recognize the role their parents might have played in their survival. Indeed, the only fact they readily acknowledged was that their parents attempted to protect them from a very dangerous situation. Participant \#6 stated that his parents "told me to leave" as southern Sudan was "becoming a war zone."

Still, their answers were quite revealing. Their parents were seen as providing the basics for them in their early years - safety, food and shelter, love and affection. Apparently there was also a great deal of communication between the parents and the boys, much of which consisted of giving advice.

Some of the boys admitted that they "can't remember all of the things that they [his parent's] taught me." Others said that some of the advice given by their parents' was to simply "ignore or overlook the bad," "go on," and "look toward the future." Still others stated that their parents emphasized the importance of obtaining an education, advising them to "look at school and study properly."

Thus, even though it was not readily apparent to the boys, their parents provided them with some advice, coping skills and, despite dire circumstances, a sense of hope or optimism for the future, with the goal of obtaining an education and ultimately having a better life. 


\section{$\underline{\text { Teachers }}$}

The boys frequently mentioned their teachers as important to their survival. But who these teachers were remains unclear. The participants would only describe these teachers as "older," and emphasized that they had a profound effect on them and their survival. They "helped us survive" was uttered repeatedly. According to Participant \#5 the teachers directed the boys, "guiding" them on their trek. Participant \#4 stated that the teachers "worried about us" and “acted like parents." They were "eager to keep us alive."

The teachers provided the boys with food when it was available and, when it was not, they helped them forage for food. The teachers even encouraged the boys to eat what they would not typically eat or drink, such as tree leaves, bark, and roots or urine. In addition, they made decisions, provided advice, offered moral lessons, set limits, and encouraged proper behavior among the boys. For example, if a boy was struggling in making a decision, if he asked the teachers for advice, they would offer advice.

When there were difficulties or conflicts, the teachers helped solve problems and institute solutions. When the boys' situation was most difficult, the teachers encouraged the boys and offered hope. If the boys had difficulty coping with the situation, the boys claimed that the teachers suggested particular coping skills. Oddly, however, no specific examples of this support could be elicited from the participants. Still, the teachers seemed to command a great deal of loyalty from these young men. When they spoke of the teachers, it was always reverently.

\section{Peer Groups That Evolved into Surrogate Families}

Another significant entity was the groups of which the boys were members - their peer groups. The groups were of different origins. Initially, some of the groups were formed spontaneously when the boys fled their villages. Other groups formed when boys joined crowds 
of other boys who fled their own villages. Still others were formed when older boys "adopted" or took charge of individual, younger boys straggling along on the road, unable to care or fend for themselves.

Some even described their group as "the ones I left the village with to live with people who were elder" than us. These elders then led the group and assisted them whenever possible. Some of the boys claimed these groups were organized by blood relation or age groups. It is, of course, quite possible that groups formed in other ways as well.

Later, some of the boys left one group but joined another. Many died in flight. However, once the groups were formed, they were remarkably stable and consistent. The boys described these groups as always together and the members always taking care of one another.

Years later, in Kenya, most of the boys were still members of the groups in which they fled. They characterized themselves, saying: "we're always in groups" that had "spend many years together" and "grew up together." All of the participants described the group or other members of the group as "like a family" or "like brothers." They all readily proclaimed that "we love each other."

As the Lost Boys' comments indicate, the groups seemed to have functioned as families over the years. Indeed, the members provided for each other's basic needs. The groups had a division of labor and according to Participant \#7 "sharing money" and "a responsibility to guide each other." The groups frequently pooled their resources and shared money. Each in the group felt responsible to "guide" the others in whatever way that was needed. For example, Participant \#7 explained that if one of the young men started using drugs, then the others would "tell him to stop." Each young man understood his responsibility in the home as well as outside. One of the most significant statements made by several of the participants was that "we learned how to live 
together." They described "helping each other in every way possible." This included obtaining information and knowledge of how to survive, taking the necessary steps in order to survive, providing advice, and offering support.

Fortunately, recognizing how significant the groups were to the boys, the integrity of the group was respected by the various nongovernmental organizations and the United States Department of Health and Human Services and Department of State. Thus, most of the participants had known each other since they were very young. At the end of one of the interviews, a very poignant remark made by Participants \#7 was: "We want to stay together."

\section{$\underline{\text { Staff of Nongovernmental Organizations }}$}

The staff of international relief organizations and United Nations agencies were viewed by the boys as essential to their survival. Those that the participants mentioned were the United Nations High Commissioner for Refugees, the United Nations International Children's Fund, The International Committee of the Red Cross, and Lutheran Relief Services. The boys understood the function of these organizations as being ultimately "responsible for refugees" and credited them with "secure[ing] our lives" and "[taking] care of us." Transportation was provided, when available, to those who became sick during their flight to the various camps. Otherwise they "prepared" for them and then "received" them at the various camps. The organizations also provided food and water, as well as medical care and medicine and "whatever else was needed."

These organizations also "constructed schools," "provided teachers," and "provided school materials." The participants attributed much of their education to United Nations schools and were extremely grateful for these opportunities. As Participant \#6 said: "Education had been 
blocked off by the crises." But, eventually "schools were constructed. [And, finally] we got a chance to go to school in Kenya. We have to go to school!" Similarly, Participant \#1 said: "They [the UN] offered some school to us and that was the time I learning [sic] how to write and read. Our life became good." Participant \#4 stated: "We were only [too] happy to get our education. That [was] heaven to us. The UN did this ... we are grateful."

Finally, the participants also viewed the United Nations as being ultimately responsible for their resettlement in the United States. For this, too, they were deeply grateful. As Participant \#6 said: "There the United States was, actually is ... just like heaven, when you hear it [the UN announcement], you hear it as it is in heaven."

\section{$\underline{\text { God }}$}

The role of a deity - God - was seen as playing a critical role in assisting these young men in their attempts to survive. Many of the participants remarked that they saw God as "controlling" the situation and that the situation was "God's way." All of the participants remarked: "I am alive because of God" and attributed His (God was expressed in the male gender by all of the participants) "intervention" to their survival. Participant \#1 stated: "He helped (us) survive."

The young men's belief in God and His involvement and power in their lives endured, as even their accounts included expressions such as, "if God allows ..." and "if God wishes." Every participant expressed gratitude to God. Remarkably, most could even recall a specific incident in which they believe that God had actually intervened to save them from death. For example, Participant \#6 characterized his escape from death as being "plucked out from a lion's mouth ..." and Participant \#4 said: “... a hand guided me across the river." 


\section{Theme \#4: Survival and Rebirth}

Despite years of horrific experiences and their struggle to survive, the participants described an incredible hope or optimism for the future. After so many bleak years they were still convinced their "future will be brighter." They saw their opportunities as limitless. They have many dreams. First and foremost, they did not want their lives to be defined by war. All of them desperately wanted to "live in peace" and be "free." Participant \#8 stated that he was anxious to embark on or "start a new life." Some wanted, like Participants \#5 and \#6, "to be independent," "be a man," and "prove oneself." Yet others, like Participant \#4, had simpler dreams of just "driving a car."

The United States was seen as the ideal place to pursue these dreams. The Lost Boys had known for quite some time about their eventual resettlement in the United States. Their anticipation, combined with the image in much of the world that the United States is "a land of opportunity" with "streets paved in gold," heightened their belief that their opportunities were limitless.

Their greatest dream was to pursue an education. In the words of Participant \#5: "to attend school and possibly college." They saw the possible attainment of an education as leading to a promising job and a long and successful career. The young men characterized the opportunity to pursue an education as making them "very, very happy ..."

However, the reality of life in the United States quickly set in. Although many said life in the United States was "really good," others found it to be unexpectedly difficult. "Difficult in a different way" was a common remark. Most of the participants realized that "there were [just] different type of demands." All were shocked at how "expensive" life was in the United States. 
They also realized that they were responsible for themselves - that they "had to support ourselves." Thus, they had to work. But, realistically, it was "difficult to balance work and school." And many of the young men were deeply disappointed at how ill-prepared they were for school in the United States. Many thought, like Participant \#6, that they simply did not have the "time to go to school." Others had plans but had not been able to determine how to balance work and school. Those who were attending college, like Participant \#4, found it to be "very, very difficult."

In addition, all of the participants felt responsible for those left behind in the Sudan other refugees, their family, and their tribe. Interspersed in the interviews was an overwhelming sense that since they had survived they had some responsibility for those left behind. Participant \#6 said: "Because we have also people back, like ... like my parents. I want to send money back to them." He continued, "In the United States here, our lives are different ... What can I do? I have to help them out as much as I can." Many spoke of frequently thinking about the Sudan, its difficulties and possible solutions to its many problems. Some thought one route to a solution was to increase awareness of the situation in the Sudan. They wanted to "increase the awareness of Americans as to what is going on in the Sudan." Thus, many were willing to participate in this study because they thought that this was one way to do so.

It was through this increased awareness that many of the Lost Boys who had been interviewed had hoped to begin to "build a relationship between Sudan and America." Their attitude was, "with help, we can do it." And what they wanted to do more than anything else was "to make peace." As Participant $\# 2$ stated: "We want there to be peace in all of the country and all of the people called Sudanese. We need to help the country as a nation, for the whole people from Sudan." For most of the young men it was their responsibility to provide for or support 
"other members of the group" as well as "parents and other relatives left in the Sudan." Others mentioned helping those who were left behind to "endure life." As Participant \#3 stated: "Yah, when I think of my parents, is that ... just give me a kind of solution sometime ... to provide back, to provide back to your parents, to your country."

For many though, the fact of their survival was guilt-inducing. Many asked, "Why did I survive?" Many felt guilty because others had died and so many more were living in "very, very difficult circumstances" in Sudan and Kenya. They wanted more than anything to do something to assuage their guilt.

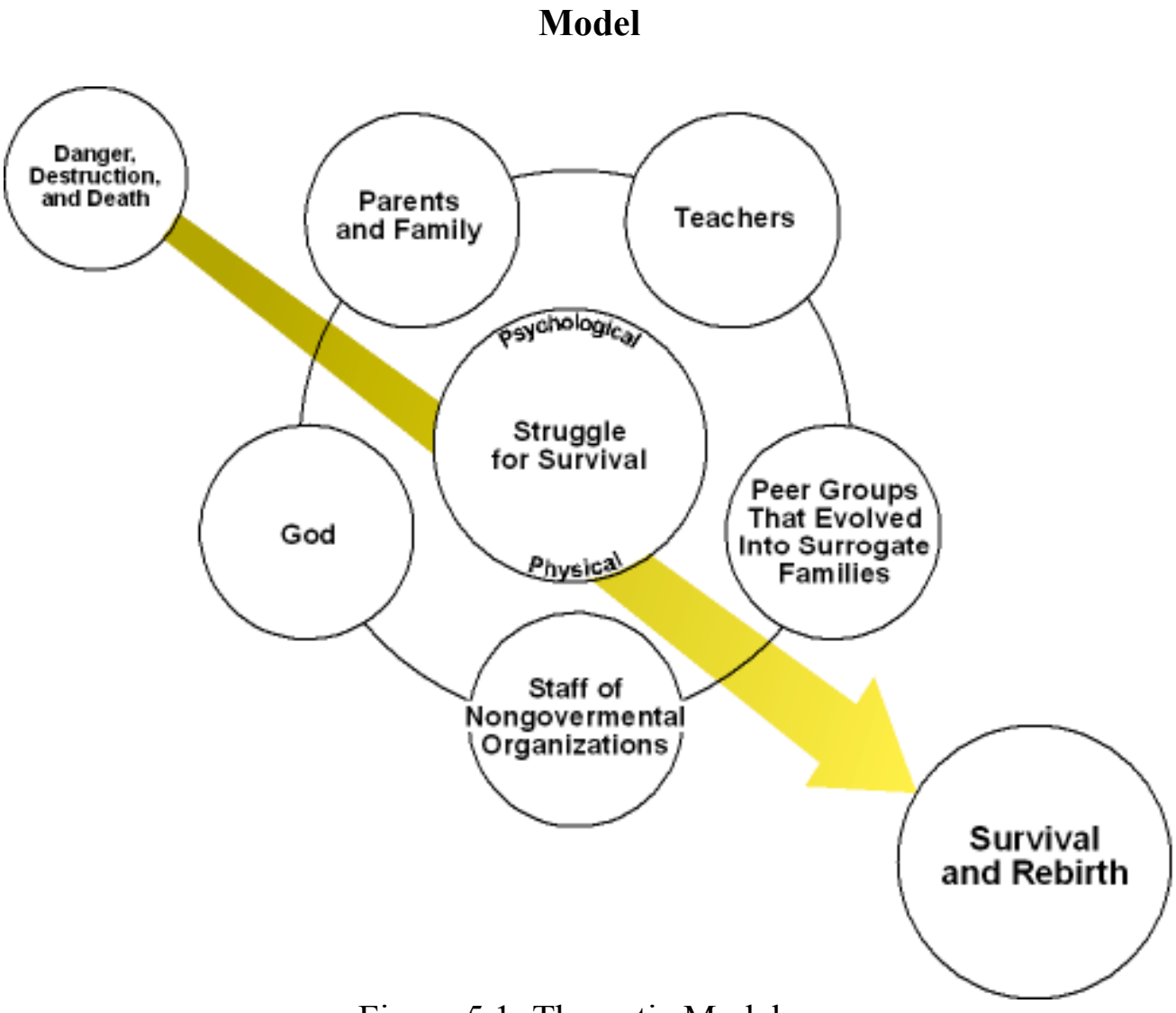

Figure 5.1: Thematic Model

I developed a model that incorporated the four themes that emerged from the data.

The model depicts how the themes of Danger, Destruction, and Death; Struggle for Survival; Assistance Provided by Others; and Survival and Rebirth fit together. See Figure 5.1. The 
experiences of the Lost Boys during the Sudanese civil wars may be seen as a passage starting with their initial exposure to danger, destruction, and death and ending with their present state of survival and rebirth. In between these two periods were years of struggling for survival, during which there were a number of protective factors. These factors - parents and family, teachers, peers groups that evolved into surrogate families, the staff of nongovernmental organizations, and God - moved the Lost Boys toward survival and eventually rebirth.

\section{Conclusion Drawing and Verification}

The third stream of analysis activity is conclusion drawing and verification.

\section{Methods of Verification}

Quantitative research has prescriptions for validity, reliability, generalization, and objectivity. Many qualitative researchers have argued that these prescriptions are not applicable to qualitative research but at the same time acknowledge the need for standards for judging their research. As a result, qualitative researchers have generated or adopted what they consider to be more appropriate terms. Lincoln and Guba (1985) prefer to emphasize what they call the truthfulness or authenticity of the data. They propose prescriptions of internal validity, or "truthvalue," consistency, authenticity, and neutrality. Within each of these, however, are strategies for demonstrating rigor during the research process as well as afterwards (Morse, Barrett, Mayan, Olson, \& Spiers, 2002).

Internal validity is similar in quantitative research to internal validity and emphasizes credibility. Credibility means that there is some believability to the data obtained with regard to the results. The researcher, during the research process, can use various strategies to enhance internal validity. Merriam (2001) recommends strategies such as acknowledging researcher biases (also referred to as bracketing), triangulation, prolonged engagement and persistent 
observation, and peer examination. Key (2006) adds referential adequacy as a strategy. For this study, I used all of these strategies.

Bracketing is relevant in that it entails clarifying the researcher's personal assumptions, worldview, and theoretical orientation at the onset of the study (Merriam, 2001). The genesis of my personal interest in the topic of study, my assumptions, and theoretical orientation are detailed in Chapter One, supplemented by professional information in Chapter Three.

Triangulation is the use of several methods, data sources, or researchers to support a finding by showing that independent measures of it agree with it or at least, do not contradict it. I used triangulation based on method as well as data source.

Referential adequacy is the use of instruments such as tape recorders and audiotapes to mechanically record data to use later for literal statements or verbatim accounts. I used tape recorders and audiotapes to record the data. The tapes were later transcribed word for word. Thus, I was able to extensively use participants' statements which I did throughout Chapters Four and Five.

Prolonged engagement is investing sufficient time in the field to build trust with the participants and learn about their experiences. And persistent observation is identifying characteristics and elements that are relevant to the research. I spent considerable time over a two week period engaging the participants and interviewing, obtaining physical artifacts, and observing the participants in the study. Also, I have articulated which elements I thought were important and my decisions to observe them.

I frequently sought feedback from peers in the doctoral program in Human Ecology, peers in other doctoral programs who were particularly knowledgeable and skilled in qualitative research, as well as professional colleagues working in the field of refugee resettlement. This is 
referred to as peer examination. I frequently requested feedback from them regarding qualitative research and procedures. I consulted them regarding the themes that emerged and tentative conclusions, asking for their feedback to ensure that alternative explanations were not overlooked or excluded by me due to my bias.

Authenticity is similar to generalizability and emphasizes transferability. Transferability refers to the ability to transfer knowledge obtained from the study and apply it to similar settings. From a qualitative perspective transferability is primarily the responsibility of the one doing the generalizing. Thus, the person who wishes to "transfer" the results to a different context is responsible for making the judgment of how sensible the transfer is. But, the qualitative researcher can use strategies to enhance transferability thus to enable others to transfer the results. Key (2006) recommends the following components:

(i) thoroughly describing the research context;

(ii) elucidating the assumptions that were central to the research;

(iii) illuminating the researcher's role and relationship with the participants;

(iv) adequately defining informant selection - such as the criteria, rationale, and decision process in the purposeful sampling;

(v) chronicling the social context - the physical, social, interpersonal, and functional social scenes of data collection;

(vi) describing the data collection process and strategies;

(vii) utilizing literal statements or verbatim accounts;

(viii) presenting the typicality (i.e., the distinct characteristics of the group);

(ix) articulating the analytic premises (i.e., the initial theoretical framework or concept that informs the study); and 
(x) retrospectively considering rival explanations for interpretations.

All of these strategies were used in the study.

Consistency is similar to reliability and emphasizes dependability, which refers to the importance of the researcher keeping records of the research and the ability of another to conduct similar research with a similar group of people and obtain similar data and results. Strategies that I used to enhance consistency are the investigator's position (which is similar to bracketing), triangulation, and audit trail (Merriam, 2001). Key (2006) also recommends the use of field logs or journals and peer examination.

The use of a field $\log$ is to maintain a $\log$ of dates, times, places, persons, and activities to obtain access to informants and for each data set collected. A field journal records the decisions made during the emerging design and the rationale, including judgments of data validity. I did not keep official field logs or journals but kept field notes of everything I did.

An audit trail occurs when the researcher describes in detail how the data were collected, how categories were derived, and how decisions were made throughout the study. A line of evidence should be traceable from initial research questions to ultimate case study conclusions. I have described this in detail in this chapter and Chapter Six.

Finally, neutrality is similar to objectivity and emphasizes confirmability. The basic issue here can be framed as one of relative neutrality and reasonable freedom from unacknowledged researcher biases - at the minimum, explicitness about the inevitable biases that exist. In short, do the conclusions depend on "the subjects and conditions of the inquiry rather than the inquirer" (Miles \& Huberman, 1994). There are a number of strategies for enhancing confirmability. The researcher can document the procedures for checking and rechecking the data throughout the study. One can have another researcher can take a "devil's advocate" role with respect to the 
results, and this process can be documented. And, after the study, the researcher can conduct a data audit that examines the data collection and analysis procedures and thereby judge the potential for bias or distortion. I have attempted to document these activities in this chapter.

\section{Research Questions and Answers}

The study's research questions and the answers to them are as follows:

\#1 What is the role of familial protective factors and processes in moderating the relationship between risk and resilience in Sudanese refugee youth exposed to political violence?

Rutter (1987) defines protective factors as influences that modify, ameliorate or alter a person's response to some environmental hazard that predisposes to a negative outcome. Familial protective factors include: (1) attachment to at least one adult in early childhood; (2) constant and consistent nurturing by the primary caretaker during the first year of life with little separation; (3) presence of the father; (4) non-conflicted relationships in the family; (5) the presence of other adult caretakers; (6) four or fewer children in the family spaced no more than two years apart; (7) sibling caretakers or young companions with whom the child can confide; (8) appropriate parental management such as providing structure, rules, and assigning responsibilities; and (9) a network of kin who share similar values and beliefs and to whom the child can turn for advice and support.

Familial protective factors appear to play a role in moderating the relationship between risk and resilience in Sudanese refugee youth exposed to political violence. However, not all familial protective factors play a role nor those that do play a role do so equally. It appears as if some factors are more important than others as indicated by their frequency of being mentioned by the participants. Those that were frequently mentioned include the presence of the father; appropriate parental management such as providing structure, rules, and assigning 
responsibilities; and a network of kin who share similar values and beliefs and to whom the child can turn for advice and support. Also, familial protective factors do not play a sole or primary role in moderating the relationship between risk and resilience.

\#2 Do these protective factors actually moderate the relationship between risk and resilience in the group in question?

Yes, it appears as if familial protective factors do moderate the relationship between risk and resilience although not in a manner or degree that was expected.

\#3 If they do, then how do familial protective factors moderate the relationship between risk and resilience?

Unfortunately a paucity of data was obtained from the interview question related to this research question. Nonetheless, it appears as if familial protective factors do moderate the relationship between risk and resilience. However, not all familial protective factors play a role nor do those that do play a role do so equally.

It seems as if some are more important than others. For example, the presence of the father; appropriate parental management such as providing structure, rules, and assigning responsibilities; and a network of kin who share similar values and beliefs and to whom the child can turn for advice and support seemed more important than others because they were mentioned frequently by the participants. In addition, familial protective factors did not play a sole or primary role in moderating the relationship between risk and resilience.

\#4 How are familial protective factors organized in order to initiate the processes that moderate the relationship between risk and resilience?

Again, a paucity of data was obtained from the related interview question. Thus, it is unclear how familial protective factors actually moderate the relationship. 
\#5 If familial protective factors do not moderate the relationship, then what factors do?

It is not that familial protective factors do not moderate the relationship but that they do not seem to be the sole or primary protective factors that do so. The study indicates that social protective factors are the primary factors or, at least in addition to, familial protective factors in moderating the relationship between risk and resilience. A social protective factor frequently by the participants was the peer group.

\#6 Does the separation of the youth from their family of origin affect the moderating relationship of the familial protective factors?

Yes, it appears as if the separation of the youth from their family of origin affects the moderating relationship of the familial protective factors. This is just supposition but it seems as if the moderating relationship of the familial protective factors diminished as the length of the separation of the participants from their family of origin increased. Yet, it is quite possible that given the developmental stages of the participants - adolescence and young adulthood that their families' influence would diminish anyway.

The following is a summary of the data collection and analysis procedures as discussed in this chapter. Eight "Lost Boys" participated in the study. Interviews, direct observations, and physical artifacts were the sources of data. Data consisted of the transcripts and field notes of my working processes and observations. The field notes also included the Contact Summary Form and, when a physical artifact was obtained from a participant, an Art Work Analysis Form. The data were cleaned, reduced, and then analyzed. In the course of the data analysis, themes began to emerge. The research questions were then reviewed and answered. 


\section{CHAPTER SIX: SUMMARY AND CONCLUSIONS}

\section{Introduction}

This chapter reviews the purpose of the study, the summaries of the procedures used and the themes, and the interpretation of the themes. The limitations of the study, implications and recommendations for policy, practice, and future research are provided and discussed.

The purpose of this qualitative study was to explore the role of familial protective factors in moderating the relationship between risk and resilience in Sudanese refugee youth exposed to political violence. The study resulted in rich, context-bound information that suggested patterns about the role of these factors in moderating the relationship between risk and resilience in Sudanese refugee youth.

Interviews, direct observations, and physical artifacts were the sources of data for the study. Eight Lost Boys participated in the study, providing narratives of their experiences of the Sudanese civil wars. They also answered questions posed about the role of familial protective factors in moderating the relationship between risk and resilience.

The interviews were recorded on audiotape and then transcribed. Data consisted of the transcripts and field notes of my working processes and observations. The field notes also included the Contact Summary Form and, when a physical artifact was obtained from a participant, an Art Work Analysis Form. The transcripts and field notes were later analyzed and coded. In the course of my analysis, themes began to emerge. The following is a summary of these themes and they are noted in order of prominence in the data.. 


\section{Themes}

\section{Theme \#1: Danger, Destruction, and Death}

Every participant discussed the danger they encountered, the destruction, and the deaths resulting from the conflicts. They chronicled this theme through three time periods: (1) the initial raid or bombardment of their village, which resulted in separation from their family, flight, and eventual arrival in Ethiopia; (2) their departure from Ethiopia and brief return to Sudan, followed by the journey to and arrival in Kenya; and (3) their life in the Kakuma Refugee Camp in Kenya.

\section{Theme \#2: Struggle for Survival}

As with the previous theme of "Danger, Destruction, and Death," every participant spoke of the struggle for survival. Each spoke of different aspects - physical as well as psychological of their struggle for survival. It seemed as if attention to both was necessary for their survival. Not only did one need to physically undertake certain activities to survive, one also needed the psychological determination - or will - to survive.

\section{Theme \#3: Assistance Provided by Others}

All of the participants spoke of other people or entities that assisted them in their struggle for survival. These included their family and parents, teachers, peer groups that evolved into surrogate families, staff of nongovernmental organizations, and God.

\section{Theme \#4: Survival and Rebirth}

Despite years of horrific experiences and struggling to survive, the participants described an incredible hope or optimism for the future. After so many bleak years they were still convinced their "future will be brighter." They saw their opportunities as limitless and they had many dreams. They regarded the United States as the ideal place to pursue those dreams. 


\section{Interpretation of Themes}

The results of the study indicate that familial protective factors play a role in moderating the relationship between risk and resilience in Sudanese refugee youth exposed to political violence. However, not all familial protective factors play a role nor those that do play a role do so equally. Some factors are more important than others as indicated by their frequency of being mentioned by the participants. Those that were frequently mentioned include the presence of the father; appropriate parental management such as providing structure, rules, and assigning responsibilities; and a network of kin who share similar values and beliefs and to whom the child can turn for advice and support seemed more important than others.

Familial protective factors do not play a sole or primary role in moderating the relationship between risk and resilience. It appeared that initially familial protective factors were the sole protective mechanism. However, once the youth were separated from their families of origin, and given their extreme circumstances and need for protection and support, they quickly sought and developed other sources of support. A social protective factor frequently mentioned was the peer group. Again, given the presence of their peers and little else as potential sources, it seems natural that the peer group evolved as a surrogate family over a period of time. Eventually the boys came to rely on their peers/surrogate families as their primary source of support.

I think one of the reasons why the surrogate families became so important to these boys and their survival was what they had not done; that is, they had not compromised their role as a protector. Their parents, if some of the journalistic reports from diplomats and relief workers are true, were either duped into sending their children to Ethiopia, or thought the opportunities were too promising and so sent their children away. Or, perhaps out of naiveté, the parents were simply unaware of the danger, and wanting the best for their children - the opportunity for an 
education - sent their children away. Regardless, their parents were not there when the participants needed to be protected. I wonder if the young men thought about this?

And, what of those "teachers"? According to many of the boys, these "teachers" led them from their villages. Why? Why would they be interested in young boys? Why would they trek children across the bush and desert? Why would they put these boys in harms way, risk their lives, that ultimately killed thousands? What was their motivation? Were they SPLA "comrades" as some of the boys admitted? Were they recruiting child soldiers and thus fodder for their armed conflict with the Sudanese government? They certainly did not protect these boys. I wonder if the young men thought about this?

And even God. Might these boys have wondered, "Why is God doing this to us? Why has God allowed this?"

\section{Ecological Framework}

The theoretical framework in which this study was grounded is the Ecological framework, specifically Bronfenbrenner (1979) and Garbarino's (1992) ecological model. Bronfenbrenner and Garbarino divide the environment into different levels (Figure 1.10). Two of the levels are the microsystem and the mesosystem. The microsystem includes the individual and all persons and groups that incorporate the individual's day-to-day environment. This would also include the individual's intellectual capacities and emotional development, level of functioning, impact of life experiences, and connections and interactions between the individual and others in the environment (Zastrow \& Kirst-Ashman, 1997). The mesosystem involves the relationship between two microsystems that are linked by some individual who exists in both microsystems. The interactions in one microsystem influence the interactions of another (Zastrow \& KirstAshman, 1997). 
The results of this study point to the importance of the microsystem but even more so the mesosystem, i.e., the relationships, or specifically the transactions, between two microsystems: the individual youth and his family of origin and the peer groups that eventually evolved into surrogate families - as the moderating medium for the protective factors.

The results of this study are consistent with the literature on the role of social protective factors and surrogate families in moderating the effects of risk. This will be discussed in the next section.

\section{Review of the Literature}

\section{$\underline{\text { Social Protective Factors }}$}

Since the early work in Britain during World War II, it has been accepted that the effects of political violence on children can be moderated by social support, with the extended family, the child's peers, and the wider community all being seen as potential sources of support. The results of this study are consistent with the literature on social protective factors. Werner \& Smith's (1981) classic study of children with "odds against them" from the Hawaiian island of Kauai stressed the importance of supportive people in the lives of the children. These people included individual teachers, school counselors, supervisors of after-school programs, coaches, mental health workers, workers in community centers, clergy, and close neighbors. It was noted that these supportive people provided esteem support or indications that one was a person of value. In addition, they offered informational support or helpful problem-solving advice as well as instrumental support in the form of specific resources or services that assist in their problemsolving. Many other studies noted that companionship support was particularly beneficial. Such support included opportunities to connect and engage in activities with others that were socially rewarding and fostered social values. 
In contrast to the numerous studies on social protective factors, fewer studies have been conducted on the role of surrogate families. The results of this study are consistent with the smaller number of studies on groups of people in extreme circumstances and the role of surrogate families. This will be discussed in the next section.

\section{$\underline{\text { Surrogate Families }}$}

In one of these studies, Tec (2003) discussed in the book, Resilience and Courage: Men, Women, and the Holocaust - in the concentration camps, both genders created surrogate families for mutual assistance and emotional support. Tec saw this effort as exemplifying the universal need among people in extreme situations for cooperation and mutual care. In Cohen's (2006) article, "The Experiences of the Jewish Family in the Nazi Ghetto: Kovno - A Case Study," she discussed the gradual disintegration of the family unit through the separation, deportation, and death of its members. Yet in spite of the physical assault on the family life in the ghetto, the inhabitants still maintained an "emotional" family life and created a surrogate family (Cohen, 2006). Often the surrogate family reversed the Nazi's policies of degradation and dehumanization of the inhabitants. For many, belonging to a group was an emotional as well as physical requirement for survival (Cohen, 2006).

Similarly, in a study of Moscow's homeless children, Stephenson (2001) countered pathological descriptions of homeless children with the claim that the children were traveling on a path from alienation to affiliation. Evidence was provided to support this claim with descriptions of the children's resourceful efforts to create surrogate families that enabled them to meet their immediate needs and long-term plans (Stephenson, 2001).

Stephenson's study showed that the children and youths initially created these families

for a number of reasons and, once created, others were attracted to these families. At the outset, 
the members of a family provided protection and temporary shelter. Later, the youths hoped that a family could assist them with their individual long-term plans. Stephenson described these families as complex social structures of extensive networks with a system of mutual obligations and trust. Mutual support was sustained by a set of quasi-familial relationships. The children and youths took on the roles of husbands, wives, fathers, mothers, brothers, and sisters. These "relatives" were engaged in a stable exchange of money and food and provided emotional support to each other. In addition, there was a taboo against involvement in illegal activity such as stealing, which was thought to bring shame on the family.

\section{Limitations}

There were two forseen limitations of the study. One was due to the qualitative nature of the study and its lack of generalizability. The other weakness was related to the type of participant. During the implementation of the study an issue arose that could also be considered a limitation.

Typical of qualitative inquiry - as well as due to the number of participants - this study, as designed, makes no claims regarding generalizability to other refugee groups or children exposed to political violence or war. In addition, the uniqueness of the study in its specific context makes it unlikely that it could be replicated exactly in another context. Those who participated in the study were those who were willing to participate. Thus, the participants were limited to those motivated and willing to participate and who were verbal and insightful enough to be able to answer the questions posed. This may have restricted in some unforeseen manner the data obtained.

In consideration of internal validity and consistency, I attempted to triangulate data sources, using several, different sources - interviews, direct observations, and physical artifacts - 
in the study. However, only two of these sources were fruitful: the interviews and direct observations. Only two participants created physical artifacts. Thus, this may limit claims of the internal validity or consistency of the study.

\section{Implications and Recommendations}

\section{Policy}

\#1 Flexible Domestic Refugee Resettlement Policy to Address the Needs of Refugees

To prevent dependence on governmental social programs, the Office of Refugee Resettlement - through the VOLAGs that administer the domestic refugee resettlement programs - provides incentives to refugees for their gainful employment within a certain period of time. This aspect of domestic refugee resettlement programs has been very successful as there are very low rates of dependence on social programs. Perhaps the programs could be made more flexible; e.g., with young adult refugees, enrollment in some sort of accredited educational program could be substituted for employment. This flexibility would indicate that the priority of the Office of Refugee Resettlement and resettlement agencies is to address and meet the needs of refugees.

\#2 Provide Individual Assessment, Basic Skills Remediation, and Tutoring as Soon as Possible

Most of the Lost Boys described their education as rudimentary at best. Yet, for them, the desire to further it is great. But, they are lacking in many basic skills. In order to assist them in this goal, individual educational assessment should be provided as soon as possible. Then, based on the results of the assessment, basic skills remediation and tutoring should be provided. 


\section{Practice}

\#1 Provide Mental Health Assessments and Intervention as Soon as Possible

In all of the interviews and in all of the literature that I have read regarding the experiences of the Lost Boys, there was never any mention of the availability of mental health services. The participants had numerous traumatic experiences and could benefit from mental health services. By any standard of care the Lost Boys should have been provided with mental health assessments and intervention. So, I recommend that mental health assessments and services be made available as soon as possible.

\#2 Facilitate the Development of Caring Relationships, Particularly with Potential Surrogate Families

The participants acknowledged that the peer groups that evolved into surrogate families were significant sources of support. Thus, I recommend that the staff of NGOs, VOLAGs, social service providers, and volunteers encourage and facilitate the development of caring relationships, particularly involving potential surrogate families. \#3 Create Opportunities for Meaningful Participation and Contribution

The participants admitted to suffering from a considerable amount of survivor guilt and a sense of responsibility to those left behind in the Sudan, their family, and other refugees. One way to assuage their guilt and help them feel responsible would be for the staff of refugee resettlement agencies to create opportunities for meaningful participation and contribution. For example, creating opportunities where refugees could serve as mentors or case managers for newly arrived refugees would be particularly helpful. 


\section{Future Research}

\section{\#1 Consider the Cultural Appropriateness of Data Sources}

As noted above, only two participants created physical artifacts. I've considered several possible explanations for this. One is that the participants may have attributed an ability to draw as evidence of an education or training. They were very self-conscious about their lack of education and may have declined to draw because they believed they lacked this training and ability. But, I think a more likely explanation is that I may have been mistaken in thinking that the participants needed this tool to facilitate communication. Despite some difficulties with grammar, they all communicated quite well. This is understandable as the Dinka have a strong oral tradition. Thus, I recommend that data sources be selected that are culturally appropriate. For example, the use of focus groups may have been more appropriate given their oral tradition. Another explanation is that the participants were anxious to initiate the interviews and tell of their experiences in the Sudanese civil wars. Most seemed to not want to be distracted by this exercise which leads to the next recommendation.

\section{\#2 Provide an Opportunity to Express Traumatic Events Prior to Initiating the Interviews}

The participants' experiences of the Sudanese civil wars were traumatic and life changing. It appears as if the participants never had the opportunity to individually or collectively discuss their experiences and process them. The interview presented an opportunity to do so. A considerable amount of time was devoted to the participant's need to discuss their experiences. However, I needed to conduct the interview. But, I could not deny them this opportunity. Thus, I recommend that opportunities to express traumatic events be provided to participants prior to initiating interviews. This would necessitate multiple meetings with the participants. Later meetings could then be devoted to the actual interview questions. 
\#3 Continue to Conduct Research on Resilience and the Role of Protective Factors with $\underline{\text { Refugees }}$

Unfortunately wars and refugees will probably always exist. So, it is imperative that research be conducted and continue to be conducted on this neglected area of study. In addition, this study is just one of a few on the role of protective factors and resilience with refugees. More studies should focus on this area.

\#2 Conduct Research that Focuses on the Specific Social Protective Factor of Surrogate Families

Given the tentative conclusions reached in this study regarding the role of familial protective factors and resilience I encourage other researchers to replicate this study or design others with this focus. For example, the groups on which to focus this research could expand to include child soldiers, children reared in orphanages or foster homes, and AIDS orphans.

\#3: Specifically Investigate the Mechanisms Involved in the Protective Process

Researchers still do not know the mechanisms involved in protective factors and processes. To acquire this knowledge, considerably more studies must be done. \#4: Consider Replicating this Research Study with Children Affected by Hurricane $\underline{\text { Katrina }}$

As I near completion of this dissertation I have returned several times to my former home of New Orleans which, almost two years after Hurricane Katrina, remains devastated. And what of its people - former and current inhabitants - particularly children? There are indications that many, like the city, remain devastated. But most are attempting to rebuild their lives. And their future? Unfortunately we really do not know the answers to either of these questions. This is because natural disasters, such as a hurricane, are similar to man-made disasters, such as political violence and civil wars, in 
that few studies are done in this area. And, even fewer studies have been conducted on the effects of natural disasters on families and children. I recommend that studies be done in this area and with this population. I also recommend that this study be replicated with children affected by Hurricane Katrina.

The results of the study, as discussed in this chapter, indicate that familial protective factors appear to play a role in moderating the relationship between risk and resilience in Sudanese refugee youth exposed to political violence. However, not all familial protective factors play a role nor those that do play a role do so equally. Also, familial protective factors do not play a sole or primary role in moderating the relationship between risk and resilience. It appears initially that familial protective factors were the sole protective mechanism. However, once the youth were separated from their families of origin and, given their extreme circumstances and need for protection and support, they quickly sought and developed other sources of support. Again, given the presence of their peers and little else as potential sources of support it seems natural that the peer group evolved as a surrogate family over a period of time. Eventually, the participants come to rely on their peers/surrogate family as their primary source of support. Finally, implications and recommendations for policy, practice, and future research were noted. 


\section{REFERENCES}

Adler, P. A., \& Adler, P. (1994). Observational techniques. In N. K. Denzin \& Y. S. Lincoln (Eds.), Handbook of qualitative research (pp. 377-392). Thousand Oaks, CA: Sage.

Ahearn, F., \& Loughry. M., \& Ager, A. (1999). The experience of refugee children. In A. Ager (Ed.), Refugees: Perspectives on the experience of forced migration (pp. 215-236). New York: Pinter.

Allodi, F. (1980). The psychiatric effects of political persecution and torture in children and families of victims. Canada's Mental Health, 28, 3-10.

Allwood, M. A., Bell-Dolan, D., \& Husain, S. A. (2002). Children's trauma and adjustment reactions to violent and nonviolent war experiences. Journal of the American Academy of Child and Adolescent Psychiatry, 41, 450-457.

Amnesty International (2002, February 22). Sudan: Bombings of civilians are unacceptable. Retrieved June 11, 2003, from http://web.amnesty.org/library/Index/ENGAFR540062002?open\&of=ENG-SUD

Anthony, E. J. (1987). Risk, vulnerability, and resilience: An overview. In E. J. Anthony \& B. J. Cohler (Eds.), The invulnerable child (pp. 3-48). New York: The Guilford Press.

Arroyo, W. \& Eth, S. (1985). Children traumatized by Central American warfare. In S. Eth \& R. S. Pynoos (Eds.), Post-traumatic stress disorder in children (pp. 183-195). Washington D.C.: American Psychiatric Press.

Athey, J. L., \& Ahearn, F. L., Jr. (1991). The mental health of refugee children: An overview. In F. L. Ahearn, Jr. \& J. L. Athey (Eds.), Refugee children: Theory, research, and services (pp. 3-19). Baltimore: The Johns Hopkins University Press.

Barker, R. L. (Ed.). (2003). The social work dictionary (5 ${ }^{\text {th }}$ ed.). Washington D. C.: NASW Press.

BBC News. (2005, August 5). Sudan bidsrebel leader farewell. Retreived November 15, 2005 , from http://news.bbc.co.uk/2/hi/africa/4126370.stm

Beardslee, W. R. (1989). Resilient adolescents whose parents have serious affective and other psychiatric disorders: Importance of self-understanding and relationships. American Journal of Orthopsychiatry, 59, 266-278.

Bixler, M. (2005). The lost boys of Sudan: An American story of the refugee experience. Athens: The University of Georgia Press.

Bliesener, T., \& Losel, F. (1992). Resilience in juveniles with high risk of delinquency. Psychology and the Law: International Perspectives, 62-75. 
Bodman, F. M. (1944). Child psychiatry in war-time Britain. Journal of Educational Psychology, $35,293-301$.

Boothby, N. (1992). Displaced children: Psychological theory and practice from the field. Journal of Refugee Studies, 5, 106-122.

Bromley, D. B. (1986). The case-study method in psychology and related disciplines. New York: Wiley.

Bronfenbrenner, U. (1979). The ecology of human development. Cambridge, MA: Harvard University Press.

Bubolz, M. M., \& Sontag, M. S. (1993). Human ecology theory. In P. G. Boss, W. J. Doherty, R. LaRossa, W. R. Schumm, \& S. K. Steinmetz (Eds.), Sourcebook of family theory and methods: A contextual approach (pp. 325-352). New York: Plenum Press.

Burgess, A., \& Holmstrom, L. (1979). Rape: Crisis and recovery. Bowie, MD: Robert J. Brady Company.

Cairns, E. (1996). Children and political violence. Cambridge, MA: Blackwell Publishers.

Central Intelligence Agency. (2005). The world factbook. Retrieved August 17, 2005, from http://www.cia.gov/cia/publications/factbook/geos/su.html

Charron, D. W., \& Ness, R. C. (1981). Emotional stress among Vietnamese adolescents: A statewide survey. Journal of Refugee Resettlement, 1, 7-15.

Chein, I. (1981). Appendix: An introduction to sampling. In L. H. Kidder (Ed.), Selltiz, Wrightsman \& Cook's research methods in social relations $\left(4^{\text {th }}\right.$ ed.). Austin, TX: Holt, Rinehart and Winston.

Cicchetti, D, \& Rogosch, F. A. (1997). The role of self-organization in the promotion of resilience in maltreated children. Development and Psychopathology, 9, 797-815.

Church World Service (n.d.) Southern Sudan: Humanitarian situation and CWS response. Retrieved August 19, 2005 from http://www.churchworldservice.org/news/Sudan/southernresponse.htm

Cohen, S. K. (2006). The experience of the Jewish family in the Nazi ghetto: Kovno - A case study. Journal of Family History, 31, 267-288.

Coleman, M., \& Ganong, L. (2002). Resilience and families. Family Relations: Interdisciplinary Journal of Applied Family Studies, 51, 101-102. 
Committee on Conscience. (n.d.). Sudan: South/Nuba mtns overview. Retrieved March 15, 2005, from http://www.ushmm.org/conscience/alert/sudan/contents/01-overview/

Conrad, M., \& Hammen, C. (1993). Protective and resource factors in high and low risk children: A comparison of children with unipolar, bipolar, medically ill, and normal mothers. Development \& Psychopathology, 5, 593-607.

Cowen, E. L., Kerley, J. H., Work, W. C., \& Wyman, P. A. (1993). The role of children's future expectations in self-system functioning and adjustment to life stress: A prospective study of urban at-risk children. Development \& Psychopathology, 5, 649-661.

Cowen, E. L., \& Work, W. C. (1988). Resilient children, psychological wellness, and primary prevention. American Journal of Community Psychology, 16, 591-607.

Cowen, E. L., Wyman, P. A., \& Work, W. C. (1988). Resilience in highly stressed urban children: Concepts and findings. Bulletin of the New York Academy of Medicine, 73, 267-284.

Crawley, M. (2000, November 7). "Lost Boys" of Sudan find new life in America. The Christian Science Monitor, pp. 1, 10.

Creswell, J. W. (1994). Research design: Qualitative \& quantitative approaches. Thousands Oaks, CA: Sage.

Deng, F. M. (1984). The Dinka of the Sudan. Prospect Heights, IL: Waveland Press.

Denzin, N. K. (1989). Interpretive Interactionism. Newbury Park, CA: Sage.

Denzin, N. K., \& Lincoln, Y.S. (Eds.). (2000). Handbook of qualitative research ( $2^{\text {nd }}$ ed.). Thousand Oaks, CA: Sage.

Eth, S., \& Pynoos, R. S. (1985). Interaction of trauma and grief in childhood. In S. Eth \& R. S. Pynoos (Eds.), Post-traumatic stress disorder in children (pp. 169-183). Washington D.C.: American Psychiatric Press.

Fast fact on Sudan. (2000). Retrieved April 12, 2002, from http://www.sudan.net

Fergusson, D. M., Horwood, L. J., \& Lynskey, M. T. (1996). Childhood sexual abuse and psychiatric disorder in young adulthood: I. Prevalence of sexual abuse and factors associated with sexual abuse. Journal of the American Academy of Child \& Adolescent Psychiatry, 35, 1355-1364.

Fraser, M. (1977). Children in conflict. New York: Basic Books.

Freitas, A. L., \& Downey, G. (1998). Resilience: A dynamic perspective. International Journal of Behavioral Development, 22, 263-285. 
Freud, A., \& Burlingham, D. T. (1943). War and children. New York: Ernest Willard.

Ganong, L., \& Coleman, M. (2002). Family resilience in multiple contexts. Journal of Marriage and the Family, 64, 346-348.

Garbarino, J. (1992). Children and families in the social environment ( $2^{\text {nd }}$ ed.). New York: Walter de Gruyter.

Garbarino, J., Kostelny, K., \& Dubrow, N. (1991). No place to be a child: Growing up in a war zone. Lexington, MA: Lexington Books.

Garmezy, N., \& Masten, A. S. (1991). The protective role of competence indicators in children at risk. In E. M. Cummings, A. L. Greene, \& K. Karraker (Eds.), Life-span developmental psychology: Perspectives on stress and coping (pp. 151-174). Hillsdale, NJ: Erlbaum.

Garmezy, N., \& Masten, A. S., \& Tellegen, A. (1984). The study of stress and copetence in children: A building block for developmental psychopathology. Child Development, 55, 97-111.

Garmezy, N., \& Rutter, M. (Eds.). (1983). Stress, coping, and development in children. New York: McGraw-Hill.

Garmezy, N., \& Rutter, M. (1985). Acute reactions to stress. In M. Rutter \& L. A. Hersov (Eds.), Child and adolescent psychiatry (pp. 152-176). Oxford, United Kingdom: Blackwell Scientific.

Geertz, C. (1973). The interpretation of cultures. New York: Basic Books.

Gold, P., Goodwin, F., \& Chrousos, G. (1988). Clinical and biochemical manifestations of depression. New England Journal of Medicine, 319, 413-420.

Goodman, J. H. (2004). Coping with trauma and hardship among unaccompanied refugee youths from Sudan. Qualitative Health Research, 14, 1177-1196.

Goodwin, J. (1988). Post-traumatic symptoms in abused children. Journal of Traumatic Stress, 1, 475-488.

Harrell-Bond, B. (2001, September 19). Are refugee camps good for children? Journal of Humanitarian Assistance. Retrieved September 26, 2003 from http:www.jha/ac/articles/u029.htm

Heller, S. S., Larrieu, J. A., D’Imperio, R., \& Boris, N. W. (1999). Research on resilience to child maltreatment. Child Abuse and Neglect, 23, 321-338.

Herman, J. (1992). Trauma and recovery. New York: Basic Books. 
Hill, R. (1949). Families under stress. Westport, CT: Greenwood Press.

Hodes, M. (2000). Psychologically distressed refugee children in the United Kingdom. Child Psychology and Psychiatry Review, 5, 57-68.

Human Rights Watch. (1995, September 1). Children in Sudan: Slaves, street children and child soldiers. Retreived June 11, 2003 from http://www.hrw.org/reports/1995/Sudan.htm

Jablensky, A., Marsella, A., Ekblad, S., Jansoon, B., Levi, L., \& Bornemann, T. (1994). Refugee mental health and well-being: Conclusions and recommendations. In A. Marsell, T. Borneman, S. Ekblad, \& J. Orley (Eds.), Admidst pain and peril: The mental health and well-being of the world's refugees (pp. 327-339). Washington D.C.: American Psychological Association.

Jensen, P., \& Shaw, J. (1993). Children as victims of war: Current knowledge and future research needs. Journal of the American Academy of Child and Adolescent Psychiatry, 32, 697-708.

Johnson, D. H. (2003). The root causes of Sudan's civil wars. Bloomington: Indiana University Press.

Key, J. P. (1997). Research design in occupational education. Module R14: Qualitative research. Retreived October 10, 2006, from Oklahoma State University web site: http://www.okstate.edu/ag/aged5980/newpage21.htm

Kinzie, J. D., \& Sack, W. (1991). Severely traumatized Cambodian children: Research findings and clinical implications. In F. L. Ahearn, Jr. \& J. L. Athey (Eds.), Refugee children: Theory, research, and services (pp. 92-105). Baltimore: The Johns Hopkins University Press.

Kinzie, J. D., Sack, W., Angell, R., Clarke, G., \& Ben, R. (1989) A three year follow-up of Cambodian young people traumatized as children. Journal of American Academy of Child and Adolescent Psychiatry, 28, 501-504.

Kinzie, J. D., Sack, W., Angell, R., Manson, S., \& Rath, B. (1986). The psychiatric effects of massive trauma on Cambodian children: I. The children. Journal of American Academy of Child and Adolescent Psychiatry, 25, 370-376.

Kuzel, A. J. (1992). Sampling in qualitative inquiry. In B. F. Crabtree \& W. L. Miller (Eds.), Doing qualitative research (pp. 31-44). Newbury Park, CA: Sage.

Kvale, S. (1996). InterViews: An introduction to qualitative research interviewing. Thousand Oaks, CA: Sage.

Lincoln Y., \& Guba, E. (1985). Naturalistic inquiry. Beverly Hills, CA: Sage. 
Lofland, J., \& Lofland, L. H. (1995). Analyzing social settings: A guide to observation and analysis $\left(3^{\text {rd }}\right.$ ed. $)$. Belmont, CA: Wadsworth.

Looney, J., Rahe, R., Harding, R., Ward, H., \& Liu, W. (1979). Consulting to children in crisis. Child Psychiatry and Human Development, 10, 5-14.

Lorch, D. (2001, March 19). Out of Africa. Newsweek, 32-35.

Lost Boys of Sudan (2001). Retrieved June 17, 2002, from http://www.sudanlostboys.com/articles/210811_nowhere\%20 to\%20run.htm

Lustig, S. L., Kia-Keating, M., Grant-Knight, W., Geltman, W. G., Ellis. H., Keane, T. et al. (2002). White paper: Child and adolescent refugee mental health. Boston, MA: National Child Traumatic Stress Network, Center for Medical and Refugee Trauma, Department of Child and Adolescent Psychiatry, Boston Medical Center.

Luthar, S. S., Cicchetti, D., \& Becker, B. (2000). The construct of resilience: A critical evaluation and guidelines for future work. Child Development, 71, 543-562.

Luthar, S. S., \& Zigler, E. (1991). Vulnerability and competence: A review of the research on resilience in childhood. American Journal of Orthopsychiatry, 61, 6-21.

Machel, G. (2001). The impact of war on children. London: C. Hurst \& Company.

Macksoud, M., Aber, J. L., \& Cohn, I. (1996). Assessing the impact of war on children. In R. J. Apfel \& B. Simon (Eds.), Minefields in their hearts: The mental health of children in war and communal violence (pp. 218-230). New Haven, CT: Yale University Press.

Malchiodi, C. A. (1998). Understanding children's drawings. New York: Guilford Press.

Marshall, C., \& Rossman, G.B. (1999). Designing qualitative research ( ${ }^{\text {rd }}$ ed.). Thousand Oaks, CA: Sage.

Masser, D. S. (1992). Psychosocial functioning of Central American refugee children. Child Welfare, 71, 439-456.

Masten, A. S., Best, K. M., \& Garmezy, N. (1990). Resilience and development: Contributions from the study of children who overcome adversity. Development and Psychopathology, $2,425-444$.

Masten, A. S. (2001). Ordinary magic: Resilience processes in development. American Psychologist, 56, 227-238.

Melville, M. B., \& Lykes, M. B. (1992). Guatemalan Indian children and the sociocultural effects of government sponsored terrorism. Social Science \& Medicine, 34, 533-548 
Merriam, S.B. (1988). Case study research in education: A qualitative approach. San Francisco: Jossey-Bass.

Merriam, S.B. (2001). Qualitative research and case study applications in education (Rev. ed). San Francisco: Jossey-Bass.

Miles, M. B., \& Huberman, A. M. (1994). Qualitative data analysis. Thousand Oaks, CA: Sage.

Miller, K.E. (1998). Research and intervention with internally displaced and refugee children. Peace and Conflict: Journal of Peace Psychology, 4, 365-379.

Mish, F. (Ed.). (2004). Merriam-Webster Dictionary. Springfield, MA: Merriam-Webster.

Morse, J. M. (1991). Strategies for sampling. In J. M. Morse (Ed.), Qualitative nursing research: A contemporary dialogue (pp. 127-145). Newbury Park, CA: Sage.

Morse, J. M., Barrett, M., Mayan, M., Olson, K., \& Spiers, J. (2002). Verification strategies for establishing reliability and validity in qualitative research [Electronic version]. International Journal of Qualitative Methods, 1, 1-19.

Office of the UN High Commissioner for Human Rights. (1989, November). Convention on the rights of the child. New York: Author.

Office of the United Nations High Commissioner for Refugees (1992, January). Handbook on procedures and criteria for determining refugee status. Geneva, Switzerland: Author.

Onyango, P. (1998). The impact of armed conflict on children. Child Abuse Review, 7, 219-229.

Parry, G. \& Shapiro, D. A. (1986). Social support and life events in working class women. Archives of General Psychiatry, 43, 315-323.

Pask, D. E., \& Jayne, A. (1984). Resettlement of minor refugees: Some interdisciplinary issues. Canadian Journal of Family Law, 3, 275-292.

Patton, M. Q. (1990). Qualitative evaluation and research methods ( $2^{\text {nd }}$ ed.). Newbury Park, CA: Sage.

Pedro-Carroll, J. L., Sutton, S. E., \& Wyman, P. A. (1999). A two-year follow-up evaluation of a preventive intervention for young children of divorce. School Psychology Review, 28, 467-476.

Petterson, D. (1999). Inside Sudan: Political Islam, conflict, and catastrophe. Boulder, CO: Westview Press. 
Preston. C. (2003). The Dinka of southern Sudan. Retrieved August 17, 2005, from Charles Stuart University, Society and Culture Association Web site: http://hsc.csu.edu.au/pta/scansw/index.html

Pynoos, R. (1992). Grief and trauma in children and adolescents. Bereavement Care, 11,2-10.

Pynoos, R. S., Frederick, C., Nader, K., Arroyo, W., Steinberg, A., \& Eth, S. (1987). Life threat and post-traumatic stress in school age children. Archives of General Psychiatry, 44, 1057-1063.

Radke-Yarrow, M., \& Brown, E. (1993). Resilience and vulnerability in children of multiple-risk families. Development \& Psychopathology, 5, 581-592.

Radke-Yarrow, M., Nottelmann, E., Martinez, P., Fox, M. B., \& Belmont, B. (1992). Young children of affectively ill parents: A longitudinal study of psychosocial development. Journal of the American Academy of Child and Adolescent Psychiatry, 31, 68-77.

Rahe, R. H., Looney, J. G., \& Ward, H. W. (1978). Psychiatric consultation in a refugee camp. American Journal of Psychiatry, 134, 407-411.

Raundalen, M., \& Melton, G. B. (1994). Children in war and its aftermath: Mental health issues in the development of international law. Behavioral Sciences and the Law, 12, 21-34.

Rayhida, J., Shaya, M., \& Armenian, H. (1986). Child health in a city at war. In J. Bryce \& H. Armenian (Eds.),Wartime: The state of children in Lebanon (pp. 87-99). Beirut: American University of Beirut.

Reeves, E. (2002, July 6). The terror in Sudan. The Washington Post, pp. A17.

Refugees International. (1998, September 9). Sudan: The lost boys. Retrieved August 24, 2005, from http://www.refugeesinternational.org/content/article/detail/752/

Ressler, E. M., Boothby, N., \& Steinbock, D. J. (1988). Unaccompanied children: Care and protection in wars, natural disasters, and refugee movements. New York: Oxford University Press.

Richman, N. (1993). Annotation: Children in situations of political violence. Journal of Child Psychology and Psychiatry, 34, 1286-1302.

Ronstrom. A. (1989) Children in Central America: Victims of war. Child Welfare, 68,145-153.

Rousseau, C. (1995). The mental health of refugee children. Transcultural Psychiatric Research Review, 32, 299-331.

Russell, D. (1975). The politics of rape: A victim's perspective. New York: Stein and Day. 
Rutter, M. (1983). Stress, coping, and development: Some issues and some questions. In N. Garmezy \& M. Rutter (Eds.), Stress, coping, and development in children (pp. 1-42). New York: McGraw-Hill.

Rutter, M. (1985). Resilience in the face of adversity: Protective factors and resistance to psychiatric disorders. British Journal of Psychiatry, 147, 598-611.

Rutter, M. (1987). Psychosocial resilience and protective mechanisms. American Journal of Orthopsychiatry 57, 316-331.

Sack, W. H., Angell, R. H., Kinzie, J. D., \& Rath, B. (1986). The psychiatric effects of massive trauma on Cambodian children: 2. The family, the home, and the school. American Academy of Child Psychiatry Journal, 25, 377-383.

Scroggins, D. (2002). Emma's war. New York: Pantheon Books.

Shirtliff, R. (2004, October/December). Darfur. Peace Magazine, October/December. Retrieved March 31, 2005, from http:/www.peacemagazine.org/archive/v20n4p24.htm

Sieber, J. E. (1992). Planning ethically responsible research: A guide for students and internal review boards (Applied Social Research Methods Series, Vol. 31). Newbury Park, CA: Sage.

Sourander, A. (1998). Behavior problems and traumatic events of unaccompanied refugee minors. Child Abuse and Neglect, 22, 719-727.

Stake, R. E. (1994). Case studies. In N. K. Denzin \& Y. S. Lincoln (Eds.), Handbook of qualitative research (pp. 236-247). Thousand Oaks, CA: Sage.

Stake, R. E. (1995). The art of case study research. Thousand Oaks, CA: Sage.

Stephenson, S. (2001). Street children in Moscow: Using and creating social capital. Sociological Review, 49, 530-547.

Strauss, A. L. (1987). Qualitative analysis for social scientists. Cambridge: Cambridge University.

Sudan. (n.d.). Retrieved August 17, 2005, from http://en.wikipedia.org/wiki/Sudan\#History

Sudan. (2003). Retrieved June 11, 2003, from http://www.africana.com

Sudan: A historical perspective. (n.d.). Retrieved April 12, 2002, from http://www.sudan.net 
Suplido, L. (1997, April 25). Preventing violence against children and war. Paper presented at the South-East Asia-Pacific Regional Conference of the International Physicians for the Prevention of Nuclear War. Retrieved February 17, 1999, from wysiwyg://122/http://www.geocities.com/HotSprings/7034/cw3.html

Tec, N. (2003). Resilience and courage: Women, men, and the Holocaust. New Haven: Yale University Press.

Thabet, A., \& Vostanis, P. (1999). Post-traumatic stress reactions in children at war. Journal of Child Psychology and Psychiatry, 40, 385-391.

Thomas, D. R. (2003). A general inductive approach for qualitative data analysis [Electronic version]. American Journal of Evaluation, 27, 237-248.

Toner, I. J. (1994). Children of "the Troubles" in Northern Ireland: Perspectives and interventions. International Journal of Behavioral Development, 17, 629-647.

United Nations High Commissioner for Refugees (n.d.). Protecting refugees. Retrieved August 24, 2005, from http://www.unhcr.ch/cgibin/texis/vtx/home?page=protect\&id=3b8373992

United Nations High Commissioner for Refugees. (2005, June 20). 2004 global refugee trends: Overview of refugee populations, new arrivals, durable solutions, asylum seekers and other persons of concern to UNHCR. Retrieved August 24, 2005, from http://www.unhcr.ch/cgibin/texis/vtx/statistics/opendoc.pdf?tbl=STATISTICS\&id=42b28 $\underline{3744}$

United Nations International Children's Fund. (1996). State of the world's children. New York: Oxford University Press.

United Nations International Children's Fund. (n.d.). The war on children. Retrieved February, 16, 1999, from http://www.unicef.org/pon95/chil0013.html

United Nations International Children's Fund (n.d.). Voices of youth - Children and war. Retrieved July 11, 2002, from http://www.unicef.org/voy/meeting/war/war-exp2.html

United Nations Office for the Coordination of Humanitarian Affairs (n.d.). Guiding principles in internal displacement. New York: Author.

United States Fund for UNICEF. (n.d.). Getting help to children in war. Retrieved March 8, 2001, from $\underline{h t t p: / / w w w . u n i c e f u s a . o r g / c o r r i d o r s / c i w . h t m l ~}$

U.S. Committee for Refugees and Immigrants. (2001, April/March) Sudanese "Lost Boys" resettle in the United States (Volume 22, Number 4) Washington D.C.: Author. 
War Child. (n.d.). Helping the innocent victims of war. Retrieved July 11, 2002, from http://www.warchild.org/aims.html

Werner, E. E. (1992). The children of Kauai: Resiliency and recovery in adolescence and adulthood. Journal of Adolescent Health, 13, 262-268.

Werner, E. E., \& Smith, R. S. (1981). Vulnerable but invincible: A longitudinal study of resilient children and youth. New York: McGraw-Hill.

Werner, E. E., \& Smith, R. S. (1988). Vulnerable but invincible: A longitudinal study of resilient children and youth. New York: Adams, Bannister, and Cox Publishers.

Westermeyer, J., \& Wahmanholm, K. (1996). Refugee children. In R. J. Apfel \& B. Simon (Eds.), Minefields in their hearts: The mental health of children in war and communal violence (pp. 75-103). New Haven, CT: Yale University Press.

Whitchurch, G. G., \& Constantine, L. L. (1993). Systems theory. In P. G. Boss, W. J. Doherty, R. LaRossa, W. R. Schumm, \& S. K. Steinmetz (Eds.), Sourcebook of family theory and methods: A contextual approach (pp. 325-352). New York: Plenum Press.

Yin, R. K. (1989). Case study research: Design and methods (Applied Social Research Methods Series, Vol. 5). (Rev. ed.). Thousand Oaks, CA: Sage.

Yin, R. K. (1993). Applications of case study research (Applied Social Research Methods Series, Vol. 34). Thousand Oaks, CA: Sage.

Zastrow, C., \& Kirst-Ashman, K. K. (1997). Understanding human behavior in the social environment $\left(4^{\text {th }}\right.$ ed.). Chicago: Nelson-Hall. 


\title{
APPENDIX A: LOUISIANA STATE UNIVERSITY, INSTITUTIONAL REVIEW BOARD, ACTION ON PROTOCOL APPROVAL REQUEST
}

\author{
Institutional Review Board \\ 203 B-1 David Boyd Hall \\ Louisiana State University and A\&M College \\ Baton Rouge LA 70803
}

(225) $578-8692$

FAX: 578-6792

irb @lsu.edu

\section{INSTITUTIONAL REVIEW BOARD}

\section{ACTION ON PROTOCOL APPROVAL REQUEST}

TO:

Pamela Monroe, Human Ecology

Michele Kelly, Human Ecology

FROM: $\quad$ Robert C. Mathews

Chair, Institutional Review Board for Research with Human Subjects

RE: $\quad$ IRB\# 2288

TITLE: "A Collective Case Study of Sudanese Refugee Youth"

New Protocol/Modification/Continuation : $\underline{\mathrm{N}}$

Review type: Full $\mathrm{X}$ Expedited ___ Review date: $\underline{\text { 01/04/2002 }}$

Approved X Disapproved

Approval Date: $\underline{01 / 28 / 2002}$ Approval Expiration Date: $\underline{01 / 28 / 2003}$

Risk Assessment: Minimal Uncertain

$\mathrm{X}$ Greater than Minimal

Re-review frequency: (annual unless otherwise stated)

Number of subjects approved:

By: Robert C. Mathews, Chairman

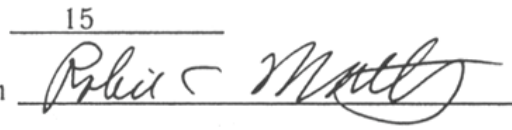

PRINCIPAL INVESTIGATOR: PLEASE READ THE FOLLOWING -- Continuing approval is CONDITIONAL on:

1. Adherence to the approved protocol, familiarity with, and adherence to the ethical standards of the Belmont Report, and LSU's Assurance of Compliance with DHHS regulations for the protection of human subjects*

2. Prior approval of a change in protocol, including revision of the consent documents or an increase in the number of subjects over that approved.

3. Obtaining renewed approval (or submittal of a termination report), prior to the approval expiration date, upon request by the IRB office (irrespective of when the project actually begins); notification of project termination.

4. Retention of documentation of informed consent and study records for at least 3 years after the study ends.

5. Continuing attention to the physical and psychological well-being and informed consent of the individual participants including notification of new information that might affect consent.

6. A prompt report to the IRB of any adverse event affecting a participant potentially arising from the study.

7. Notification of the IRB of a serious compliance failure.

8. SPECLAL NOTE:

*All investigators and support staff have access to copies of the Belmont Report, LSU's Assurance with DHHS, DHHS (45 CFR 46) and FDA regulations governing use of human subjects, and other relevant documents in print in this office or on our World Wide Web site at http:/Www.osr.Isu.edw/osr/comply.html 


\title{
APPENDIX B: LOUISIANA STATE UNIVERSITY, INSTITUTIONAL REVIEW BOARD APPLICATION
}

\author{
LSU INSTITUTIONAL REVIEW BOARD (IRB)
}

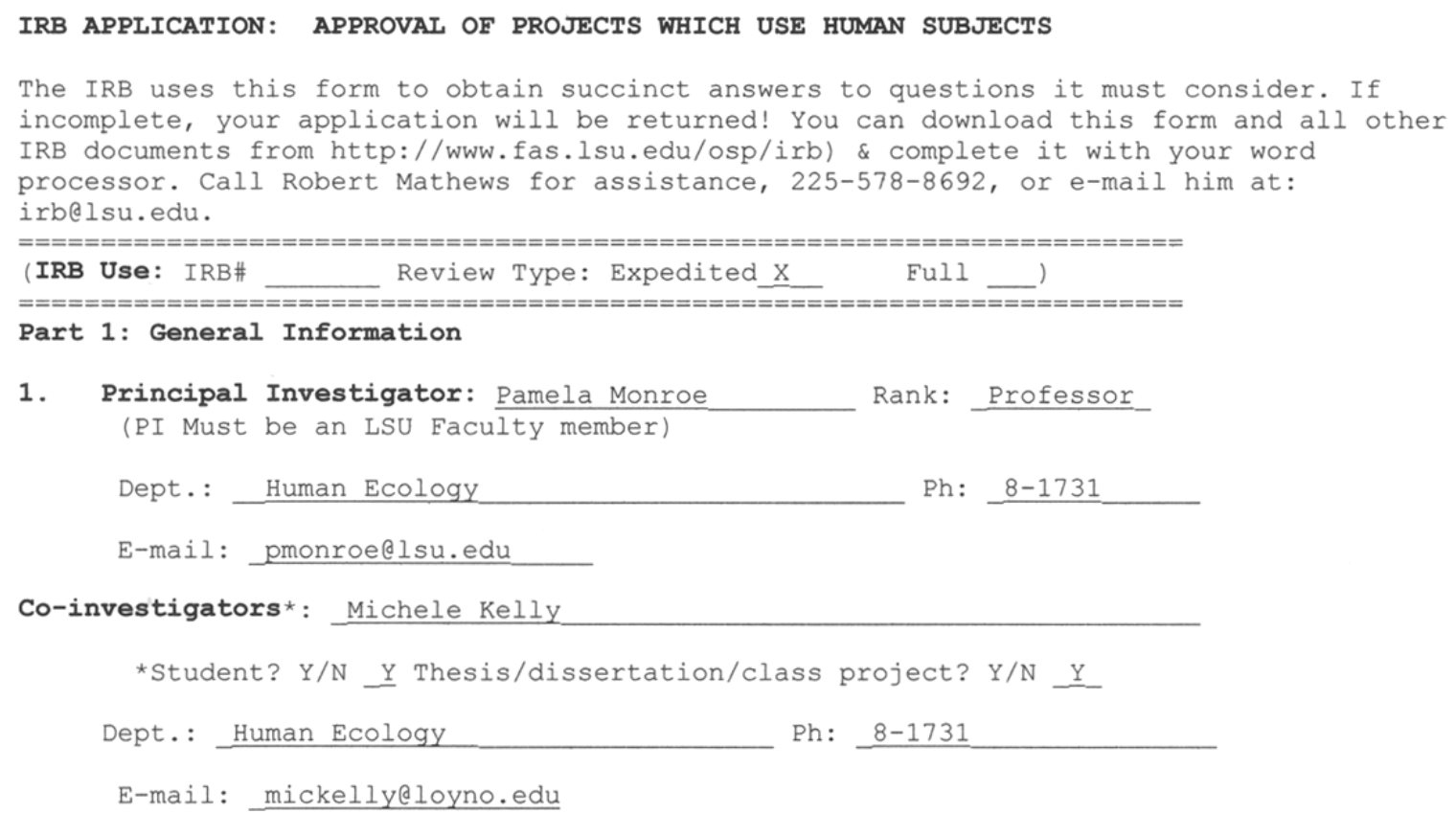

B. ASSURANCE OF STUDENT/PROJECT COORDINATOR named above

I agree to adhere to the terms of this document and am familiar with the documents referenced above.

Signature Date

Part 2: $\quad$ Project Abstract - provide a brief abstract of the project.

Part 3: $\quad$ Research Protocol 


\section{APPENDIX B: PRE-SCREENING INTERVIEW PROTOCOL}

Introduce self

My name is Michele Kelly and I am a doctoral candidate at Louisiana State University where I am attempting to undertake a dissertation study for my doctoral degree.

Discuss what I would like to do and why I would like to do it In this study I would like to explore the role of particular family factors that may have protected and assisted you in remaining strong through the Sudanese civil war.

I would like to do this study because this study may help me in understanding how particular family factors may have protected and assisted you in remaining strong through the Sudanese civil war.

Ask if interested and willingness to participate in the study?

Are you interested in this study?

Are you willing to participate in this study?

Set up an appointment to conduct the interview

May we set up a time to conduct the interview?

Set up a period of time in which to conduct direct observations

Is it possible to spend the day, or a period of time observing you?

Exchange contact information

How may I reach you to confirm this date and time or if it needs to be changed?

Let me give you my contact information in case you need to reach me

Thank participant

Thank you for you interest in and willingness to participate in this study 


\section{APPENDIX B: INFORMED CONSENT FORM}

1. Study Title: A Collective Case Study of Sudanese Refugee Youth

2. Performance Sites: Participating, refugee resettlement agencies affiliated with the United States Conference of Catholic Bishops, Migration and Immigration Services.

3. Investigators: The following investigators are available for questions about the study, M-F 9:00a.m. - 4:30p.m.

Pamela Monroe, Ph.D.

(225) $578-1731$

Professor

Michele Kelly

(504) 482-4096

Doctoral Candidate

4. Purpose of the Study: The purpose of the study is to explore the role of particular family factors that may have protected and assisted you in remaining strong through the Sudanese civil war.

5. Subject Inclusion: Sudanese youth resettled by the participating refugee resettlement agencies affiliated with the United States Conference of Catholic Bishops, Migration and Refugee Services.

6. Number of Subjects: $12-15$

7. Study Procedures: The study will consist of open-ended and focused interviews. There will be two interviews, each of approximately 1 to $1 \frac{1}{2}$ hours in length. At the beginning of the first interview, you will be asked to create several pieces of artwork. The first interview will be open-ended and assume a conversational manner, but will loosely follow a set of questions pertaining to your experiences, particularly the Sudanese civil war and your family. At the end of the first interview you will be asked to make daily recordings in a journal over a period of several weeks of your memories of the Sudanese civil war and your family. The second interview will be more focused seeking specific answers to questions or confirming information.

8. Benefits: The study may help the investigators understand how particular family factors may have protected and assisted you in remaining strong through the Sudanese civil war.

9. Risks/Discomforts: You may feel said or upset if you recall some unpleasant events or feelings associated with these events. If you would like to discuss feeling sad or upset you may do so with the investigators. The coinvestigator is a Licensed Clinical 
Social Worker who is skilled in providing counseling and psychotherapy to children, adolescents, and young adults. She will be sensitive to the possibility that in thinking about the answers to some of the questions you might recall some unpleasant events that may make you feel said or upset. If you become sad or upset the interview will be temporarily ended. The interview will start again only once you are feeling comfortable and with your permission. If your feelings return then the interview will be ended again and you will be encouraged to contact your case manager or the Resettlement Director of the refugee resettlement agency for a possible referral to a mental health professional in your community. We will talk to you about your feelings and thoughts at the end of every interview.

10. Right to Refuse: Your participation is strictly voluntary. You have the right to refuse to answer particular questions or limit your involvement in any way with this study without consequence. Also, you have the right to withdraw your consent and end your participation at any time with this study without consequence.

11. Privacy: The coinvestigator will protect your privacy and identity. Your name will not be attached to the data. However, you will be asked to provide a pseudonym (a name you make up) to the coinvestigator, which will be used to identify you. Your name and pseudonym will be on a separate piece of paper, which will be kept separate from the data and all other materials pertaining to the study. Only the investigators will have access to this information. Your location and the name of the refugee resettlement agency will be concealed. Your pseudonyms, signed consent form, artwork, audiotapes, interview transcripts, and journals will be kept securely confidential unless release is legally compelled.

12. Signature: The study has been discussed with me and all of my questions have been answered. I may direct additional questions regarding study specifics to the investigators. If I have any questions about participants' rights or other concerns, I can contact Robert Matthews, Chairman, LSU Institutional Review Board (225) 578-8692. I agree to participate in the study described above and acknowledge the investigators' obligations to provide me with a copy of this consent form if signed by me.

Signature of Participant

Date 


\section{APPENDIX B: INTERVIEW PROTOCOL}

1. Could you tell me what events led to you coming to the United States? prompts- refugee status, how did you become a refugee?, civil war ...

2. Could you tell me about the Sudanese civil war? prompts- I understand it is the longest running civil war, When did it start?, How did it start? ...

3. Could you tell me about your experiences in the civil war? prompts-Did you live close to any fighting?, Did you hear people talk about their fighting?, Did you hear/see any fighting?

4. How did the civil war affect you? (I am not seeking any psychologically related responses but responses such as "My family was uprooted..., We were separated...)

5. You have experienced events in your life that many people might describe as difficult or stressful. How did you (do you) deal with or cope with these events?

6. Many people might describe someone who dealt with or coped (well) with these events as strong or resilient. What helped you in being (becoming) strong or resilient? (The informant might mention individual, familial, or community based protective factors. I will acknowledge all of the responses but will focus on familial protective factors.)

7. In what ways did your (relationship with your) family help you in coping? (I am seeking specific familial protective factors.)

8. Could you give me an example? Then? Now?

9. How do you think your family or your relationship with your family was able to help you despite being separated from them and not knowing their status?

(I am looking for a description of a process.)

10. Could you give me an example? Then? Now?

11. Is there anything that you think is important for me to know about familial protective factors that I have not asked? Or is there anything else you would like to add? 


\section{APPENDIX C: CONTACT SUMMARY FORM}

Contact Type:

Participant:
Site:

Contact Date: Today's Date:

1. What were the main issues or themes that struck you in this contact?

2. Summarize the information you got (or failed to get) on each of the topics (or questions) you had for this contact.

3. Was there anything else that struck you as interesting, illuminating, or important in this contact?

4. What new topics (or questions) that were illuminating from this contact that you might use with the next participant? 


\section{APPENDIX D: ART WORK ANALYSIS FORM}

Contact type:

Participant:

Name or description of the artwork

Contact with which document is associated

Significance or importance of the document

Summary of analysis
Site:

Contact Date:

Today's Date: 
APPENDIX E: ART WORK

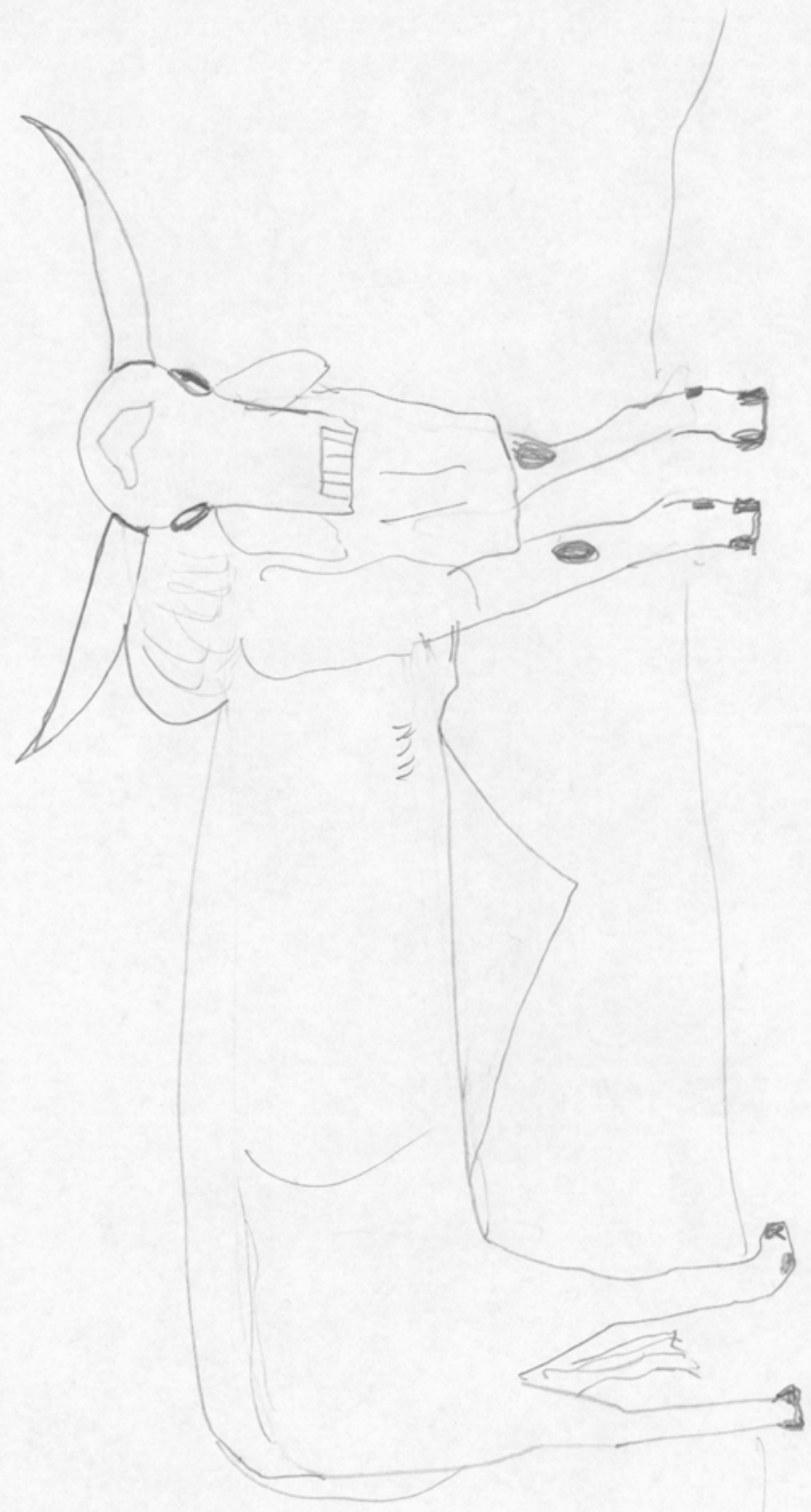




\section{APPENDIX E: ART WORK}

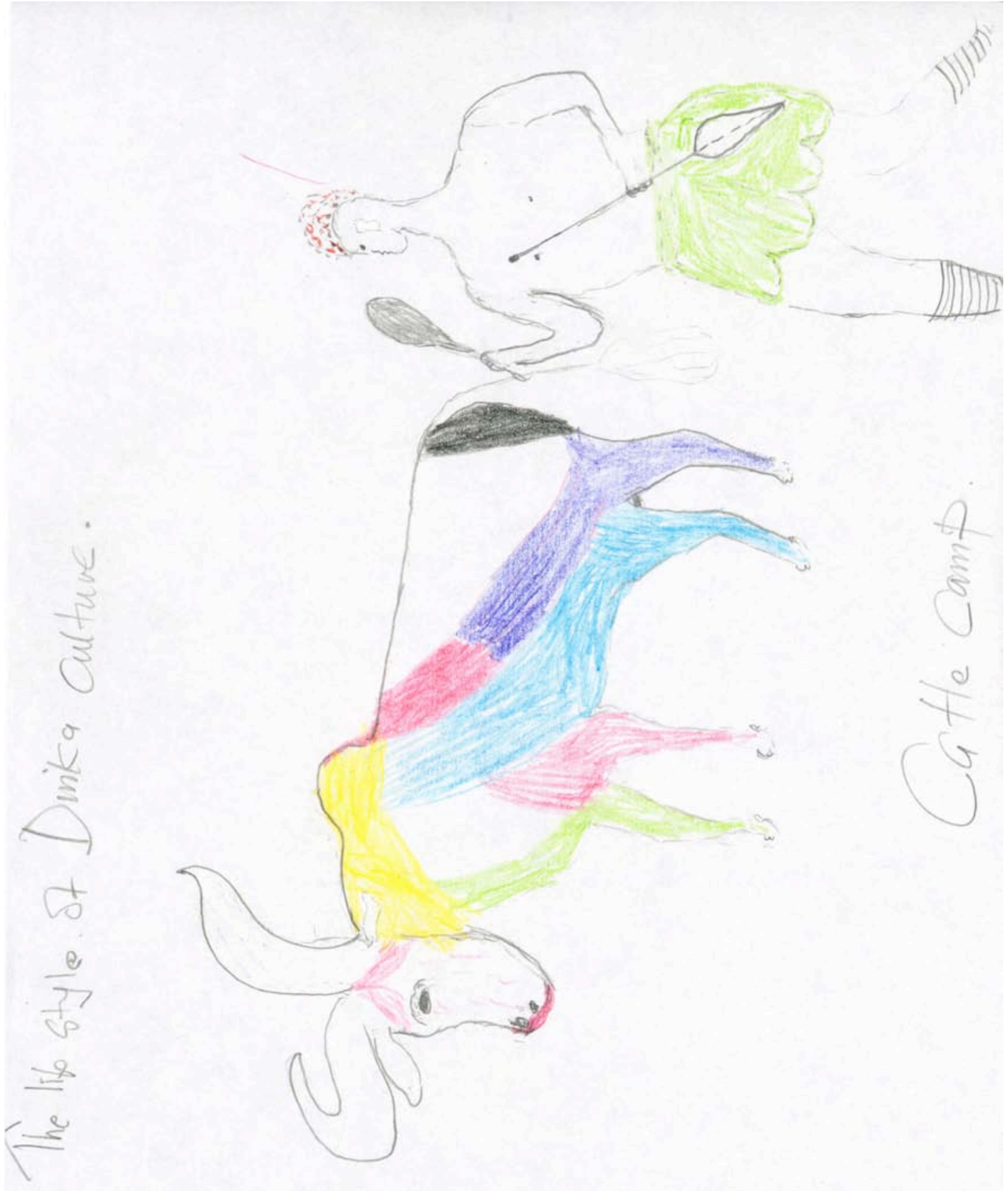




\section{VITA}

Michele Kelly was born in Pottsville, Pennsylvania, and was reared in Hockessin, Delaware, and New Orleans, Louisiana. She currently resides in Washington D.C., with her 5 year old son, Patrick who attends Aidan Montessori School. Her husband, Ghazi Assali is employed and resides in Kuwait City, Kuwait.

She graduated from St. Mary's Dominican College in 1982 with a Bachelor of Science degree in biology. She also attended Tulane University where she graduated in 1985 with a Master of Social Work degree. Michele is a Licensed Clinical and Academy Certified Social Worker and has practiced social work for over 20 years. She has worked with children and families providing clinical social work and designing, implementing, managing, and monitoring and evaluating case management and other social service programs. Most recently Ms. Kelly was an adjunct instructor of social sciences at Our Lady of Holy Cross College and an instructor of sociology at Loyola University New Orleans, where she was the coordinator of the social work sequence. She has also held clinical instructor appointments through Southern University and Tulane University Schools of Social Work. Ms. Kelly has served on a number of advisory and governing boards of social service organizations in the Greater New Orleans area and the state of Louisiana. She is also a member of several professional organizations. 